\section{D) Check for updates}

Cite this: Mater. Adv., 2021, 2, 2773

Received 28th January 2021, Accepted 28th March 2021

DOI: 10.1039/d1ma00077b

rsc.li/materials-advances

\title{
A post-functionalization toolbox for diazonium (electro)-grafted surfaces: review of the coupling methods
}

\begin{abstract}
Christelle Gautier, (D) * Isidoro López and Tony Breton (D) *
The surface modification by organics has been booming over the past twenty years in the context of the development of 2D nanomaterials for a wide range of applications. The diazonium salt chemistry represents a valued approach since it allows the covalent attachment, under mild experimental conditions, of functional moieties to various substrates. The potential of this method can be greatly enhanced by exploiting it to prepare reactive organic layers intended for the coupling of more complex molecular structures. This two-step approach, called "post-functionalization", has been successfully exploited to provide working surfaces for a wide variety of applications such as sensors, catalysis, energy storage or nanoelectronics. This review aims to detail all the chemical coupling methods implemented on modified substrates via the diazonium chemistry (352 references), with an emphasis on the experimental conditions used and on the efficiency of the couplings. An overall table collects the references, classified by coupling method, modified substrate and targeted application.
\end{abstract}

\section{Introduction}

Assigning a specific property or a specific function to a surface via a modification at the molecular scale has become usual for the development of smart materials. Among the existing

Univ Angers, CNRS, MOLTECH-ANJOU, F-49000 Angers, France.

E-mail: christelle.gautier@univ-angers.fr, Tony.breton@univ-angers.fr

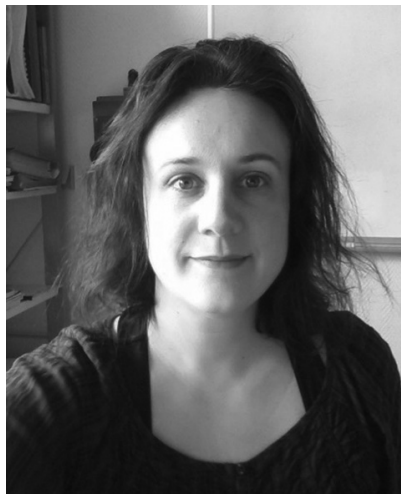

Christelle Gautier
Christelle Gautier is a CNRS researcher in MOLTECH-Anjou laboratory at the University of Angers (France). She received her PhD in Physical chemistry from the University of Le Mans in 2006. After a post-doctoral position in Montréal (Canada) with Daniel Bélanger and another one in the Commisariat à l'énergie Atomique in Saclay (France), she started her actual CNRS position in 2010. Her research interests concern the immobilization of organic molecules on surfaces and the study of the impact of these molecules confinement of on their properties. methods, diazonium grafting, or electrografting, raises a lot of interest probably because of the sustainability of the obtained organic layers and the large panel of substrates modifiable by this technique. Developed since the 90's, the diazonium reduction technique has reached maturity even if several mechanistic points remain to be clarified to obtain well controlled and defined layers. Immobilizing a small molecular structure from the corresponding isolated diazonium salt

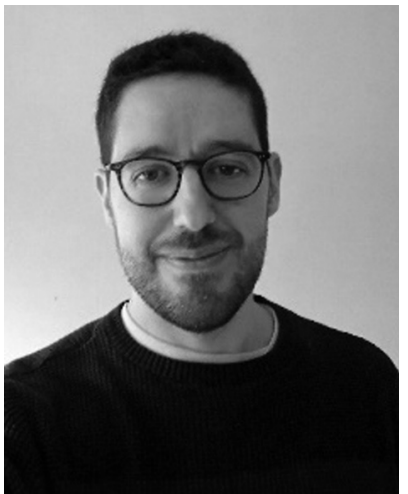

Isidoro López
Isidoro Lopez received his $P h D$ in 2013 from the Institute of Chemical Research of Catalonia and Universitat Rovira $i$ Virgili working under the supervision of Prof. Antoni Llobet in the study of new water oxidation electrocatalysts. At the Universite d'Angers, he worked on the functionalization of conducting surfaces via the controlled reduction of diazonium salts. He is currently a postdoctoral researcher at the Université de Pau et des pays de l'Adour, where he analyses interphases in lithium solid-state batteries. The research interests of Isidoro Lopez include the modification of electrode surfaces and the spectroelectrochemical study of processes at electrified interfaces. 
represents an ideal way, which cannot be extended to every molecule for synthetic or stability reasons. To work out this issue, the classical approach consists in exploiting a postfunctionalization step, by first preparing a reactive layer, and then couple the target molecule. This option allows to considerably simplify the modification scheme but presents some weaknesses due to incomplete heterogeneous coupling reactions and/or steric hindrance limitations.

In most cases, several types of linkages could be considered for the same surface modification, but the choice of a coupling reaction is more often due to the work habits of the research groups than to time-consuming systematic studies. Only a few studies have indeed looked at the comparison of the results obtained via several post-functionalization techniques. This observation may appear surprising knowing that the expression of the nanomaterial properties is not only linked to the surface coverage, but is also governed by the chemical function accessibility, interactions with the substrate and organization of the molecules constituting the nanofilms. We offer here a review focused on the post-functionalization methods for tailoring electrode surfaces involving a molecular reactive platform prepared via diazonium grafting. This review is an opportunity to take a step back on the different approaches employed in the literature while keeping in mind that the efficiency of a postfunctionalization strategy is strongly dependent on the preparation of the surface and the reaction conditions. We firmly believe that a broad community can be interested in this kind of investigation because of the wide range of applications concerned.

A recurring question when planning to immobilize a molecular structure is "what reaction scheme should I use to ensure an efficient grafting?". There is no clear answer to this question because of the lack of fundamental studies focused on this issue, and also because of the great diversity of the molecular target which makes reaction efficiencies difficult to predict. This review presents a detailed analysis of the available coupling

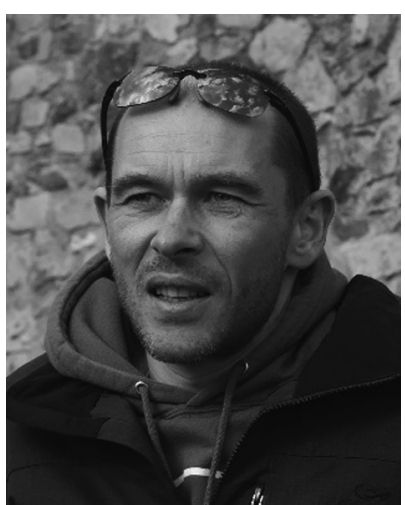

Tony Breton
Tony Breton was born in La Rochelle (France) in 1977. He received his $P h D$ in organic electrosynthesis from the university of Poitiers in 2004. After a 1 year postdoctoral research study on the electrochemical modification of surfaces with Professor Daniel Belanger (Montreal - Canada), he joined the MOLTECH-Anjou laboratory at the University of Angers (France) where he is currently professor. His current work concerns the elaboration and characterization of functionalized conductive surfaces in the aim of establishing controlled structure-properties relationships. methods with a particular emphasis on the reaction conditions and surface coverages obtained. A large table collecting the different grafted entities, substrates and coupling reactions found in the literature is built and aims to serve as a toolbox.

\section{Post-functionalization routes}

A wide variety of post-functionalization methods have been carried out from modified surfaces by reduction of diazonium salts. In most cases, the choice of the coupling reaction is dictated by the constraints related to (i) the reactive layer preparation (substrate reactivity, compatibility of the anchoring function with the diazonium chemistry) and (ii) the synthesis of the molecular structure to be grafted. However, the diversity of the coupling techniques and, above all, the diversity of experimental conditions pertaining to those techniques, require careful consideration of the results obtained in terms of ease of implementation and efficiency.

\subsection{Amide coupling}

Peptide coupling, which is of fundamental importance in organic chemistry, is probably the most simple and popular method for post-functionalizing a beforehand modified surface via the diazonium chemistry. The reaction between carboxylic acid and amine functions requires the use of so-called coupling reagents to provide satisfactory yields. Carboxy components can be activated as acyl halides, acylimidazoles, anhydrides or esters for example. The reactive intermediate can be isolated prior aminolysis or in situ prepared in the presence of the amine, by the addition of a coupling agent. Depending on the diazonium salt used for the first functionalization step and the targeted molecular structure, two main approaches can be distinguished: a coupling of an amine derivative on a carboxytethered surface, or a coupling of a carboxy derivative on an aminated surface.

2.1.1. Coupling in aqueous medium. Preparation of a carboxy- or amino-modified surface can easily be achieved by reduction of a diazonium salt respectively bearing a carboxylic or amine function under standard conditions on various substrates using spontaneous or electrochemically induced reduction. The first example of amide bond formation in aqueous medium was reported by Pinson et al. on a 4-phenylacetic modified glassy carbon electrode to attach glucose oxidase (GOx). ${ }^{1}$ Activation of the acid function was achieved using 0.1 M 1-cyclohexyl-3-(2-morpholinoethyl)carbodiimide metho$p$-toluene sulfonate (CMCT) in acetate buffer for $30 \mathrm{~min}$ before dipping overnight the electrode in $1 \mathrm{mg} \mathrm{mL}^{-1} \mathrm{GOx}$ solution at $5{ }^{\circ} \mathrm{C}$. The catalytic activity recorded after glucose addition was found similar to that obtained on a carbon electrode pretreated by a drastic oxidation and then post-functionalized following the same way, but allowed to lower the background current and perform more precise kinetic measurements. From the catalytic current, the authors extracted a surface concentration of active enzyme of $1.8 \times 10^{-13} \mathrm{~mol} \mathrm{~cm}^{-2}$. A similar chemistry using CMCT was exploited by Tan et al. for the 
immobilization of GOx on an electrochemically modified electrode by reduction of trans-4-cinnamic acid diazonium. ${ }^{2}$ The unsaturated active platform exhibited a good ability to detect and quantify glucose as well as a selective suppression of interfering species oxido-reduction signals compared to unmodified electrode. The CMCT coupling chemistry was also used to attach dopamine on carbon-fiber electrode by Anderson et al. ${ }^{3}$ However, in this case, starting from modified carbon fiber by electroreduction of 4-carboxyphenyldiazonium, the covalently attached dopamine was not electrochemically detectable, probably due to inhibited electron transfer across the film.

Following to those 3 pioneering works, the carbodiimide chemistry was mostly exploited using 1-ethyl-3-(3-diméthylaminopropyl)carbodiimide (EDC) as coupling agent. One of the main advantages of EDC is its water solubility, which allows direct coupling without prior organic solvent dissolution. However, $\mathrm{pH}$ conditions have to be strictly controlled as the reactive ester formed can be rapidly hydrolyzed. Typically, buffer solution prepared from 2-( $N$-morpholino)ethanesulfonic acid (MES), 4-(2-hydroxyethyl)-1-piperazineethanesulfonic acid (HEPES) or phosphate are used. To increase the stability of the active ester, $\mathrm{N}$-hydroxysuccinimide (NHS) or $\mathrm{N}$-hydroxysulfoxuccinimide (sulfo-NHS) can be used. The addition of Sulfo-NHS stabilizes the amine-reactive intermediate by converting it to an aminereactive Sulfo-NHS ester, thus increasing the efficiency of EDCmediated coupling reactions. Gooding has undoubtedly played an important role in the generalization of the use of this technique to manage heterogeneous coupling with substrates modified by diazonium salt reduction. His first work in this field demonstrates the possibility to attach ferrocenemethylamine on glassy carbon and gold modified with 4-carboxyphenyl groups (Fig. 1). ${ }^{4}$ Activation of the carboxyl groups was carried out in $40 \mathrm{mM}$ EDC/10 mM NHS aqueous solution for $1 \mathrm{~h}$ and the coupling was performed by adding $5 \mathrm{mM}$ of ferrocene derivative in HEPES buffer solution for $24 \mathrm{~h}$. Despite a carboxyphenyl surface coverage estimated to $7 \times 10^{-10} \mathrm{~mol} \mathrm{~cm} \mathrm{~cm}^{-2}$ before coupling, the ferrocene surface coverage did not exceed $0.73 \times 10^{-10} \mathrm{~mol} \mathrm{~cm}{ }^{-2}$, corresponding to a coupling yield of $10 \%$. The reason of such low reaction efficiency was attributed to interactions existing between redox centers.

Metal complexes. EDC chemistry is appropriate to attach water-soluble metal complexes on surfaces. As those structures are electroactive, useful information can be obtained on the coupling efficiency. In 2007, Cavlo et al. were the first to report

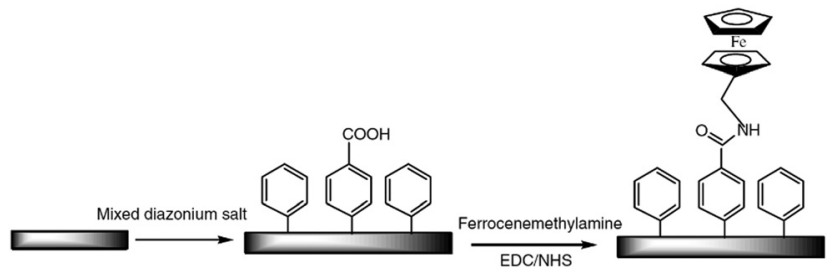

Fig. 1 Scheme of ferrocenemethylamine covalently immobilized on mixed monolayers of 4-carboxyphenyl and phenyl moieties. Reprinted with permission from ref. 4. an osmium complex immobilization on carboxyphenyl tethered gold surface prepared by diazonium reduction. ${ }^{5}$ In this work, electrochemical properties of the covalently grafted osmium complex were compared to those obtained using classical thiol adsorption and no significant differences were observed in terms of surface coverage $\left(\approx 1 \times 10^{-10} \mathrm{~mol} \mathrm{~cm}{ }^{-2}\right)$ and electron transfer rate $\left(\approx 100 \mathrm{~s}^{-1}\right)$. Further work was published on the same osmium complex and also conclude that the surface coverages determined for both immobilization strategies were similar. ${ }^{6}$ Moreover, scanning tunneling microscopy images showed very similar organic film morphology, allowing to confirm that near-monolayers were obtained independently of the grafting route. A third study on osmium complex immobilization was reported starting from two diazonium platforms: a classical carboxyphenyl one, and a tetrafluorinated carboxyphenyl one. ${ }^{7}$ The work demonstrated that, under strongly reducing conditions, multilayers are formed when the carboxyphenyl reactive layer is used, due to radical attack on already grafted species, whereas the use of fluorinated diazonium allows easy formation of a monolayer platform. Similar electrochemical surface coverages were obtained for both post-functionalized films but the monolayer material exhibited higher electron transfer rate $\left(3\right.$ versus $\left.1.4 \times 10^{5} \mathrm{~s}^{-1}\right)$. In comparison, Leech et al. reported the immobilization of the same osmium complex via EDC coupling to a phenylpropionic acid active layer on glassy carbon. ${ }^{8}$ A very stable electroactive material was obtained, characterized by an electron transfer rate of $90 \mathrm{~s}^{-1}$, close to that obtained with shorter chain length. ${ }^{7}$ Interestingly, a surface coverage of $2.9 \times 10^{-10} \mathrm{~mol} \mathrm{~cm}^{-2}$ was determined by cyclic voltammetry, which corresponds to approximately 3 times the theoretical monolayer coverage, what was attributed to the carbon roughness compared to previously reported results on gold.

Metal cation sensors. A series of copper sensors on carbon and gold was developed by Gooding et al., exploiting the postfunctionalization of phenylcarboxy-modified surfaces by Gly-GlyHis moieties. 0.1 M MES buffer solution containing $20 \mathrm{mM}$ EDC/4 mM NHS was used to form the activated ester and the amine derivative was fixed at $0.1 \mathrm{M}$. Thanks to the $\mathrm{Cu}^{2+}$ surface concentration measured at saturated complexation (i.e. $2.19 \times$ $10^{-10}$ and $0.59 \times 10^{-10} \mathrm{~mol} \mathrm{~cm}{ }^{-2}$ for gold and glassy carbon respectively), the coupling yield was estimated at $34 \%$ on modified gold substrate ${ }^{9}$ and only $8 \%$ on glassy carbon one. ${ }^{10}$ This important difference was attributed to a better EDC/NHS activation on gold due to the higher electron density, thus leading to a better orbital mixing between the electrode surface and the organic layer. An extension of the approach was reported on pyrolyzed photoresist film (PPF) and showed that this substrate provides very similar results to glassy carbon in terms of sensitivity and detection limit for sensing applications. ${ }^{11}$ Miniaturized copper sensor on gold was also developed using the same Gly-Gly-His attachment on carboxy-modified back-side contact transducers. An equimolar $50 \mathrm{mM}$ EDC/NHS solution was used for the ester activation. ${ }^{12}$ This protocol allowed to reach a complexed copper concentration of $5.7 \times 10^{-10} \mathrm{~mol} \mathrm{~cm}{ }^{-2}$ at 
saturation, which is 2 order of magnitude higher than the value obtained on a Gly-Gly-His derivated 16-mercaptohexadecanoic acid self-assembled monolayer following an identical protocol. Peptide grafting was also reported on graphite-epoxy composite electrodes (GEC) by del Valle et al. for $\mathrm{Cu}^{2+}, \mathrm{Cd}^{2+}$ and $\mathrm{Pb}^{2+}$ detection. ${ }^{13}$ A 26 mM EDC/35 mM NHS solution was employed to activate the 4-carboxyphenyl tethered surface prior to the coupling reaction in the presence of a $0.16 \mathrm{M}$ peptide solution. Satisfactory differential pulse voltammetric response were obtained for each metal cation but the work highlights the interfering phenomenon encountered for the simultaneous detection of the three metals. One year later, the same group reported the preparation of 2 crown ether modified GEC (i.e. 15-crown-5 and 18-crown-6) assisted by lysine using identical coupling conditions and obtained selective results for the multimetal stripping thanks to the crown-ether cavity sizes. ${ }^{14}$ Aminophenyl modified carbon surfaces were also used to build metal sensors. By electrografting of 4-nitrobenzene diazonium and subsequent electroreduction into amine function, Gupta et al. reported the attachment of graphene oxide (GO) on glassy carbon, activated in $0.1 \mathrm{M}$ EDC solution. ${ }^{15} \mathrm{~A}$ full characterization showed that the GO was well bound on the carbon substrate, and was suitable for the detection of copper and cadmium ions.

Enzyme based biosensors. EDC coupling represents a method of choice for the preparation of surfaces grafted with enzyme for the development of biosensors as water-soluble activation agent is needed. In this field, the experimental conditions strongly vary in terms of coupling agent concentrations but, in most of the cases, the formation of the NHS-ester as stable intermediate is involved. Due to the molecular weights and the deposition protocols used, the exact concentration of the enzyme used for the attachment step remains approximate, but is clearly lower than in the case of smaller molecules. Prior to the first report of enzyme immobilization via the diazonium approach, Gloaguen et al. reported the pertinence of the $\mathrm{H}_{2}$ ase surface chemistry by grafting of an organometallic model of the [FeFe] hydrogenase active center. ${ }^{16}$ In this work, glassy carbon was modified by nitrophenyl groups and then electroreduced to give an aminophenyl reactive platform. The coupling of a pre-synthesized NHS-derivative of a dithiolate-bridged diiron complex in mild condition led to a surface coverage of $9 \times 10^{-10} \mathrm{~mol} \mathrm{~cm}{ }^{-2}$. This value is $30 \%$ higher than the one obtained by direct coupling on a $\mathrm{NH}_{2}$-tethered surface prepared by polishing in ammonia. The first example of grafted enzyme via the diazonium chemistry was reported in 2005 by Lacey et $a .^{17}$ In this work, highly oriented pyrolytic graphite (HOPG) was modified by nitrophenyl groups and then electroreduced to give an aminophenyl reactive platform able to react with activated hydrogenase by an EDC/NHS mixture (36/18 mM respectively). The stability of the catalytic current compared to just deposited hydrogenase confirmed the robust link between the surface and the enzyme. Using the same two-step approach, consisting in the nitrophenyl grafting followed by its electroreduction, horseradish peroxidase (HRP) was covalently fixed to screen printed carbon electrode (SPCE) after EDC/NHS activation. ${ }^{18,19}$ By the use of gold substrate, Vas-Dominguez et al. reported the possibility of mixing diazonium chemistry and thiol adsorption for the attachement of laccase. ${ }^{20}$ In this work, an aminophenyl platform was mixed with 6-mercapto-1hexanol adsorption to generate a sublayer before amide coupling with the enzyme. A full spectroscopic and AFM monitoring demonstrated that, despite a lower enzyme density $(1.20 \pm$ $0.32 \times 10^{-12} \mathrm{~mol} \mathrm{~cm}{ }^{-2}$ ) than the one obtained using a pure aminothiophenyl platform, the material provided better catalytic performances due to a higher electron transfer rate. Efficiency of the laccase immobilization by the use of aminophenyl and carboxyphenyl platforms were compared on carbon rods in the work of Jolivalt et al. ${ }^{21}$ In both cases, the coupling was activated by an EDC (4.5 mM)/NHS (11 mM) mixture and led to similar laccase surface coverage (i.e. $1.5 \times 10^{-12} \mathrm{~mol} \mathrm{~cm}^{-2}$ ). However, significantly higher dioxygen reduction current was observed when carboxyphenyl platform is used, what could be explain by a more appropriate orientation of the protein leading to a better electron transfer.

Starting from carboxy-tethered surface, an original approach for enzyme immobilization was reported by Gooding et al. using glassy carbon electrodes modified by electroreduction of a mixture of poly(ethylene glycol) diazonium, and oligo(phenylethynyl) carboxy derivatives (Fig. 2). ${ }^{22}$ Coupling conditions were inspired from their previous work dealing with the ferrocene immobilization (i.e. $40 \mathrm{mM}$ EDC/10 mM NHS in HEPES buffer), ${ }^{4}$ to attach HRP as a model protein to probe electron transfer rate and catalytic activity toward $\mathrm{H}_{2} \mathrm{O}_{2}$ reduction. The surface concentration of the HRP, determined by cyclic voltammetry, was estimated to $6.2 \times 10^{-12} \mathrm{~mol} \mathrm{~cm}^{-2}$, value close to the one expected for a compact monolayer (i.e. $8.5 \times 10^{-12} \mathrm{~mol} \mathrm{~cm}{ }^{-2}$ ). Identical mixed molecular platform was later exploited to develop an amperometric immunobiosensor for detecting glycosylated haemoglobin. ${ }^{23}$ A different mixed approach, in which poly(ethylene glycol) moieties were replaced by carboxyphenyl groups, was exploited to attach GOx on glassy carbon, leading to a maximum surface coverage of $2.4 \times 10^{-12} \mathrm{~mol} \mathrm{~cm}^{-2}$ when the optimal diazonium ratio is used. $^{24}$ In both cases, the modified carbon surfaces were characterized by a faster electron transfer rate, attributed to the molecular wire structure of the layer, and better catalytic stability compared to sensors involving enzyme physisorption. Those results are consistent with a high coupling yield of the proteins and confirm that ester-activation conditions are appropriate. An alternative way to increase the Gox surface coverage has recently been published by Liu et al. ${ }^{25}$ The strategy involved the preparation of an amino reactive platform directly using the in situ diazotized paraphenylenediamine. This reactive platform was then coupled to GO sheets, themselves functionalized by gold nanoparticles functionalized by GOx. In this way, a larger specific surface area was achieved allowing to reach a higher coverage (i.e. $3.65 \times 10^{-12} \mathrm{~mol} \mathrm{~cm}^{-2}$ ).

Grafting of GOx on glassy carbon has also been reported on phenyl- $\mathrm{C}_{n} \mathrm{H}_{2 n}-\mathrm{COOH}$ (C $=1,2$ or 3 ) platforms prepared by reduction of in situ generated diazonium. ${ }^{26}$ Activation of the 

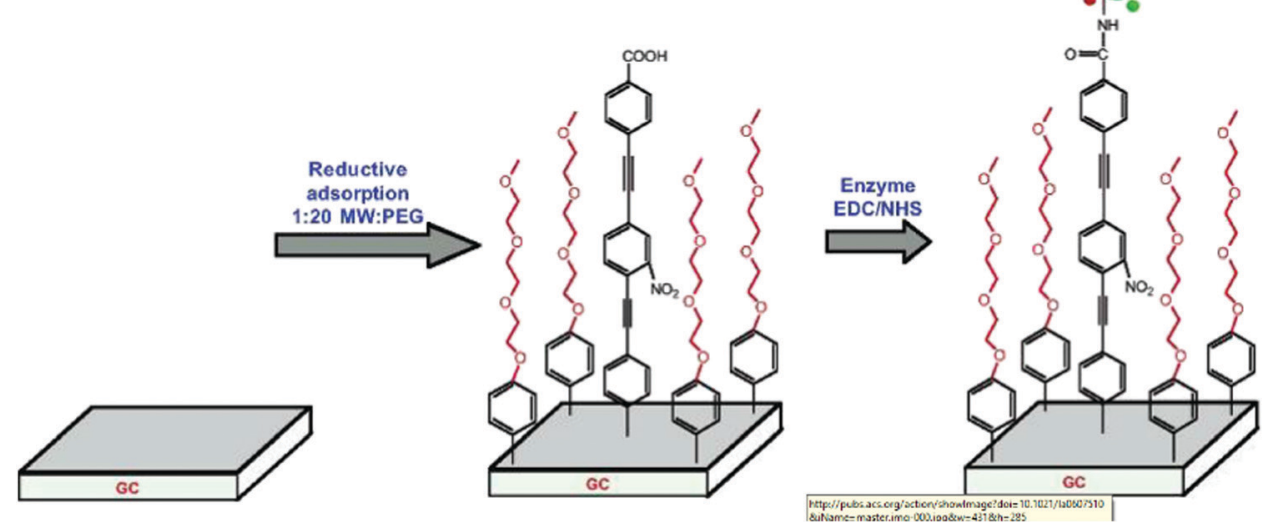

Fig. 2 Schematic of the glassy carbon interface for protein electrochemistry. Reprinted with permission from ref. 22.

carboxy-tethered glassy carbon electrodes was carried out in a $30 \mathrm{mM}$ EDC/90 mM NHS solution followed by an immersion in a $1 \mathrm{mg} \mathrm{mL} \mathrm{mL}^{-1} \mathrm{GOx}$ solution for $45 \mathrm{~min}$. It was found that the covalent link provided by the amide coupling greatly increases the stability compared to physically adsorbed enzymes and that longer alkyl chain lengths slightly increase the interfacial reactivity. In the same vein, the in situ generation of a diazonium salt was also carried out from 4 -aminobenzoic acid by Radi $e t$ al. to prepare a reactive platform able to react with HRP. ${ }^{27}$ The surface concentration of HRP was found independent on the electroreduction time used for the reactive platform elaboration, demonstrating that a compact sublayer is not necessary to attach sterically hindered structures as enzymes. The covalent immobilization of the HRP leads to fast amperometric $\mathrm{H}_{2} \mathrm{O}_{2}$ detection, clearly showing that the underlying organic porous film provides the necessary conduction pathway for a direct electron transfer between the enzyme active sites and the electrode surface. 4-Carboxybenzene diazonium can also be reduced without electrochemical induction to prepare a reactive platform. This strategy was exploited by Baffert et al. to attach hydrogenase on pyrolytic edge graphite following a short activation in a $36 \mathrm{mM}$ EDC/18 NHS mixture. ${ }^{28}$ The activity of the enzyme (i.e. $\mathrm{H}_{2}$ oxidation) does not suffer from the covalent attachment, and, contrary to that observed for physically adsorbed hydrogenase, no current correction is necessary to compensate the desorption. Similar conclusions were recently reported for the development of a cholesterol biosensor based on the covalent immobilization of cholesterol oxidase onto nano-sized carbon interdigitated electrodes decorated with gold nanoparticles. ${ }^{29}$ It must be mentioned that relatively important concentrations of activating agents (i.e. $100 \mathrm{mM}$ for $\mathrm{EDC}$ and NHS) were used for the coupling in this study. However, as reported by Zhao et al., amide bond formation without the use of NHS remains possible for protein immobilization. Such coupling conditions were employed for the attachment of
Hemoglobin $(\mathrm{Hb})$ and Cytochrome $c$ (Cyt. $c$ ) on carboxyphenyl modified glassy carbon to prepare amperometric $\mathrm{H}_{2} \mathrm{O}_{2}$ biosensors. $^{30}$ Thanks to the redox process of heme $\mathrm{Fe}(\mathrm{III}) /$ $\mathrm{Fe}(\mathrm{II})$, surface coverages of 8.3 and $6.8 \times 10^{-11} \mathrm{~mol} \mathrm{~cm}^{-2}$ for $\mathrm{Hb}$ and Cyt. $c$ were respectively estimated, which is close to the theoretical surface coverage calculated for a fully packed monolayer. This approach was successfully extended, with similar results, to the functionalization of boron-doped diamond (BDD), which offers very low capacitive background current, high electrochemical stability and superior biocompatibility. ${ }^{31}$ More recently, a comparison between thiol adsorption and diazonium electrografting on nanoporous gold electrodes for the covalent attachment of fructose deshydrogenase was reported. ${ }^{32}$ After covalent attachement via CMCT activated coupling, the enzyme activity was found similar but the diazonium mediated grafting provided a better stability.

Immunosensors. The increasing development of immunosensors via the covalent attachment of proteins onto various substrates has contributed to the exploitation of the EDC activated coupling involving the multiple amine functions of those structures with carboxy-tethered electrodes. After the development of a one-step electro-addressing immobilization strategy using aryl diazonium modified biomolecules, ${ }^{33}$ the group of Marquette reported the preparation of modified gold electrodes for biomolecule immobilization dedicated to plasmon resonance imaging. ${ }^{34,35}$ Following electroreduction of the in situ generated 4-carboxymethylbenzene diazonium, protein $\mathrm{A}$ and bovin serum albumin (BSA) were coupled using EDC/NHS (0.1 M/0.1 mM) activation. Surface Plasmon Resonance measurements were then recorded following rabbit igG injection and evidenced a high specific response and regeneration potentialities. Compared to functionalized surface prepared by thioacetic acid adsorption (i.e. self-assembled monolayer technology), the 4-carboxymethyl platform led to very low non- 
specific binding of protein, attributed to a better carboxyl group surface coverage. Gold surface was also modified to generate a diazonium salt-based immunosensor for the detection of methotrexate (MTX) via electrochemical impedance spectroscopy. ${ }^{36}$ In this work, Tesfalidet et al. reported the attachment of anti-MTX antibody onto phenylcarboxy-modified electrode via EDC/NHS (0.1 M/0.02 mM) activation. The originality of the study resides in the deposition of a blocking polymer in the pinholes of the modified electrode, able to minimize nonspecific interaction with the surface. Antifouling properties coupled to immunosensor properties have been previously developed on indium tin oxide (ITO) in the elegant work of Gooding et al. by the way of the co-immobilization of a zwitterionic diazonium and phenylbutiric acid diazonium. ${ }^{37}$ In this work, derived from their previous fundamental study on mixed layer preparation, ${ }^{38}$ the properties of the zwitterion prevent the nonspecific protein adsorption while the acid functionalities is used to attach Ab-1 protein for the selective recognition of TNF- $\alpha$ (i.e. tumor necrosis factor). Relatively high concentration of the EDC/NHS mixture (i.e. $0.16 \mathrm{M} / 0.26 \mathrm{M}$ respectively) was necessary in this example to activate carboxy functions of the mixed layer, contrary to that reported in the work of Sedeno et al. for an antibody grafting on SPCEs (i.e. $0.025 \mathrm{M}$ of both reactants). ${ }^{39}$ Immunosensors were also developed by attachment of smaller molecules as ochratoxin on gold $^{40}$ or okadaïc acid on SPCEs ${ }^{41,42}$ via the same approach, starting from carboxyphenyl platforms. Folic acid was also grafted via this reactive platform on nanostructured gold using very low EDC/Sulfo-NHS concentration to prepare a SERS (Surface Enhanced Raman Scattering) sensor dedicated to cell recognition. ${ }^{43}$ Recently, a new approach was reported by Kerman et al. to form carboxyphenyl reactive layers, dedicated to antibodies attachment on SPCE and glassy carbon surfaces. ${ }^{44}$ This method involved the electrografting of the 4-methoxybenzene diazonium salt, followed by an electrooxidation step to produce the corresponding carboxylic groups, subsequently activated by a 10/40 mM EDC/NHS mixture. SPCE-based immunosensors provided good impedimetric responses and were found less sensitive than glassy carbon ones to crosscontamination issues. Finally, Jabin and Lagrost have recently developed a calixarene chemistry allowing the grafting of those structures on gold nanoparticles ${ }^{45}$ and polymers ${ }^{46}$ for on-surface chemistry via EDC/NHS activated coupling. The last work reported the attachment, via this route, of peptides for biosensing applications and demonstrated that the surface coverage of the biologic material can be easily tuned by varying the molar fraction in solution. $^{47}$

Aminophenyl tethered surfaces were exploited in parallel to build immunosensors. Brozil et al. reported in 2007 a welldocumented study on the pyrroloquinoline quinone (PQQ) immobilization for the NADH (reduced $\beta$-nicotinamide adenine dinucleotide) detection on gold electrode arrays. ${ }^{48}$ Starting from nitrophenyl platform elaborated under different electroreduction conditions, they have highlighted marked impact on the subsequent coupling yield of the PQQ as well as important changes in the catalytic response in the presence of NADH. For thick layers, despite a low coupling yield of the PQQ on grafted aminophenyl moieties, the interfacial activity was found maximum. As illustrated by Gooding et al., EDC activated amide coupling can also be exploited with aminophenyl platforms directly prepared from reduction of in situ diazoniated $p$-phenylenediamine. Using this technique, attachment of biotin on gold surface for the detection of anti biotin $\operatorname{IgG},{ }^{49}$ or generation of oligo (ethylene glycol) antifouling layers on glassy carbon for detection of HbA1c in human blood were reported. ${ }^{50,51}$ The one-step platform preparation was also tested on fluorine tin oxide in the context of an immunofluorescence assay implementation. ${ }^{52}$ In this case, EDC was replaced by its analog $N, N^{\prime}$-diisopropylcarbodiimide (DPC) using classical coupling conditions.

The booming of high-surface carbon substrates as nanotubes or graphene recently led to their exploitation in the field of immunosensors. Johnson et al. reported the attachment of Borrelia burgdorferi flagellar antibodies on carboxyphenyl modified single-walled carbon nanotubes (SWNT) to detect Lyme desease antigen via field-effect transistors. ${ }^{53}$ Low concentrations of EDC and sulfo-NHS ( 2 and $9 \mathrm{mM}$ respectively) were used to activate grafted acid functions, leading to satisfactory coupling, as evidenced by atomic force microscopy (AFM) measurements. The group of Sedeno has exploited reduced graphene oxide (rGO) and GO as stable and highsurface substrates to respectively attach anti-PYY (peptide tyrosine-tyrosine amide) antibodies ${ }^{54}$ and anti-EE2 (antiethynylestradiol) $^{55}$ following an activation of the carboxytethered surface by EDC/sulfo-NHS (0.1 M each). The efficiency of the covalent bonding ensured excellent analytical performance and a remarkable sensitivity compared to commercially available tests. Similarly, carboxy functions of graphene were exploited to immobilize antibody for the development of electrochemical immunosensing, demonstrating the versatility of the strategy. ${ }^{56}$ In the same vein, graphene, under the form of chemical vapor deposited monolayer, was modified by carefully controlled reduction of in situ generated carboxybenzene diazonium to provide a monolayer reactive platform dedicated to ovalbumin antibody grafting. After the coupling step (EDC $0.1 \mathrm{M} / \mathrm{NHS} 0.02 \mathrm{M}$ ), a selective impedimetric detection of ovalbumin was evidenced. Nanoparticules can also be advantageously exploited for the immobilization of biomolecules. A proof of concept based on Fe-core/carbon-shell functionalization by green fluorescent protein (GFP) was reported by Postnikov et al. ${ }^{57}$ After spontaneous grafting of 4-carboxybenzene diazonium and activation with EDC $0.05 \mathrm{M} / \mathrm{NHS} 0.1 \mathrm{M}$, nanoparticules were post-functionalized by GFP. Immobilization of the GFP was shown by IR absorption and the fluorescent microscopy confirmed that the protein retains its conformation after immobilization.

DNA-based sensors. The study of biological systems has led to the development of DNA arrays to obtain genomic and proteomic information. In this research field, diazonium functionalized electrodes have shown certain advantages over the more common assembly of thiol onto gold chemistry, including a strong covalent bond and a wider potential window for 

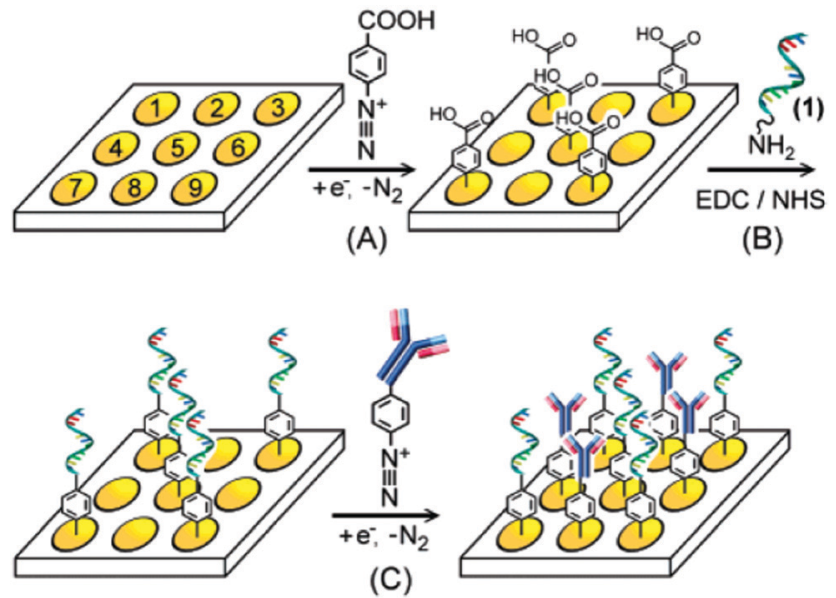

Fig. 3 DNA and antibody probe electrode array selectively functionalized via electroaddressable deposition of diazonium salts. Adapted with permission from ref. 58.

electrochemical detection methods. In 2007, Brozik et al. reported the first example of DNA immobilization via amide bond formation on diazonium-modified surface (Fig. 3). ${ }^{58}$ The DNA-microarrays were prepared by post-functionalization of a carboxyphenyl modified gold substrate driven by EDC/NHS activation. The authors demonstrated that a subsequent diazonium modified antibody reduction can lead to a bi-functional sensor able to selectively detect DNA and proteins.

Going further, one-pot immobilizations of mixed layers were reported by Piro et al. to build an electrochemical transduction DNA sensor. ${ }^{59}$ Co-reductions of 5-hydroxy-1,4-naphthoquinone derivative (JUG) diazonium with a series of carboxylic acid benzenediazonium derivatives were carried out on glassy carbon to characterize the attachment of DNA. Coupling conditions were varied to find optimal values for the activation (i.e. $[\mathrm{EDC}]=0.1 \mathrm{M}$, $\left.[\mathrm{NHS}]=0.1 \mathrm{M},\left[\mathrm{H}_{2} \mathrm{~N}-\mathrm{DNA}\right]=1 \mu \mathrm{M}\right)$ and the efficiency of the DNA attachment was found dependent on the chain length between the surface and the acid function. A full characterization by X-Ray photoelectron spectroscopy (XPS) and fluorescence measurements gave a maximum DNA surface coverage of 4-6 $\times$ $10^{-12} \mathrm{~mol} \mathrm{~cm}{ }^{-2}$, what is slightly lower than the theoretical value, and clearly illustrating that the acid function surface coverage is not the limiting factor of the coupling step. To increase the surface area and enhance electron transfer properties, Fragoso et al. exploited the functionalization of carbon nano-onions deposited on glassy carbon. ${ }^{60}$ Electroreduction of phenylacetic acid diazonium allowed to immobilize streptavidin and incubation of a biotinylated DNA capture probe to prepare an efficient immunosensor with enhanced sensitivity. A similar approach was followed by Ortiz et al. to attach a biotin-Rubpy-DNA capture probe for the implementation of an electrochemiluminescent labelled DNA sensor. ${ }^{61}$ In this case, an original 3,5-bis(4-diazophenoxy) benzoic acid platform was grafted via Zn-mediated reduction on glassy carbon, followed by the streptavidin intermediate coupling. This functionalization method, which was recently reported by the group, ${ }^{62}$ allowed to generate thinner layers than those obtained by electroreduction, and led to similar postfunctionalization yield using EDC/NHS coupling. Two examples of label free aptamer-based sensors elaboration have also been reported by modification of SPCEs for the detection of Lysozyme $^{63}$ and Salmonella. ${ }^{64}$ In both cases, carboxyphenyl tethered surfaces were involved to attach aptamers via EDC/ NHS chemistry and the detection was based on impedimetric measurements. For the preparation of the reactive acid platform, it was shown that electrografting of the diazonium led to higher aptamer surface concentration (i.e. 2 times) than the one obtained via Zn-mediated electrografting. ${ }^{64}$ More recently, carboxyphenyl platforms, were exploited on gold and graphite by the Marty's group to prepare aptamer-based sensors respectively dedicated to the detection of ochratoxin $A^{65}$ and cadmium(II). ${ }^{66}$ In both cases, in situ generation of the carboxyphenyl diazonium was exploited and the coupling reaction was implemented with a large excess of the EDC/NHS couple (i.e. $400 / 200 \mathrm{mM}$ ). This platform preparation protocol was also used by Rather et al. to prepare an estradiol femtosentisive aptasensor. The functionalization of GO, deposited on a glassy carbon surface, allowed to increase the specific area of the substrate and enhanced the aptamer surface concentration $\left(4.3 \times 10^{-10} \mathrm{~mol} \mathrm{\textrm {cm } ^ { - 2 }}\right)$ compared to previously reported approaches. ${ }^{67}$ As demonstrated by O'Sullivan et al., the carboxyphenyl platform can also be prepared from a precursor containing two anchoring diazonium groups. ${ }^{68}$ This strategy was used in the field of DNA detection to attach a HRP-labelled secondary probes on gold. The number of diazonium anchoring groups was not found to improve any performance of the sensing layer but the study highlighted a better thermal stability of the modified surfaces compared to similar layers prepared from self-assembled monolayers. On the other hand, phenylamine platforms, obtained from electroreduction of diazoniated $p$-phenylenediamine, were also exploited to fix DNA for the development of an enzyme-amplified amperometric DNA hybridization assay. ${ }^{69}$ In this work, carboxymethylated dextran was first attached to the phenylamine tethered surface, leading to a carboxyl surface concentration of $4 \times 10^{-9} \mathrm{~mol} \mathrm{~cm}^{-2}$, and then coupled to amine functions of DNA. Both couplings were carried out using $50 \mathrm{mM}$ EDC/20 mM NHS.

\subsubsection{Coupling in organic medium}

DCC activation. The coupling via amide bond formation can be exploited in organic medium via the carbodiimide chemistry by the use of dicyclohexylcarbodiimide (DCC), which is the most common derivative. Several examples of this coupling strategy were reported in the field of immunosensors development. In 2009, Gooding et al. published the preparation of an anti-biotin IgG sensor elaborated by attachment of chemically cut carbon nanotubes (CNTs) onto a glassy carbon surface. ${ }^{70}$ After electrografting of 4-nitrobenzenediazonium and subsequent electroreduction, DCC activated coupling in DMF allowed to obtain vertically aligned nanotubes, which were further functionalized with ferrocene and biotin. This approach represents a good alternative to molecular wires co-grafting, playing the role of electron transfer channel, developed in the field of antibiotin ${ }^{71}$ and drug detection. ${ }^{72}$ Based on the same 
system, glassy carbon was functionalized by a mixed layer of phenyl/carboxyphenyl groups to prepare an immunosensor having antifouling properties. For this, single walled carbon nanotubes (SWCNT) were coupled to the carbon via DCC activation, and subsequently linked to ferrocene and endosulfan hapten for the recognition of endosulfan. ${ }^{73}$ In the same way, Mendes et al. reported an ITO functionalization by reduction of in situ diazoniated $p$-phenylenediamine to generate a reactive platform, subsequently coupled with oxidized SWCNT. Vertical alignments were obtained and exploited for intracellular sensing. ${ }^{74}$ A similar approach was followed by Downard et al. to obtain vertically aligned carbon nanotubes on graphitic carbon. ${ }^{75}$ Starting from in situ diazoniated $p$-aminobenzenediazonium, an amine tethered surface was coupled to carboxyl-terminated CNTs under DCC activation. A careful electrochemical characterization has shown that the alignment of CNT allows fast electron transfer reactions, contrary to that observed when the postfunctionalization is achieved on aliphatic amine-terminated film. The authors also pointed out that the route followed for the aminophenyl platform preparation (i.e. reduction of in situ diazoniated $p$-aminobenzenediazonium or reduction of 4-nitrobenzene diazonium subsequently reduced into amine) led to identical results. This strategy was extended to the attachment of single walled nanotubes on doped silicon by the group and it was shown that the prepared nanomaterial exhibited excellent electrochemical stability in aqueous environment. ${ }^{76}$ The same group reported, by exploiting the silicon functionalization, a simple and convenient photolithographic method for patterning electrografted aminophenyl films on this substrate, allowing to covalently attach biotin for biosensing devices. ${ }^{77}$ DCC coupling chemistry can also involve the use of NHS in various proportions to stabilize the reaction intermediate and increase the reaction yield. Two examples of graphene ${ }^{78}$ and $\mathrm{rGO}^{79}$ functionalization were reported using this combination. In both cases, a carboxyphenyl platform was deposited and subsequently coupled to a Zn-phthalocyanine bearing aminophenyl functions. In addition to the possibility to introduce functions on the carbon substrate, the acid layer was found to efficiently increase the graphene dispersibility in polar solvents. Dimethyl-aminopyridine has also been used to promote the carbodiimide activated coupling reaction to prepare catalytic surfaces. In the work of Breton et al., the amide coupling of a nitroxyl derivative on controlled aminophenyl monolayer led to a surface coverage of $4.3 \times 10^{-10} \mathrm{~mol} \mathrm{~cm}^{-2}$, corresponding to a coupling yield of $69 \%$ of the amine surface functions (Fig. 4). ${ }^{80}$ On a multilayer, a similar surface coverage was found, demonstrating that the coupling only occurs at the surface of the polyphenylene-like (15\% coupling yield). Importantly, the surface concentration of electroactive redox centers was found strongly dependent on the scan rate for multilayer functionalized film contrary to that obtained on controlled layer, and higher electrocatalytic performances were highlighted.

Acyl halide activation. The preparation of acyl halides represents one of the most common way for activate carboxylic acids in view of coupling with amine derivatives. The two-step procedure consists in the formation of the acyl derivative,
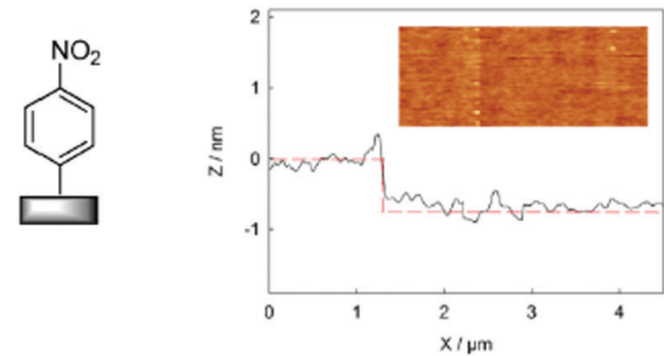

$6 \mathrm{~nm}$
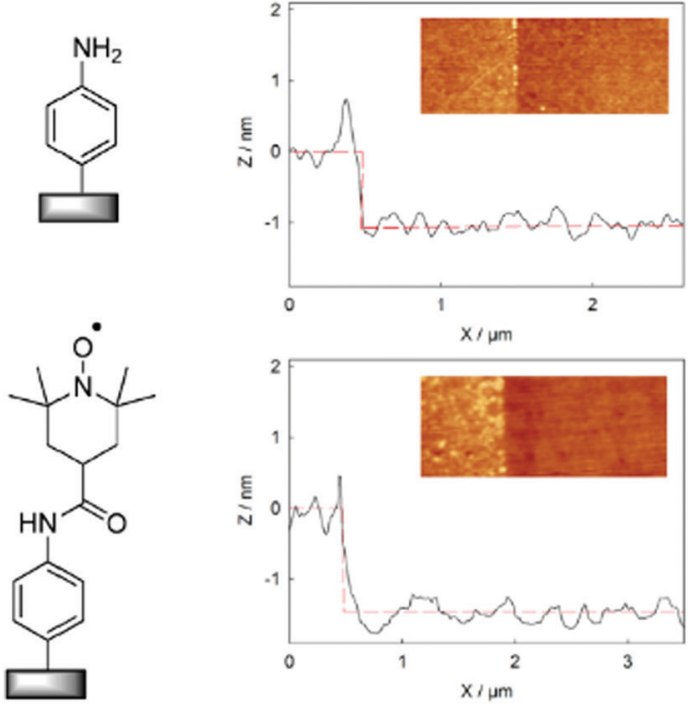

$-5 \mathrm{~nm}$

Fig. 4 AFM topography images $(3.3 \times 1.3 \mathrm{~mm})$ and the corresponding depth profiles of the modified PPF with 4-nitrobenzene diazonium in the presence DPPH, after reduction, and after coupling with 4-carboxyTEMPO. Reprinted with permission from ref. 80 .

followed by immediate treatment with the amine. The main drawback of this approach is its sensitivity to water traces, which can cause rapid hydrolysis of the intermediate. Oxalyl chloride $(\mathrm{COCl})_{2}$ is generally used for on-surface chemistry to generate acyl chlorides from their corresponding acids. Depending on the starting immobilized function (i.e. amine or acid), the resulting layer can present very different chemical behavior and/or electronic properties. Two studies, published by Hapiot et al., are centered on those aspects, exploiting the ferrocene $(\mathrm{COCl})_{2} /$ pyridine activated post-functionalization of glassy carbon electrodes tethered by aminophenyl and carboxyphenyl under-layers. In the first one ${ }^{81}$ it was shown that, for both sublayers, the coupling reaction to ferrocene units only occurs at the upper layers of each type of films, leading to identical surface coverages for any thickness. Interestingly, the ferrocene surface concentration of films prepared from aminophenyl sublayer is four-fold higher than that obtained from carboxyphenyl ones (i.e. $2.3 \times 10^{-9}$ vs. $5.3 \times 10^{-10} \mathrm{~mol} \mathrm{~cm}^{-2}$ ). This difference was explained by the fact that the $\mathrm{Ar}-\mathrm{NH}_{2}$ film is more porous, allowing coupling reactions inside the structure. In the second paper, redox properties were examined using scanning electrochemical microscopy, and very similar electrochemical characteristics were obtained for both layers. ${ }^{82}$ The same group applied the ferrocene post-functionalization to a 
monolayer of carboxy-calix[4]arenediazonium derivatives grafted on gold and PPF surfaces using identical coupling conditions. ${ }^{83}$ It was determined by XPS and voltammetric measurements that roughly $80 \%$ of the calixarenes reacted with aminoferrocene moieties, leading to a surface coverage of $6.9 \times 10^{-10} \mathrm{~mol} \mathrm{~cm}^{-2}$. The authors extended this work to the preparation of mixed layers starting from various ratio of functionalizable and nonfunctionalizable calixarenes on gold. ${ }^{84}$ The voltammetric quantification of the attached ferrocene groups evidenced a higher amide coupling yield for diluted carboxy-calixarenes, demonstrating that the steric hindrance has an impact on the interfacial reactivity. More recently, the calix[4]arene platform was exploited to attach calix[6]arene $\mathrm{Cu}$ complex via $(\mathrm{COCl})_{2}$ activation to prepare a sensing surface dedicated to the electrochemical transduction of neutral molecule recognition, as isopropylamine or acetonitrile. ${ }^{85}$ The authors reported that, contrary to the thiol-based monolayer, which is responsive only in water, the calix[4]arene-based monolayer prepared from diazonium chemistry is responsive in both aqueous and organic media.

Optimization of the oxalyl chloride mediated heterogeneous coupling was presented on elegant studies reported by Downard et al., aiming to develop well-defined reactive tether monolayer for on-surface chemistry. For those works, amine ${ }^{86}$ and carboxylic acid tethered carbon surfaces were prepared via the grafting of Fmoc-protected (fluorenylmethyloxycarbonyl) diazonium precursors. After deprotection, aminophenyl and carboxyphenyl modified monolayer surfaces were respectively coupled with carboxy and amino derivatives of nitrophenyl and ferrocene moieties using oxalyl chloride and pyridine in dichloromethane. Starting from carboxyphenyl modified electrodes ${ }^{87}$ nitrophenyl and ferrocene surface coverages, electrochemically determined, were found identical (i.e. $4.1 \times 10^{-10} \mathrm{~mol} \mathrm{~cm}^{-2}$ ), demonstrating that the steric hindrance is not a limiting factor on such loosely packed layers (Fig. 5). The low nitrophenyl surface coverage (i.e. $0.4 \times 10^{-10} \mathrm{~mol} \mathrm{~cm}{ }^{-2}$ ) obtained after a blank experiment carried out without activating agent confirmed the efficiency of oxalyl chloride for this heterogeneous reaction. Starting from aminophenyl modified electrodes, surface coverages of 3.2 and $2.5 \times 10^{-10} \mathrm{~mol} \mathrm{~cm}^{-2}$ were obtained after coupling with nitrophenyl and ferrocene derivatives respectively. Those values are significantly lower than those obtained using the carboxyphenyl tethered surface. The use of Boc (tert-butoxycarbonyl) protecting group, instead of Fmoc for the reactive layer preparation, allows to increase the surface coverage of nitrophenyl and ferrocene up to
5.4 and $4.5 \times 10^{-10} \mathrm{~mol} \mathrm{~cm}^{-2}$, respectively. This result was explained by the low steric hindrance of the Boc group, which allows the formation of multilayer on the surface, and consequently increases the aminophenyl surface concentration.

Thionyl chloride $\left(\mathrm{SOCl}_{2}\right)$, instead of oxalyl chloride, has been used for acid activation in few studies involving carboxyphenyl modified surfaces. The Downard's group exploited this postfunctionalization route to pattern carbon, silicon and metal surfaces with thin organic films by microcontact printing. ${ }^{88}$ An AFM monitoring using the scratching method was performed on PPF. It was shown that the peptide coupling of nitroaniline onto carboxyphenyl tethered surfaces increased the layer thickness from $1.0 \pm 0.3 \mathrm{~nm}$ to $2.0 \pm 0.5 \mathrm{~nm}$, what is consistent with the addition of a nitroaniline unit on the top of the layer. Thionyl chloride activation has also been used after spontaneous grafting of in situ generated carboxyphenyl diazonium. ${ }^{89}$ In this work, Freire et al. studied the impact of the multi walled carbon nanotubes (MWCNT) modification method on their optical properties. It was shown that a simple $\mathrm{Zn}$ (II)porphyrin physisorption route provided a lower surface concentration than that obtained by a covalent attachment (i.e. peptide coupling on carboxy-tethered MWCNT). However, as evidenced by fluorescence and infra-red spectroscopy, the post-functionalization led to weaker interactions between porphyrin units compared to physisorbed ones, probably because of the absence of stacking imposed by the covalent immobilization constraints. The same approach was reported for nanotubes and graphene post-functionalization for electrochemically-aided atom transfer radical polymerization (e-ATRP) and reversible addition chain transfer polymerization (RAFT) ${ }^{90}$ Initially modified by reduction of in situ generated carboxyphenyl diazonium, the carbon surfaces were then coupled to e-ATRP and RAFT initiators to obtain a supported polymerization. The poly(pyrrole) modified nanotubes exhibited an enhanced capacitance and stability compared to unmodified ones, validating this anchoring method.

A last option consists in the use of an acyl chloride previously prepared and isolated, to be coupled with a surface modified by diazonium electroreduction. Bartlett et al. have exploited this approach on glassy carbon to study the coupling of a series of 13 hydroxybenzene derivatives. ${ }^{91}$ First, Bocprotected diazoniated $\mathrm{NHCH}_{2} \mathrm{C}_{6} \mathrm{H}_{4}$ was electrochemically attached to the carbon surface, and after Boc-deprotection, dimethoxybenzoyl chlorides were coupled to $\mathrm{C}_{6} \mathrm{H}_{4} \mathrm{CH}_{2} \mathrm{NH}-$ modified electrodes in a pyridine/dichloromethane mixture.
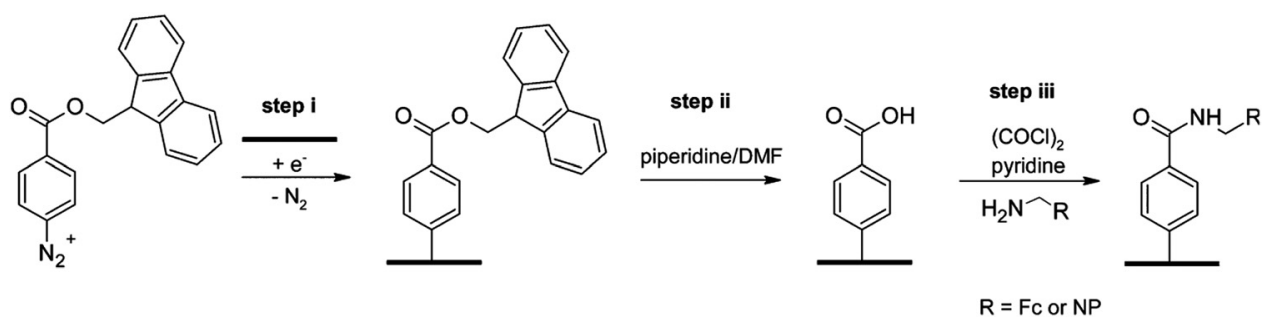

Fig. 5 Strategy for preparation of the Ar- $\mathrm{COOH}$ monolayer and for coupling Fc and NP groups to the layer. Reprinted with permission from ref. 87. 
Surface coverages, extracted from cyclic voltammetry, were comprised between 2.4 and $6.8 \times 10^{-10} \mathrm{~mol} \mathrm{~cm}^{-2}$ depending on the dihydroxybenzene ring pattern substitution. Values for the peak separation vary from 64 to $150 \mathrm{mV}$, what is consistent with a quasi-reversible behavior. All the results were compared with those obtained by replacing the diazonium electrografting by an anodic grafting of an ethylenediamine linker. The electrochemical characterization did not show any surface coverage difference but a trend for smaller peak separation, corresponding to faster electron transfer rate. Acyl chloride was also exploited by Geneste $e t$ al. to post-functionalize aminophenyl tethered graphite surfaces obtained by 4-nitrobenzene electrografting, subsequently electro-reduced. ${ }^{92}$ The coupling of a bifunctional spacer (i.e. 5-chlorocarbonyl-pentanoic acid methyl ester) in toluene containing trimethylamine led to a reactive surface exploitable for the attachment of sensitive biomolecules as antibodies. The surface coverages, estimated before and after post-functionalization through voltammetric study of the nitrophenyl groups were respectively equal to 9 and $14 \times$ $10^{-9} \mathrm{~mol} \mathrm{~cm}^{-2}$, showing the efficiency of the immobilization process. The surface coverage increase appeared difficult to explain but the authors argued in favor of a partial electroactivity of the nitrophenyl groups after the first step (i.e. electrografting of the corresponding diazonium). A similar approach was recently developed by Blacha-Grzechnik to attach phenothiazines dedicated to the generation of singlet oxygen for wastewater treatment. ${ }^{93}$ The aminophenyl tethered glassy carbon surface was obtained by the classical 4-nitrobenzene diazonium reduction followed by its electroreduction in acidic medium. Coupling of the terephthaloyle chloride, playing the role of bi-functional spacer, was carried out in THF at high concentration $(0.1 \mathrm{M})$ and in the presence of triethylamine. The last step involved the amino-phenothiazine coupling following the same protocol. From a nitrophenyl surface coverage close to $10^{-9} \mathrm{~mol} \mathrm{~cm}^{-2}$, a final surface concentration tenfold lower was estimated after phenothiazine coupling. This drop was attributed to the steric hindrance of the polycyclic photoactive structures but the authors pointed out that a surface concentration of $10^{-9} \mathrm{~mol} \mathrm{~cm}^{-2}$ can be reached by direct diazotization of the phenothiazine.

Anhydride activation. Another practical way to highly increase the electrophilicity of the carboxylic acid function and reach high coupling reaction yield is to exploit the reactivity of the anhydride derivative. This strategy was only used a few times to attach chemical groups on $\mathrm{NH}_{2}$-tethered surfaces. Wang and Carlisle were the first authors reporting this post-functionalization route to prepare a glucose sensor on ultrananocrystalline diamond (UNCD) ${ }^{94}$ Such substrate is characterized by a very low background current, associated to a wide working potential window and a high resistance upon chemical oxidation. The strength of the strategy presented lies in the proposition of a general approach including the electrografting of the 4-nitrobenzene diazonium, its electrochemical reduction into an aminophenyl group and its subsequent post-functionalization by a $2 \mathrm{~h}$-dipping in $0.1 \mathrm{M}$ of succinic anhydride. XPS analysis of the so-obtained reactive platform confirmed an efficient immobilization of the carboxy functions (O/C ratio about 18.4\%). GOx was then attached via a classical EDC/NHS coupling and showed good ability to detect glucose, demonstrating that the film generated by postfunctionalization remains permeable to hydrogen peroxide. Anhydride derivatives was then used by Bélanger $e t$ al. in two different studies to characterize aminophenyl tethered gold surface and carbon powder. In those works, trifluoroacetic anhydride acid (TFAA) was used as fluor-containing probe for infrared spectroscopy and XPS measurements to highlight the presence of amine functions. In a first report, gold substrates directly modified by in situ mono-diazotization of $p$-phenylenediamine were left to react with TFAA in dry THF to form amide link..$^{95}$ In addition to the peaks corresponding to amide and trifluoromethyl stretching vibration observed on infrared spectroscopy spectra, XPS measurements unambiguously revealed the efficiency of the coupling. The modification of the $\mathrm{N} 1 \mathrm{~s}$ core level spectrum allowed the authors to estimate a coupling yield of $70 \%$. This value was confirmed via the calculation of the $\mathrm{F} / \mathrm{N}$ atomic ratio (i.e. 2.32), corresponding to a yield of $77 \%$ for the transformation. The second report dealed with the modification of carbon black by aminobenzyl groups, obtained from chemical reduction of cyanophenyl modified powder (Fig. 6). ${ }^{96}$ In this study, XPS measurements, based on the same determination method, confirm that the yield of the acylation is near $100 \%$, but the authors conceded that an accurate calculation of the coupling remained difficult due to an overlapping of the trifluoroacetamide and cyano $\mathrm{N}$ 1s components. An interesting comparison was made with a TFAA coupling using aminophenylmodified carbon, for which the reaction yield did not exceed 55\%. The higher reactivity of the aminobenzyl-modified carbon was attributed to the fact that the amine of the benzyl group is better nucleophile.

Uronium salt activation. The use of benzotriazole derivatives as uronium salt for the activation of amine tethered surface has also been reported. This strategy allows to avoid a two-step acyl activation and leads to an amide bond formation in very mild conditions. Bartlett and Kilburn were the first to follow this way for heterogeneous coupling in the aim of developing a flexible approach for the covalent attachment of organic groups on carbon. ${ }^{97}$ The first step consists in the electrografting of the BocNH- $-\mathrm{CH}_{2} \mathrm{C}_{6} \mathrm{H}_{4}$ protected diazonium by cyclic voltammetry. Following the amine deprotection in acidic conditions ( $\mathrm{HCl}$ $4 \mathrm{M}$ ), a carboxylic derivative of anthraquinone was coupled in DMF at room temperature for $16 \mathrm{~h}$ with the amine tethered carbon in the presence of 1.2 equivalent of hexafluorophosphate benzotriazole tetramethyl uranium (HBTU). The surface coverage, calculated by integration of the redox voltammetric signal of the anthraquinone group, was estimated to $7 \times$ $10^{-10} \mathrm{~mol} \mathrm{~cm}^{-2}$, value in the order of a monolayer. A parallel strategy exploiting the ethylene diamine oxidation instead of diazonium electrografting for the preparation of the reactive layer led to a $30 \%$ increase of the ferrocene surface coverage and an enhanced electron transfer rate. Those observations were attributed to the greater steric hindrance of the phenyl ring compared to the ethylene diamine structure. In a second 


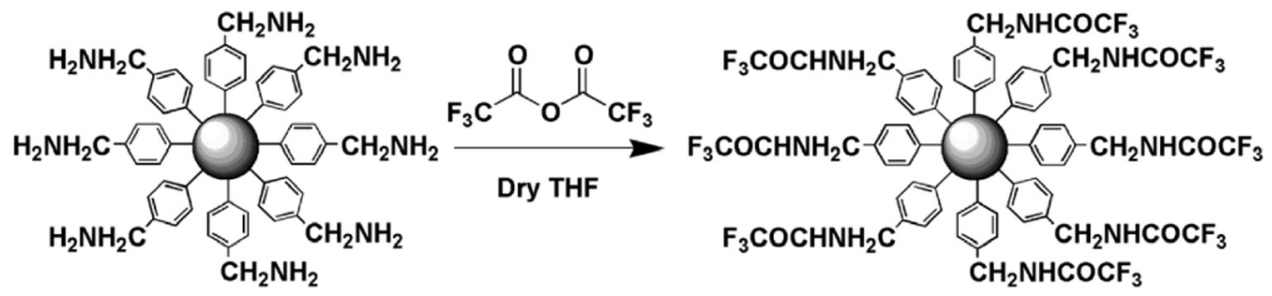

Fig. 6 Chemical derivatization of aminobenzyl-modified carbons by reaction with trifluoroacetic acid anhydride. Reprinted with permission from ref. 96 .

study exploiting the same strategy, the authors compared the results obtained for the attachment of anthraquinone and nitrobenzene groups. ${ }^{98}$ Interestingly, contrary to that observed for anthraquinone modified surfaces, no difference in terms of surface coverage (i.e. around $10 \times 10^{-10} \mathrm{~mol} \mathrm{~cm}^{-2}$ ) and electron transfer rate was found between nitrobenzene tethered carbon obtained via diazonium reduction and amine oxidation techniques. Bartlett and Kilburn have successfully extended their HBTU assisted post-functionalization protocol to the grafting of anthraquinone on nanostructured gold electrodes (Fig. 7) ${ }^{99}$ and MWCNT, ${ }^{100}$ demonstrating the robustness of the link between substrate and organics. This approach was exploited to prepare anthraquinone and antracene tethered glassy carbon electrode dedicated to the adsorption of Trametes hirsuta laccase (ThL). ${ }^{101}$ Functional surfaces thus prepared contained only $5 \%$ of an estimated compact monolayer but were able to catalyse oxygen reduction. In 2013, those authors applied the same coupling protocol to graft anthraquinone on modified nanotubes without electrochemical induction. ${ }^{102}$ By refluxing the carbon nanotubes with the BocNH- $\mathrm{CH}_{2} \mathrm{C}_{6} \mathrm{H}_{4}$ diazonium derivative to prepare the reactive layer, the final anthraquinone surface coverage was found slightly higher than the one obtained using cyclic voltammetry (0.21 and $0.19 \mathrm{mmol} \mathrm{g}^{-1}$ respectively) and three times higher than that previously reported by Biernat et al. by exploiting an in situ generated diazonium salt. An interesting point is that the redox current calculated from the voltammetric study is directly proportional to the loading of modified CNT, what is consistent with a full electroactivity of the material and consequently an absence of multilayers. This sequential spontaneous grafting of Boc-aminophenyl benzene followed by solid phase coupling was exploited by Bartlett and coworkers for the combinatorial preparation and electrochemical screening of a library of modified electrodes designed to catalyse the NADH oxidation. ${ }^{103}$ In this study, zinc and ruthenium metal complexes were attached to glassy carbon via four different linkers before complexation of the redox active 1,10phenanthroline-5,6-dione. The diazonium technique was found less efficient than the amine oxidation route regarding the obtained surface coverages (around $0.3 \times 10^{-10} \mathrm{~mol} \mathrm{~cm}^{-2}$ ), thus providing lower catalytical activity. This result was attributed to the lack of flexibility of the structure which can limit the ability of the 2,2'-bipyridine ligand to coordinate the metal ion of this large complex. Very recently, SWCNTs, modified by Fmoc-protected phenylamine, were post-functionalized by fluorophores using hexafluorophosphate azabenzotriazole tetramethyl uronium (HATU) activation. In this work, Kruss et al.
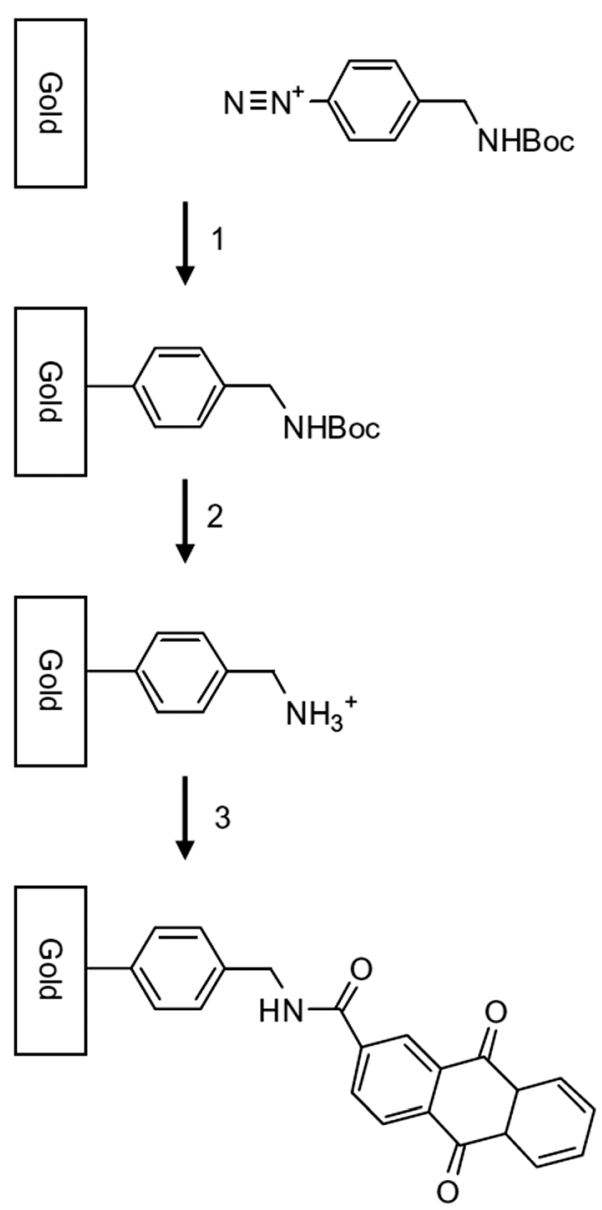

Fig. 7 Covalent modification of gold surface by electrochemical reduction of a Boc-protected diazonium salt followed by removal of the Boc protecting group and then coupling of anthraquinone-2-carboxylic acid. Reprinted with permission from ref. 99.

exploited quantum defects of the surface to successfully anchor peptides and proteins. ${ }^{104}$

Two other fundamental studies, focused on the post functionalization efficiency using various approaches, were reported by Downard and coworkers. In the first one, $\mathrm{NH}_{2}$-tethered carbon surfaces were obtained by electrografting and deprotection of Boc- and Fmoc protected aminobenzyldiazonium salts. $\mathrm{FcCH}_{2} \mathrm{COOH}$ and $\mathrm{FcCOOH}$ were then coupled to those surfaces via HBTU activation to generate an amide bond. ${ }^{86}$ The ratio benzotriazole/carboxylic acid was the same as that used by the Bartlett group with a concentration twice as small. 
The modified electrodes showed surface coverages comprised between 0.5 and $1.4 \times 10^{-10} \mathrm{~mol} \mathrm{~cm}{ }^{-2}$ for monolayers and around $4 \times 10^{-10} \mathrm{~mol} \mathrm{~cm}{ }^{-2}$ in the case of multilayered $\mathrm{NH}_{2}$ terminated sublayers. Interestingly, the surface concentration of ferrocene attached via the coupling of $\mathrm{FcCH}_{2} \mathrm{COOH}$ was systematically higher than the one observed when $\mathrm{FcCOOH}$ was used. This observation was attributed to both steric and electronic effects, and can be balanced with the conclusion drawn by the Bartlett's group regarding the flexibility required for the structure to be gratfed. ${ }^{103}$ In a second study, focused on the development of a back-filling strategy of sparse monolayers, Downard and coworkers exploited the HBTU assisted coupling to postfunctionalize $\mathrm{NH}_{2}$ and $\mathrm{COOH}$ tethered carbon surfaces with ferrocene derivatives. ${ }^{105}$ Surface coverages, determined by voltammetric study of the $\mathrm{Fc} / \mathrm{Fc}^{+}$system, were found higher for $\mathrm{COOH}$ starting reactive surfaces than for $\mathrm{NH}_{2}$ ones (i.e. 2.8 and $1.4 \times$ $10^{-10} \mathrm{~mol} \mathrm{~cm}{ }^{-2}$ respectively). The difference was explained by the fact that the amino ferrocene derivative can not only react with the sparse carboxy tethered layer by peptide coupling, but is also able to directly attack the ungrafted areas of the carbon surface. This layer backfilling leads to a doubling of the surface coverage.

\subsection{Click chemistry}

The term "click chemistry" was introduced by Sharpless and coworkers in 2001 to describe a category of synthetic methods that meet the criteria set out in the following sentence: "The reaction must be modular, wide in scope, give very high yields, generate only inoffensive byproducts that can be removed by nonchromatographic methods, and be stereospecific (but not necessarily enantioselective)". ${ }^{106}$ Among all reactions listed in "click chemistry" the most famous is undeniably the copper(I)catalyzed Huisgen 1,3 dipolar cycloaddition. ${ }^{107}$ Three years after its first description in homogeneous medium, the method has been used to modify surfaces. ${ }^{108}$ To reach this goal, the authors managed the immobilization of acetylene modified ferrocene derivatives on azido-terminated self-assembled monolayers. This mild, convenient and high yielding coupling method quickly turned out to be a powerful tool for functionalizing surfaces. After several examples reported on selfassembled monolayers, ${ }^{109-112}$ the reaction was extended in 2008 to reactive organic interfaces obtained by reduction of a diazonium salt on SWCNT ${ }^{113}$ or on carbon electrodes. ${ }^{114}$ At once the reactivity of an azide or acetylene-terminated layer toward ethynyl or azido ferrocene, respectively, was highlighted. ${ }^{114}$ These azide- or alkyne-modified surfaces react efficiently and rapidly with compounds bearing an acetylene or an azide function respectively, thus forming a covalent 1,2,3triazole linkage by means of click chemistry.

This approach, compatible with a myriad of electroactive groups, has been exploited to immobilize ferrocene, ${ }^{105,114-141}$ porphyrin, ${ }^{142}$ phthalocyanin, ${ }^{113,143-146}$ tetrathiafulvalene, ${ }^{147}$ fluorene, ${ }^{148,149}$ BODIPY, ${ }^{150,151}$ metallic complexes, ${ }^{85,152-154}$ TEMPO $^{155}$ or nitrophenyl derivatives. ${ }^{138}$ The role of the redox probe varies according to the nature of the studies undertaken. When the latter are biological application-oriented, chemical coupling with a redox entity constitutes the preliminary step to optimize the reaction, assess the robustness of the linkage and estimate the maximum coupling yield, since the biomolecules to be grafted are biggest than the redox species. ${ }^{114,129,136,141,156}$ In these studies, ferrocene, which gives a reversible and stable redox signal, is commercially available, inexpensive and easily chemically functionalizable, was chosen as model molecule. These reasons also motivated the use of this redox probe to validate and better understand different concepts including functionalization of non-conventional electrodes, ${ }^{132,135,140,157,158}$ electron transfer, ${ }^{125,127,128,159}$ formation of more or less compact monolayers, ${ }^{105,115,123,124,130,137,139}$ fabrication of mixed (mono)layers, ${ }^{105,116,120,122,138}$ surface structuring, ${ }^{117,126,131,133}$ building of dendrimer modified surfaces. ${ }^{119}$ Immobilization of this molecule on a reactive platform is also a good way to compare the effectiveness of different functionalization methods. ${ }^{118,121,134}$ Even if more than half of the studies based on the immobilization of redox probes by click chemistry rely on the use of ferrocene, other less conventional redox probes have made it possible to widen the field of study and applications of electroactive surfaces. Additional spectroscopic analyzes (Raman, absorption or emission spectroscopies) have provided additional information on organic layers modified by fluorene, ${ }^{148}$ BODIPY, ${ }^{150,151}$ porphyrin $^{142}$ or phthalocyanin ${ }^{113}$ derivatives. Targetted applications have also boosted the development of the latter (phthalocyanin-based surfaces), ${ }^{143-146}$ since they are characterized, similarly to surfaces based on TEMPO ${ }^{155}$ or metal complexes, ${ }^{153,154,156,160}$ by good electrocatalytic properties. Immobilization of metal complexes has also been exploited for the development of molecular switches ${ }^{152}$ or electrochemical sensors for alkylamine ${ }^{85}$ and that of TTF for the formation of charge transfer complexes with tetracyanoquinodimethane (Fig. 8). ${ }^{147}$

The mild conditions required for the anchoring of the entities by click chemistry make it a very convenient method for the immobilization of biological material, mainly for the development of biosensors. This way has led to the elaboration of DNA (or aptamer), ${ }^{129,161-164}$ enzyme, ${ }^{114,141,165,166}$ non enzymatic protein, ${ }^{167}$ peptide ${ }^{136}$ or amino acid $^{168}$-modified surfaces.

The other studies, not falling into the two aforementioned categories (immobilization of redox molecules or biomolecules), relate to the modification of reactive platforms by gold nanoparticles, ${ }^{169-171}$ polymers (already synthesized ${ }^{172,173}$ or via direct growth from the surface $\mathrm{e}^{174-176}$ ), or other molecules like azobenzene ${ }^{177}$ or azlactone. ${ }^{178}$

Excluding the rare examples based on thiol-ene ${ }^{156,179}$ or thiol-yne reactions, ${ }^{180,181}$ click chemistry on surface consists in a reaction between an azide and an alkyne functions. Thus, two strategies can be envisaged: a coupling of an alkyne terminated target on an azide tethered surface, or a coupling of an azide derivative with an alkyne modified surface. These two routes which are rarely compared in a same study, ${ }^{114,162}$ will be developed in the two following paragraphs.

Reaction between an azide platform and an alkyne terminated target. According to the required needs of the intended organic final layer, azide platform can be obtained either by 


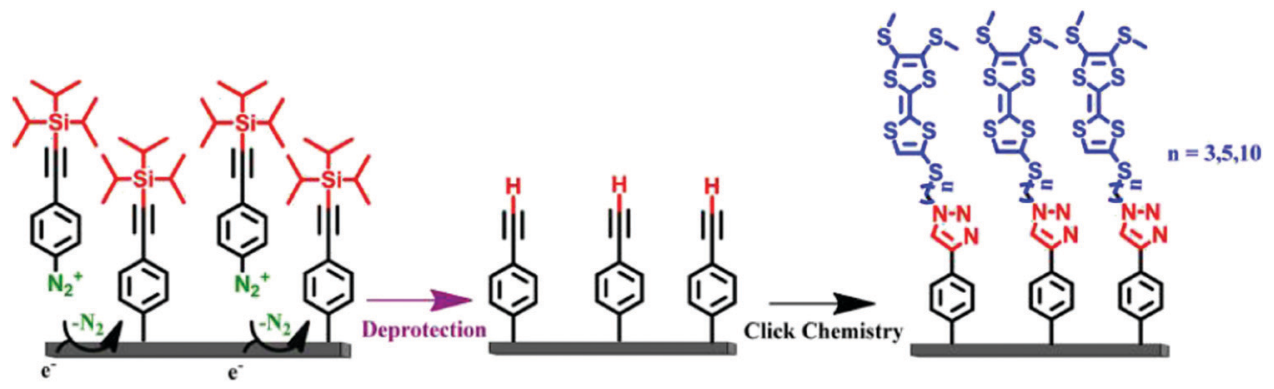

Fig. 8 Functionalization of carbon surfaces by TTF-Terminated Monolayers. Reprinted with permission from ref. 147.

direct reduction of an azidobenzene diazonium or by chemical modification of a grafted azide precursor.

Only very few articles report the latter approach, likely thanks to the ease of azide synthesis involved in the first one. ${ }^{150,172}$ An other advantage of the first route lies in the possibility of limiting uncontrolled growth during the deposition by the use of cleavable bulky protecting groups ${ }^{130}$ (this strategy, which is much more common from an acetylene-based platform will be developed in the next paragraph). The introduction of the azido function on the modified surface has also been included in an intricate multistep sequence ${ }^{170}$ allowing, for example, the formation of a thermoresponsive polymer layer enabling the variation of the distance between the substrate and subsequent immobilized gold nanoparticles. ${ }^{182}$

The direct grafting of a diazonium bearing an azide moiety, which is undoubtedly the less hazardous way, is generally preferred since azido-functionalized layers can be obtained with a limited number of steps. Most of the reported studies are based on the 4-azidobenzene diazonium grafting or on the grafting of its in situ diazotized corresponding amine precursor. The latter compound (4-azidoaniline) is itself classically obtained from 4-iodoaniline or 4-bromoaniline.

Concerning the reaction between the azido-functionalized platform and the acetylene derivatives, reaction conditions are close to those used in homogeneous medium but can vary from one CuCAAC reaction to another. Especially, the protocol followed for the copper(I) preparation (and consequently the solvent), the reaction duration and the concentration of the reagents differ:

- Due to its spontaneous oxidation into $\mathrm{Cu}(\mathrm{II})$, copper(I) is not stable under atmospheric conditions, which justifies that the reaction is often carried out under argon or nitrogen. ${ }^{120,130,138,151,155,170,172,182}$ It can be obtained from three main routes. The first one, the most usual one, involves the chemical reduction (by L-ascorbic acid or L-sodium ascorbate) of various $\mathrm{Cu}$ (II) salts (generally sulfate or acetate) to form $\mathrm{Cu}(\mathrm{I}){ }^{114,117,118,120,129-131,133,136,141,152,153,156,159,161,170,171,182}$ Large excess in reducing agent (molar ratios [reducing agent/Cu(II)] varying from $1^{114,133}$ to $50^{171}$ ) guarantees a sufficient $\mathrm{Cu}(\mathrm{I})$ concentration in the medium, even when the reaction mixture is not kept under inert atmosphere. $\mathrm{Cu}(\mathrm{I})$ can also be generated electrochemically by reduction of $\mathrm{Cu}(\mathrm{II})^{126,167,169}$ or oxidation of $\mathrm{Cu}(0)$ (Fig. 9). ${ }^{131}$ This "electro-click" method offers the opportunity to locally trigger the coupling reaction by using scanning a) Approach

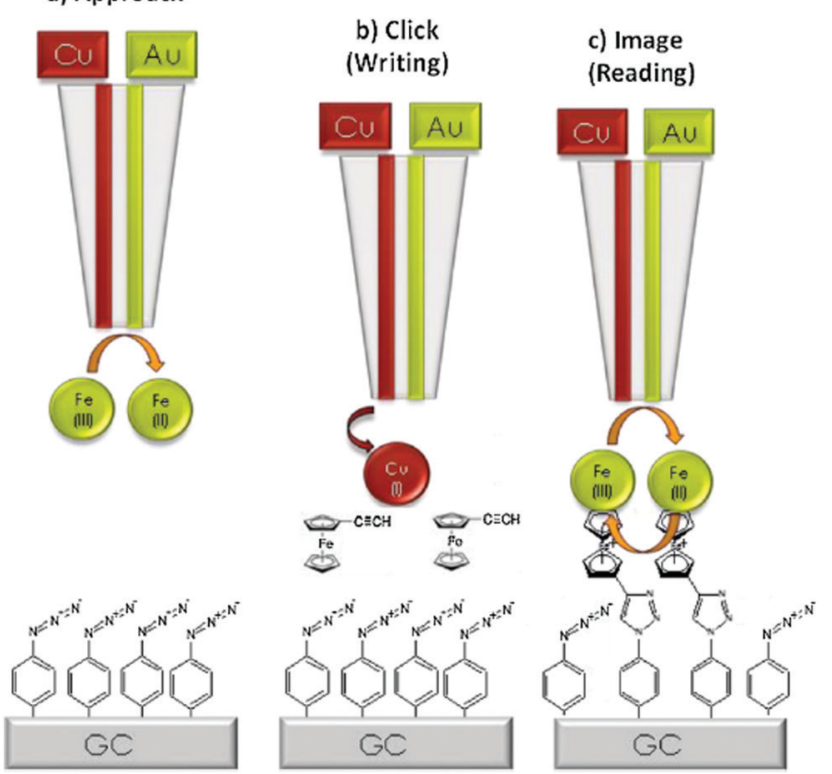

Fig. 9 Procedure for the localized electroclick reaction with a dual goldcopper microelectrode. Reprinted with permission from ref. 131.

electrochemical microscopy. ${ }^{126,131}$ Lastly, $\mathrm{Cu}(\mathrm{I})$, often stabilized by a ligand, can be directly added in the reactional medium. ${ }^{129,138,143-146,150,151,154,155,162,172,174}$

- The reaction duration can vary from a few minutes, for electrochemically driven $\mathrm{Cu}(\mathrm{I})$ generation, ${ }^{126,167,169}$ to $48 \mathrm{~h} .^{120,150,151}$ The reaction is usually carried out at room temperature, but in few rare cases, the authors resort to heating. ${ }^{120,151,174}$ It appears that the use of harsher experimental conditions (long reaction times and high temperatures) concerns the modification of particles (carbon-coated cobalt nanoparticles, carbon nanotubes or exfoliated $\mathrm{MoS}_{2}$ nanosheets).

- The concentration of the reagents is of course dependent on their solubility, ${ }^{169}$ availability (commercially available, or synthesized) and comparative reactivity. Whatever the experimental conditions chosen by the authors, the quantities of available functions on the surface (azide functions) are very much lower than those of the reactants required in solution. It is however difficult to precisely determine the number of equivalents of reactants required in solution because the quantification of azide functions (particularly those which are accessible to post-functionalization) is not trivial. There is no 
universal truth regarding the [alkyne/Cu(I)] ratio used and the concentrations vary considerably from one study to another. Copper (II or I), ligands, ascorbic acid or sodium ascorbate, which are inexpensive reagents, are often introduced in large excess (from $0.25 \mu \mathrm{M}^{169}$ to $0.1 \mathrm{M}^{138,155}$ ). Even if the proportions of the different introduced species are not justified by the authors, because they often result from optimized procedures, it seems very likely from a review of published studies, that the synthetic difficulties or the cost dictate the amount of alkyne employed. In particular, reactions involving biological species (proteins, ${ }^{136,167}$ aptamer, ${ }^{161}$ or DNA $^{162}$ ), which have a high added value, are carried out with very low concentrations of acetylene derivative (which becomes the limiting reagent in this type of reaction).

Since surface reactions are considered, the coupling yields, which are more difficult to determine than for experiments carried out in solution, are rarely reported. However, in a few studies, the "clicked species" have been quantified, most often thanks to the charge calculated from electrochemical studies of immobilized electroactive species. Whatever the experimental conditions used to carry out the cycloaddition, the ferrocene surface coverages obtained from the coupling between a ferrocenyl acetylene derivative and an azide platform obtained by reduction of 4-azidobenzenediazonium, are comprised between $1.5^{136}$ and $4.9^{118} 10^{-10} \mathrm{~mol} \mathrm{~cm}{ }^{-2}$. These values are of the order of that expected for a close-packed ferrocenyl self-assembled monolayer $^{183}$ and no increase of this value has been evidenced with an increasing thickness of the azido-benzene sublayer. Such result shows that only the upper part of the multilayers is concerned by the coupling reaction. In some special cases, a variation of this value can be observed. In particular, for azide platforms obtained by successive modifications of an organic layer bearing cleavable bulky groups, the ferrocene surface coverage is much lower (i.e. $8 \times 10^{-11} \mathrm{~mol} \mathrm{~cm}^{-2}$ ), probably due the low yield arising from the multi-step procedure involved in the reactive platform formation. ${ }^{130}$ Conversely, the elaboration of nanostructured azide derived films using self-assembled polystyrene spheres as templates drives to the obtaining of porous materials enabling the immobilization of $13.8 \times 10^{-10} \mathrm{~mol}$ of ferrocene per $\mathrm{cm}^{2} .^{117}$

Logically, electroactive molecules of comparable sizes led to similar electrochemical surface coverages $\left(3.1 \times 10^{-10} \mathrm{~mol}\right.$ $\mathrm{cm}^{-2}$ for cobaltocenium or $3 \times 10^{-10} \mathrm{~mol} \mathrm{~cm}{ }^{-2}$ for TEMPO) and larger molecules led to lower values $\left(3.9 \times 10^{-11} \mathrm{~mol} \mathrm{~cm}^{-2}\right.$ for a bulky ruthenium complex). To determine the reaction yield, these data have to be compared with the initial quantity of azide functions on the surface, but the electro-inactivity of the latter makes impossible the determination of the coupling efficiency by electrochemistry. It is however possible to give an estimation using XPS, by monitoring the disappearance of the characteristic signal of the azide central nitrogen, characterized by a higher binding energy $(\sim 404 \mathrm{eV})$ than the two other nitrogen atoms. ${ }^{143,146,153}$

We have identified only two articles exploiting both azide and alkyne platforms to perform the reaction with acetylene and azide derivatives, respectively. ${ }^{114,162}$ One of them was interested in the comparative reactivity of the two approaches. It appears from this study that the ferrocene surface concentration is doubled upon passing from acetylene- to azidemodified electrode. Two hypotheses have been put forward by the authors to explain this difference. (i) the electrode functionalization by electroreduction of 4-ethynylbenzene diazonium is less effective than exploiting electroreduction of 4-azidobenzene diazonium, (ii) the click-coupling yield is lower from a phenylacetylene layer than from a phenylazido one. This interesting article, published in 2008, was the first to study the post-functionalization of an electrode by click chemistry. ${ }^{114}$ In the light of the work published later (vide supra), the second hypothesis seems to be the most likely since a multilayer does not allow the immobilization of a greater amount of molecules than a monolayer do (the species buried within a thick layer being inaccessible for post-functionalization due to steric hindrance).

Reaction between an alkyne terminated platform and an azide terminated target. Many of the observations made in the aforwritten paragraph remain true in this one, so, to avoid repetitions, we especially emphasize here on the differences observed with this second post-functionalization route.

The panel of chemical species immobilized on surface via this second approach is similar to that observed for the first one (i.e. starting from an azide platform) since about $2 / 3$ of the reactions are based on the immobilization of redox groups (27 refs out of 40 against 22 refs out of 34 in the previous paragraph). The remaining 13 studies deal with the immobilization of bio-entities, ${ }^{162-166,168}$ small organic molecules ${ }^{158,177,178}$ or polymers ${ }^{173}$ (or the initiator allowing polymerization from the surface $\left.^{175,176}\right)$.

Whether they are carried out in one direction or another (azide surface and alkyne in solution, or the opposite), the couplings are made under similar operating conditions. Cupper(I) is always used as a reaction catalyst (directly added, ${ }^{134,148,162,173,175}$ or formed in situ from cupper(II) and a reducing agent ${ }^{85,105,113-115,119,121-124,127,128,132,135,139,140,142,147,149,157,158,160, ~}$ $163-166,168,177,178$ or electrochemically generated $\left.{ }^{137,176}\right)$. The most common option relies on the combined use of copper(II) sulfate and ascorbic acid (or sodium ascorbate, usually in excess) as reducing agent. Otherwise, in some cases, the authors resort to the use of a chelating agent to stabilize copper(I).

A disparity in reaction times, similar to that observed when azide platform is used, must be noted (varying from $5 \mathrm{~min}^{163}$ to $72 \mathrm{~h}^{142}$ ). Even though the vast majority of reactions are carried out at room temperature, low temperatures $\left(4{ }^{\circ} \mathrm{C}\right.$, for the immobilization of biological entities ${ }^{164,165}$ ) or high temperatures $\left(150{ }^{\circ} \mathrm{C}\right.$, for the immobilization of porphyrin on carbon nano-onions, Fig. $10^{142}$ ) may be required depending on the needs and the stability of the molecular structures used. As already been observed for azide platforms, $\mathrm{Cu}$ /azide molar ratios, governed by the commercial availability, the cost or the reactivity of the entities involved, are very different from one study to another.

Most often, the phenylacetylene diazonium is directly reduced to give access to the reactive alkyne platform. However, 


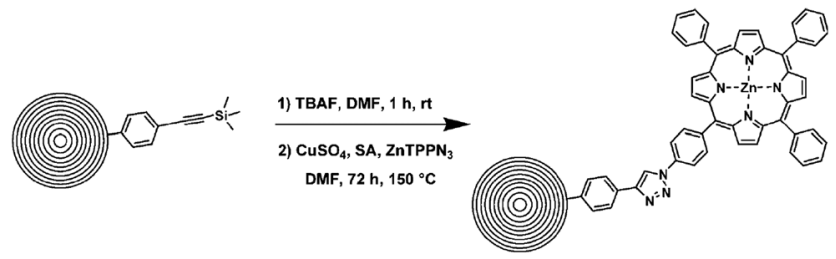

Fig. 10 Deprotection of functionalized carbon nano-onion followed by coupling with the zinc monoazaporphyrin. Reprinted with permission from ref. 142

the reduction of a precursor, leading after modification of the organic layer formed, to an alkyne platform exhibiting particular properties, can have advantages. The work initiated by Leroux and Hapiot is a good illustration of this point. Indeed, terminal alkyne can easily be protected with silyl groups; this pathway has been exploited by the authors to graft bulky diazoniums avoiding the formation of multilayers. ${ }^{115,116,119,122,123,127,128,147,149,177}$ The protecting group, which is compatible with diazonium electroreduction is then cleaved on the surface, allowing the post-reaction with an azide function. This strategy has been first validated by the electroreduction of a triisopropylsilyl (TIPS)-protected ethynyl aryldiazonium salt and the subsequent immobilization of azidomethylferrocene, after TIPS deprotection. ${ }^{115}$ AFM studies of the obtained layers before click reaction evidenced the obtaining of thin films and the cyclic voltammetry of ferrocene immobilized by click reaction showed surface coverages similar to those obtained on self-assembled monolayers $(4.4 \times$ $\left.10^{-10} \mathrm{~mol} \mathrm{~cm}{ }^{-2}\right) \cdot{ }^{115}$ This approach has been exploited also for the design of binary films by sequential electrografting of TIPSprotected aryldiazonium and nitrobenzene diazonium. ${ }^{116,122}$ The use of smaller protective groups (trimethylsilyl or triethylsilyl) resulted in a decrease in size of the pinholes (formed on the surface after deprotection of the silyl groups), thus leading to an increase in the surface coverage of redox species immobilized by post-functionalization. ${ }^{123}$

This approach have been exploited by other groups to develop an amperometric biosensor by covalent immobilization of a HRP azide on an ethynyl monolayer-modified electrode,${ }^{166}$ to anchor an azide-functionalized initiator, allowing the controlled radical polymerization of $N$-isopropylacrylamide ${ }^{176}$ or to prepare monolayer platforms for the surface functionalization by Sonogashira, ${ }^{121,184}$ Glaser coupling, ${ }^{121}$ or Huisgen 1,3 dipolar cycloaddition. ${ }^{139,184}$

In fine, the results obtained starting from monolayers (prepared by deprotection of silyl groups) or multilayers both highlight surface coverages around few $10^{-10} \mathrm{~mol} \mathrm{~cm}^{-2}$, excluding major differences in terms of interfacial reactivity.

\subsection{Post-diazotization}

As it has been discussed above, the immobilization of diazonium salts can be used to anchor a layer of an aminobenzene derivative which is subsequently subjected to a peptide coupling or click reaction to tether the desired molecule to the surface. An alternative strategy for the post-functionalization of aminobenzene-based coatings consists in the diazotization of the amino group and the utilization of the rich reactivity ${ }^{185}$ of the obtained diazonium functionality to bind a particular compound or nanostructure.

The interfacial diazotization reaction can be carried out in acidic aqueous solutions or in organic solvents. In aqueous media, the nitrosating reagent is usually sodium nitrite $\left(\mathrm{NaNO}_{2}\right.$ ) dissolved in $0.1 \mathrm{M}-0.5 \mathrm{M} \mathrm{HCl},{ }^{25,186-190}$ as diazonium salts are only stable at $\mathrm{pH}<4 .{ }^{185}$ Reactions in organic solvents are commonly performed in acetonitrile using nitrosyl tetrafluoroborate, tert-butyl nitrite or isoamyl nitrite as nitrosating reagent. Both methods have been compared by Downard et al. concluding that similar concentrations of the diazonium group are obtained. ${ }^{191}$ However, the stability of the diazonium layer prepared in water is lower, probably as a consequence of the reaction with water molecules trapped into the film. The lifetime of diazonium immobilized groups is short and degradation processes are favoured by moderate heating (full disappearance after 2 hours at $50{ }^{\circ} \mathrm{C}$ ) or UV light irradiation (full disappearance after few minutes). ${ }^{186}$ Therefore, the diazotized surfaces are preferentially used for subsequent postfunctionalization reactions immediately after the diazotization process. Another fundamental aspect is the yield in the conversion of amino functionalities into diazonium groups. Quantification of this value is challenging due to the chemical instability of the diazonium moiety. ${ }^{192}$ Gooding et al. estimated, on the basis of the direct quantification of the diazonium peaks in the XPS spectrum of the film, that only $10 \%$ of the aminoaryl molecules immobilized on an Au surface are transformed. ${ }^{193}$ In contrast, Brousse et al. observed the almost complete disappearance of the $\mathrm{N} 1 \mathrm{~s}$ amino peak for an aminoaryl coating on graphite flakes or carbon nanotubes, after diazotization and interfacial reaction with Si nanoparticles. ${ }^{194,195}$ This experiment indirectly suggests a nearly quantitative conversion of the amino groups into diazonium.

The interfacial diazotization reaction is by far the most widespread method to elaborate diazonium-terminated films. However, as shown by Locklin et al., the electrochemical reduction of the benzene(bisdiazonium) salt can be fine tuned to selectively reduce one of the diazonium groups while preserving intact the second. ${ }^{196}$ As a result, a monolayer of benzenediazonium molecules can be directly anchored on the surface of Au or glassy carbon electrodes. Later on, the same group showed that the same bis(diazonium) compound can be spontaneously grafted on Au and ITO surfaces. ${ }^{197}$ Although the process is less efficient for the semiconductor and only affords a physisorbed film on this substrate when it is carried out in water.

The diazonium-terminated structures have been commonly engaged in two kind of reactions: the immobilization of nanoobjects, as nanoparticles or CNTs, and the grafting of molecular species. In the next sections, some illustrative examples of the two processes are briefly described.

Immobilization of nano-objects. In view of the strong covalent bond formed between aryl radicals and various surfaces, this reactivity can be exploited to attach benzenediazonium 
immobilized layers to another nanostructures. The reduction of the diazonium group can be electrochemically triggered ${ }^{25,186,190,193,198}$ or being spontaneous. ${ }^{186,190,194,195,199}$ There are also two examples of reduction promoted by adding a reducing reagent. ${ }^{200,201}$

The group of Tour was pioneering in the use of the diazonium post-functionalization strategy to attach CNTs on an H-terminated Si surface. ${ }^{192,202}$ The reaction between diazonium groups and nanotubes was spontaneous and confirmed by AFM analysis. Pinson et al. employed a similar approach to immobilize CNTs on $\mathrm{Si}$ and $\mathrm{Ti}$ trenches patterned in $\mathrm{SiO}_{2}$ substrates. ${ }^{187}$ SEM imaging of the material evidenced selective covalent deposition of the nanotubes on the metallic strips whereas the oxide was not functionalized. Similarly, CNTs have been also grafted on the surface of common $\mathrm{Au}$ and glassy carbon electrodes using this strategy. ${ }^{188}$ Post-functionalization reactions based on diazonium immobilized platforms have also been successfully exploited by Brousse et al. for the elaboration of nanocomposites with improved performances in lithium-ion batteries ${ }^{194,195}$ and supercapacitors (Fig. 11). ${ }^{199}$

The immobilization of Au nanoparticles on electrode surfaces decorated with benzenediazonium molecules has been extensively studied by the group of Gooding. They have shown that the attachment of nanoparticles following this strategy was more robust than with similar architectures containing phosphonate or thiol anchoring groups. ${ }^{193,198}$ As it was stated above, the diazotization reaction of the aminobenzene film only converted $10 \%$ of these functionalities into diazonium groups. Interestingly, the unreacted amino substituents were exploited to tether poly(ethylene oxide) chains which are known to exhibit anti-fouling properties for the non-specific adsorption of proteins and cells. ${ }^{203}$ The hybrid materials were successfully implemented in electrochemical immunosensors. ${ }^{50,51}$

Recently, 3,3'-dimethoxy-[1,1'-biphenyl]-4,4'-bis(diazonium) was anchored to a silicon surface through selective reduction of only one of the two diazonium groups and the remaining immobilized one was used to spontaneously attach an Au STM tip. ${ }^{204}$ The Si-molecule-Au junction showed an enhanced lifetime compared to similar architectures based on physisorbed or thiol-immobilized compounds.

Immobilization of molecular species. Benzenediazonium films react spontaneously with ferrocene via a Gomberg
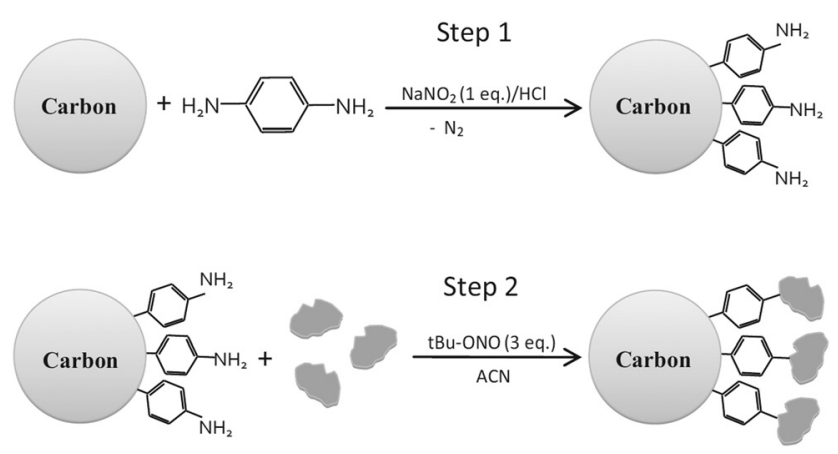

Fig. 11 Schematic reaction pathway for grafting carbon particles to $\mathrm{MnO}_{2}$ grains. Reprinted with permission from ref. 199. arylation process. ${ }^{196,197}$ As a consequence, ferrocene forms a covalent bond with the phenyl ring and thus surface-tethered through an aromatic system. This conjugated linkage enhances the heterogeneous electron transfer kinetic constant. The difference in surface concentration of ferrocene anchored on a benzenediazonium coating on glassy carbon and Au electrodes have been analysed by the group of Downard. ${ }^{191}$ It was found that this value is approximately 7 times higher for the benzenediazonium film immobilized on the Au surface. The striking difference was attributed to the poorer stability of the diazonium coating on the glassy carbon surface as a result of an enhanced spontaneous reduction of the diazonium group by the glassy carbon surface before the ferrocene addition.

On the other hand, a number of nucleophilic compounds, like pyridine derivatives or polyamidoamine (PAMAM) dendrimers, have been grafted following the diazonium postfunctionalization strategy. ${ }^{186}$ Although the exact mechanism was not elucidated. The immobilization of fullerene has been also reported on silicon and opens the way for interesting applications in molecular electronics (Fig. 12). ${ }^{205}$

Several synthetic and nature occurring polymers have been grafted on benzenediazonium platforms. The first report of this approach on an electrode surface was published by Dequaire and coworkers. ${ }^{189}$ They immobilized a synthetic oligonucleotide which was used as a capture probe for a PCRamplified 406 base-pairs sequence of the human cytomegalovirus (HCMV) DNA. Later on, similar strategies were employed, by other research groups, in the immobilization of HRP, ${ }^{206}$ GOx, ${ }^{207}$ and diverse DNA strands. ${ }^{207,208}$ The efficient and spontaneous formation of covalent bonds between the diazonium platform and biological molecules relies on the large amount and rich variety of nucleophilic groups in proteins and nucleic acids. ${ }^{207}$ In this sense, chitosan, an abundant naturalderived polymer containing multiple $-\mathrm{OH}$ and $-\mathrm{NH}_{2}$ groups, has been recently attached to stainless steel. ${ }^{209}$ The coated surface exhibited an improved resistance to corrosion in $0.01 \mathrm{M}$ $\mathrm{H}_{2} \mathrm{SO}_{4}$.

All the above approaches involve the reaction between a previously synthesized or isolated polymer and the immobilized diazonium platform. Thus, this kind of strategy is usually known as "grafting to" method. However, anchored diazonium compounds are potentially good polymerization initiators in virtue of the formation of aryl radicals after reduction. Therefore, certain polymers can be directly grown from a diazonium

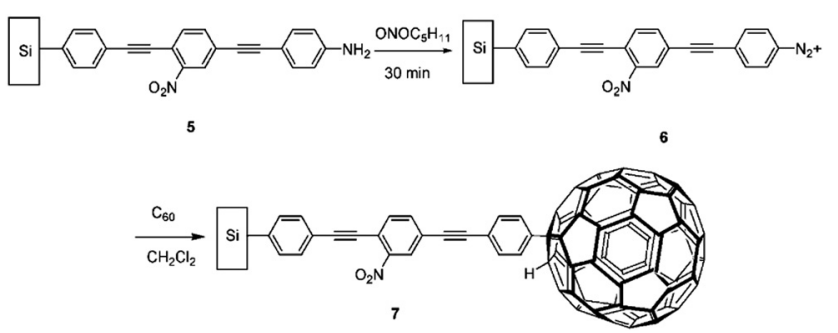

Fig. 12 Diazotization of amine tethered layer followed by the coupling of a C60 unit. Reprinted with permission from ref. 205. 
coating in the presence of a suitable monomer in solution. This strategy falls in the category of "grafting from" methods. Viel and coworkers exploited this route to achieve the electropolymerization of methyl methacrylate from a diazoniumterminated film on $\mathrm{Au} .{ }^{186}$ Similarly, Tamimi and coworkers succeed in the immobilization of poly(methyl methacrylate) and poly(bisphenol A-glycidyl methacrylate) on a variety of dental alloys by using Fe powder or $\mathrm{H}_{3} \mathrm{PO}_{2}$ as reducing agents to promote the formation of aryl radicals and trigger the

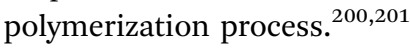

\subsection{Polymer growth}

The examples presented in this part concern only the growth of polymers initiated from a surface modified by a diazonium precursor. We include in this paragraph the studies in which a chemical modification of the surface is needed before the polymerization step (notably to immobilize the polymerization initiator) because the issues arising are the same as those encountered by the authors who directly immobilized the diazonium dedicated to the polymerization initiation. However, examples relating to the post-functionalization of the surface with polymers already formed are dealt with in the paragraphs corresponding to the method used.

The vast majority of the studies presented here relates to radical polymerization. This type of polymerization, if carried out without special precautions, gives access to polymer chains whose size is not controlled. To overcome this issue, several control methods have been developed for accessing polymers with chains of identical and controlled sizes. Three of these controlled radical polymerization methods, well described in solution, have also been adapted to surface modification by reduction of diazonium salts: atom transfer radical polymerization (ATRP), reversible addition/fragmentation chain transfer polymerization (RAFT polymerization) and polymerization controlled by an iniferter.

The most widely used method for growing a polymer from an initiator attached to the surface (obtained after reduction of the diazonium containing the initiating entity, or after a subsequent post-functionalization step) is ATRP. This method, described for the first time in solution in 1995 by Matyjaszewski's ${ }^{210,211}$ and Sawamoto's ${ }^{212}$ groups, requires a catalytic complex allowing the exchange of a halogen atom with the radical propagating species. It was adapted on iron surface modified by reduction of a brominated aryl diazonium salt ten years later by a group of French researchers involving electrochemists and polymerists (Fig. 13). ${ }^{213}$

This surface-initiated ATRP (SI-ATRP) requires the use of a copper(I) complex in solution able to reversibly capture the bromine atom of the surface-grafted species to generate $\mathrm{R}^{\bullet}$ radicals and the copper(II) complex. The immobilized initiator radical $\mathrm{R}^{\bullet}$ can then react with a monomer molecule in solution (methyl methacrylate: MMA, $n$-butyl acrylate: BA or styrene: S) to form the radical species $\mathrm{RM}^{\bullet}$, which can immediately lead to the $\mathrm{RM}-\mathrm{Br}$ species and to the initial $\mathrm{Cu}(\mathrm{I})$ complex or react with the monomer to form propagating species $\left(\mathrm{Pn}^{\bullet}\right)$. This reversible equilibrium, involving active $\mathrm{Pn}^{\bullet}$ and dormant $\mathrm{Pn}-\mathrm{Br}$ species,

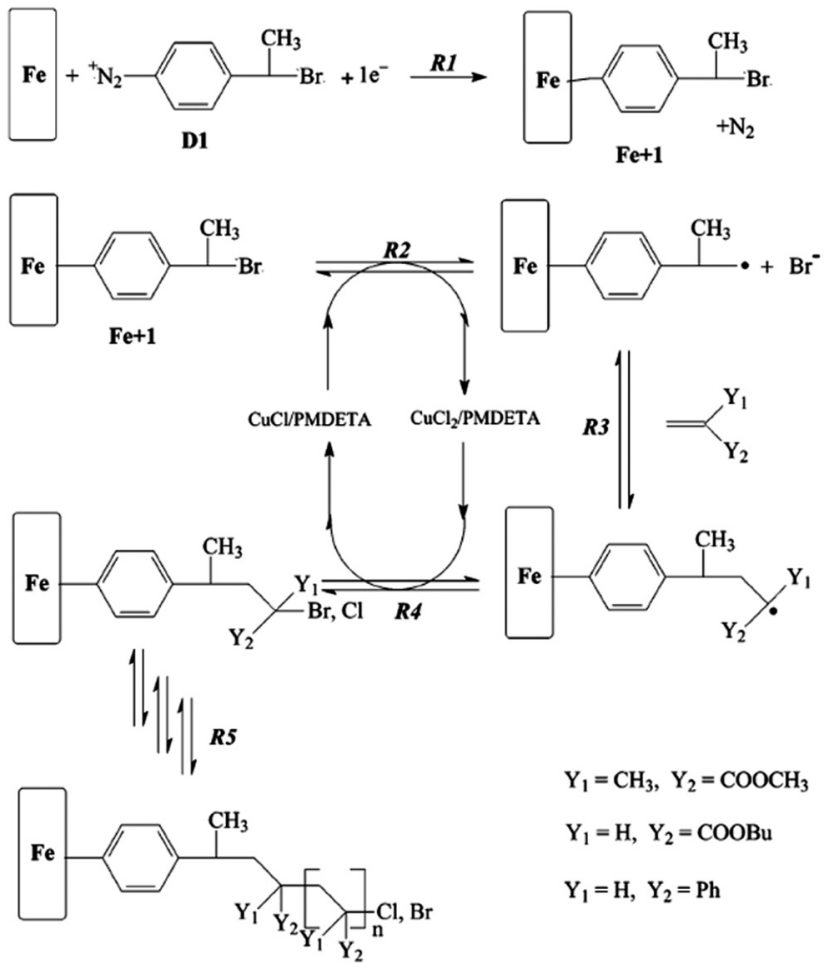

Fig. 13 Surface modification of iron by the electrochemical reduction of brominated aryldiazonium salts and subsequent surface-initiated ATRP of a vinylic monomer. Reprinted with permission from ref. 213.

makes possible the control of the polymer growth. This strategy was then used to develop polymer/MWCNT hybrids by directly growing PMMA and PS brushes on carbon nanotubes ${ }^{214}$ and to graft densely-packed poly( $n$-butyl methacrylate) chains on iron substrate. $^{215}$ Only two other articles, in addition to the three aforementioned ones, exploited a direct immobilization of the brominated initiator. The first one is focused on the grafting of cyclam-functionalized polyglycidyl methacrylate on carbon fibers for copper adsorption ${ }^{216}$ while the second one, published by a Danish team, highlights the limits of direct immobilization of the brominated initiator due to bromine abstraction reactions occurring during the grafting process. ${ }^{217}$ This parasitic reaction, which lower the bromine concentration of the grafted layer, can be circumvent by enriching the film with bromine through a Wohl-Ziegler bromination before the ATRP. Other authors have chosen to prepare initiator-modified surfaces by a two-step procedure including first the electrochemical reduction of aryl diazonium salts to produce active layers and second the post-functionalization of the modified substrate with the initiator. In most cases, 4-(2-hydroxyethyl) benzene diazonium, synthetized from the corresponding commercial aniline precursor, is used to prepare a reactive platform with hydroxyethyl functionalities inducing addition-elimination reaction on an acyl bromide (bromopropionyl bromide ${ }^{182}$ or 2-bromoisobutyryl bromide ${ }^{218-221}$ ). The second postfunctionalization option considered is based on the formation of a carboxyphenyl platform on which the initiator is immobilized via a one-step ${ }^{222}$ or a three-step ${ }^{90}$ procedure. Alison Downard and 
her team, for their part, chose to take advantage of the method developed by Leroux and Hapiot to form monolayers of ethynylphenyl groups ${ }^{115}$ and to electro-reduce $\mathrm{Cu}$ (II) to $\mathrm{Cu}(\mathrm{I})$ to catalyze both the clicking of azido-derivatized initiator to surface and SI-ATRP. ${ }^{176}$

Most of the thirteen aforementioned articles related to SI-ATRP concern rather fundamental studies which aim either to finely characterize the polymer chains, better understand the mechanisms involved during surface polymerization or to check the controlled nature of the polymeric growth. Three of them are more focused on applicative aims such as the design of a new plasmonic device, ${ }^{182}$ copper adsorption ${ }^{216}$ or development of nano-composites for energy storage. ${ }^{90}$ Transmission Electron Microscopy images of these nano-composites, also obtained in parallel by another controlled radical polymerization route, called RAFT polymerization, showed that the morphology of the products obtained was similar whether they were obtained by ATRP or RAFT polymerization. This last method, developed in 1998 by Rizzardo and coworkers, ${ }^{223}$ is based on the principle of a reversible transfer made possible thanks to the use of a transfer agent (which can be a dithioester, a dithiocarbamate or a dithiocarbonate). This species is immobilized (according to a one- ${ }^{175}$ or two-step ${ }^{90}$ post-functionalization procedure) to carry out the on-surface polymerization.

The third controlled radical polymerization method used on diazonium-modified surfaces was described for the first time in solution in 1982 by Otsu and coworkers. ${ }^{224,225}$ It is based on the use of an iniferter, a compound capable of initiating polymerization (INI) and participating in reversible transfer (FER) and reversible termination (TER) reactions. Clay-polymer nanocomposites ${ }^{226}$ and hybrid silica particles ${ }^{227}$ were prepared via this method, from surface-anchored phenyl diethyldithiocarbamate groups, immobilized from the corresponding diazonium tetrafluoroborate salt.

The other types of radical polymerizations, whether initiated by photochemical, chemical or electrochemical means, give access to the formation of polymers of uncontrolled size.

Radical photopolymerization is based on the combined use of a photosensitizer and a hydrogen donor. This approach, called surface-initiated photopolymerization (SIPP), involves the growth of polymer chains from the surface, and thus requires the immobilization of the photosensitizer ${ }^{228-232}$ or hydrogen donor ${ }^{229,230,233}$ to generate a grafted radical able to initiate the polymerization of vinylic monomers. The hydrogen abstraction can be carried out by the grafted photosensitizer (benzoylphenyl group) from hydrogen donor in solution or from the grafted hydrogen donor, upon the concomitant action of UV light and the photosensitizer in solution. After this initiation step, propagation occurs by addition of monomers.

Grafted radicals can also be formed by reduction, via iron powder $^{200}$ or hypophosphorous acid addition, ${ }^{201}$ of attached aryldiazonium groups, prior obtained by mono-diazotization and subsequent chemical reduction of para-phenylene diamine.

Two examples based on the use of electrochemical techniques (for the polymerization) were reported. In the first one, by
Lacroix et al., a combination of electroreduction of diazonium salts and electropolymerization of aniline has been used to functionalize glassy carbon electrodes. ${ }^{234}$ In the second one, by Daasbjerg and coworkers, ${ }^{235}$ repetitive voltammetric cycles were recorded in a 4,4'-disulfanediyldibenzene diazonium solution. This protocol led first to the diazonium reduction, producing a multilayered film, and second to the reductive cleavage of S-S bonds. Polymerization can then occur since the thiophenolate thus formed can react with electrochemically reduced diazoniums. An alternative route, involving the reaction of the diazonium with the thiophenolate to form a diazosulfide group prior being reduced, was also proposed.

The analysis of the various examples of polymerizations initiated on a surface has shown that almost all the polymerizations existing in solution have also been tested on the surface.

Two last types of polymerization will now be treated in this paragraph: anionic polymerization and step-growth polymerization.

Even if a very small part of their article is dedicated to anionic polymerization, Doswald and Stark have shown that it was possible to polymerize glycidol by anionic ring opening polymerization from naphthol functionalized carbon-coated cobalt nanoparticles. ${ }^{236}$

Concerning step-growth polymerization, it proceeds by independent steps. Monomers with two or more functional groups react to form first dimers, then longer trimers and oligomers, and then long polymer chains. The reactions linking the monomers together can be of different natures. The wellknown example of the polyaddition of diols to diisocyanates leading to polyurethanes has been illustrated on $\mathrm{Ti}_{6} \mathrm{Al}_{4} \mathrm{~V}$ alloy previously modified using 4-hydroxymethylbenzendiazonium salts, in order to develop protective layers in endoprosthesis. ${ }^{237,238}$ Also, a polyaddition based on successive 1,3-Huisgen cycloadditions of clickable diazido and diethynyl monomers allowed the construction of MWCNT-polymer nanocomposites at the surface of clickable azido-functionalized MWCNTs. ${ }^{174}$

\subsection{Pd-Catalyzed $\mathrm{C}-\mathrm{C}$ coupling}

The advent of Pd-catalyzed $\mathrm{C}-\mathrm{C}$ coupling reactions has dramatically expanded the scope of synthetic organic and inorganic compounds over the last 40 years. ${ }^{239-241}$ These methods have a number of advantages justifying its successful employment in the preparation of new molecules: they exhibit good tolerance for a large number of functional groups, they are usually run under mild reaction conditions, they need a low amount of Pd catalyst and they can provide a high yield and selectivity of the final product. ${ }^{242}$ These features also make convenient the use of Pd-catalyzed coupling methods for interfacial reactions with immobilized organic films. ${ }^{243,244}$

Pd-Catalyzed coupling reactions are commonly carried out at moderate temperatures $\left(50-100{ }^{\circ} \mathrm{C}\right)$ to achieve high conversion yields. Thus, one of the fundamental prerequisites to perform this kind of catalyzed process on an anchored organic film is the thermal stability of the bond linking the organic layer to the underlying substrate. The diazonium salts 
reduction affords a strong bond between the molecular species and the surface, ${ }^{185}$ particularly in the case of carbon-based materials such as glassy carbon or HOPG. The strength of the surface linkage prevents the desorption of the organic film at moderate temperatures for carbon substrates (the bond is thermally stable at temperatures below $200{ }^{\circ} \mathrm{C}$ under atmospheric conditions). ${ }^{245,246}$ However, the range of temperatures usually used in on-surface catalytic $\mathrm{C}-\mathrm{C}$ coupling reactions is not compatible with thermosensitive compounds as proteins. This limitation explains why the whole molecules immobilized by this method up to date are low molecular weight and thermally stable organic and inorganic compounds, contrary to other procedures like peptide coupling for which the grafting of enzymes is highly popular (vide supra).

The term of "Pd-catalyzed coupling reaction" comprises a plethora of processes involving the reaction of a halide or pseudohalide compound with a coupling organic molecule. The nature of this second species has been traditionally used to classify each kind of Pd-catalyzed process. ${ }^{242}$ Despite the vast availability of current Pd-catalyzed coupling reactions, only three of them have been employed for the post-functionalization of organic films derived from diazonium salts: Suzuki, Sonogashira and Stille coupling reactions. Additionally, the Glaser-Hay C-C coupling, a Cu-catalyzed reaction, has also been explored.

Suzuki coupling. The Suzuki coupling typically consists in the cross-reaction between an arylboronic acid $\left(\mathrm{ArB}(\mathrm{OH})_{2}\right)$, or an arylboronic ester with an arylhalide (or pseudohalide like triflate) in the presence of 2 equivalents of a base and a catalytic amount of a Pd complex. Although, the scope of the method has enormously increased and nowadays, alkyl, alkenyls and alkynyls compounds can also be used. ${ }^{247,248}$

In order to carry out the reaction on organic films immobilized from diazonium salts, the first question that arises is which interfacial process is the most efficient: the reaction of an arylhalide layer with a dissolved boronyl compound or conversely? There is no favoured strategy in the literature and the success of the reaction seems to depend on the particular nature of the coupling partners. For instance, the reaction of an organic dye containing a Br-thiophene scaffold with a BDD electrode decorated with an arylboronic ester layer is more efficient than the opposite reaction. ${ }^{249}$ However, the coupling of dissolved (4-aminophenyl)boronic acid pinacol ester with a film of bromophenyl immobilized on a BDD substrate provides good yields. $^{250}$

The reactions are usually carried out at moderate temperatures $\left(60-80{ }^{\circ} \mathrm{C}\right)$ for a significant duration (12-18 hours). Early works paid little attention on the choice of the Pd catalyst and the inorganic base. Thus, the first reports ${ }^{251,252}$ on interfacial Suzuki coupling made use of simple $\mathrm{Pd}\left(\mathrm{PPh}_{3}\right)_{4}$ as catalyst and $\mathrm{NaOAc}$ or $\mathrm{Na}_{2} \mathrm{CO}_{3}$ as base. Recently, Yeap, Haenen et al. have shown $^{249,250}$ that screening of these two chemical reagents is critical to optimize the coupling (Fig. 14). Indeed, their Suzuki reactions on BDD electrodes in presence of $10 \mathrm{~mol} \% \mathrm{Pd}\left(\mathrm{PPh}_{3}\right)_{4}$ produced hybrid materials exhibiting very low surface coverages (0.04-0.05 ML with ML = "monolayer", relative to a high quality reference monolayer of dodecanethiol on $\mathrm{Au}$, as

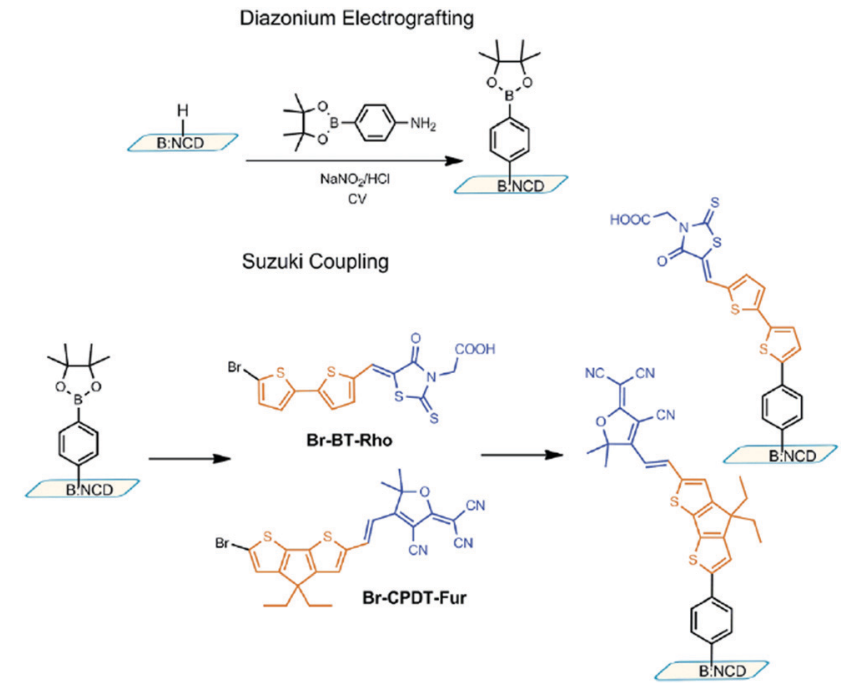

Fig. 14 Diazonium electrografting and Suzuki cross-coupling towards effective boron-doped nanocrystalline diamond functionalization. Reprinted with permission from ref. 249 .

determined by XPS of the desired product). Replacing this traditional catalyst with $\mathrm{Pd}$ complexes based on more electron-rich and sterically hindered phosphine ligands dramatically increases the interfacial reaction yield (surface coverages ranging from 0.43 to $0.60 \mathrm{ML}$ for the catalytic system 1:1 $\left.\mathrm{Pd}(\mathrm{OAc})_{2} / \mathrm{SPhos}\right)$. This elegant approach emphasizes the importance of a convenient choice of the catalytic system to reach the best conversion of the grafted molecular film.

On the other hand, assessment of the presence of $\mathrm{Pd}$ impurities in the obtained materials has only been reported in one work. ${ }^{253}$ Analysis by XPS of the final structure showed no detectable amounts of the noble metal.

Sonogashira coupling. In the Sonogashira reaction, an arylhalide (or pseudohalide) is coupled with a terminal alkyne. The process typically requires the traditional Pd catalyst and a base, but also a copper(I) co-catalyst. The role of the $\mathrm{Cu}$ compound is the formation of an alkyne-Cu transient species and the subsequent transmetalation of the activated alkyne to the key Pd-aryl intermediate. ${ }^{242}$

The Sonogashira coupling has been carried out on a small number of organic films immobilized from diazonium salts. As for Suzuki coupling, there is no preference in the literature on which of the two coupling partners must be previously tethered to the surface to favour the interfacial reaction. This aspect has only been recently discussed ${ }^{184}$ by Cougnon and coworkers, founding that ethynylferrocene reacts efficiently with a molecular platform of 4 -iodobenzene whereas the reaction of iodoferrocene with immobilized ethynylbenzene does not proceed.

In order to optimize the catalysts and other reaction conditions, two interesting different strategies have been conducted. A fist approach, implemented by Rosenthal, Watson et al., ${ }^{121}$ relies on the optimization of the analogue homogeneous reaction, that is, a free-diffusing homologue of the grafted molecule is reacted with the same coupling partner employed in the 


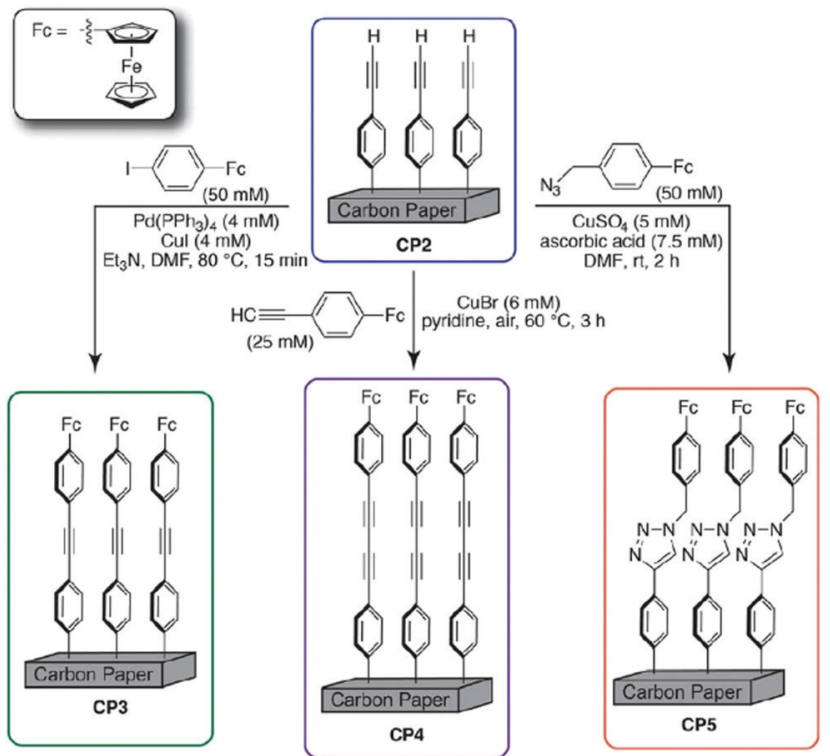

Fig. 15 On-surface synthetic methodology developed for modular construction of ferrocene capped molecular wires on a conductive carbon paper support. Reprinted with permission from ref. 121

interfacial process (Fig. 15). The second method, exploited by Maes, Rezek et al., consists in the direct screening of different catalysts, bases, or solvents in the interfacial reaction. ${ }^{254-256}$ This last methodology was inspired by the previous work of Yeap, Haenen et al. in the optimization of interfacial Suzuki couplings (vide supra).

As in Suzuki couplings, the reactions are typically carried out by heating at moderate temperatures $\left(50-80{ }^{\circ} \mathrm{C}\right)$ for several hours (16-24 h) under Ar. However, it has been reported one reaction achieving maximum conversion after only $15 \mathrm{~min}$ at $80{ }^{\circ} \mathrm{C},{ }^{121}$ another one performed in an ultrasonic bath (highest reached temperature equal to $45^{\circ} \mathrm{C}$ ) for $1 \mathrm{~h},{ }^{257}$ and a last one at $60{ }^{\circ} \mathrm{C}$ for $4 \mathrm{~h}^{258}$ Regarding to chemical reagents, $\mathrm{PdCl}_{2}$, $\left[\mathrm{PdCl}_{2}\left(\mathrm{PPh}_{3}\right)_{2}\right]$ and $\left[\mathrm{Pd}(\mathrm{PPh})_{4}\right]$ have been used as catalysts and $\mathrm{CuI}$ predominantly as co-catalyst. However, it is worth to mention two Sonogashira reactions conducted under "copperfree" conditions aiming at decreasing the competitive homogeneous $\mathrm{Cu}(\mathrm{II})$-catalyzed homocoupling of soluble ethynylaryl compounds, (i.e. Glaser coupling, vide infra). ${ }^{184,257}$ The base is commonly an amine compound like triethylamine (TEA), diisopropylamine (DIPA) or pyrrolidine.

The presence of $\mathrm{Cu}$ and Pd impurities in the final materials has been more studied than in films elaborated from Suzuki coupling. ${ }^{121,254-256}$ In all cases, XPS analysis revealed only trace amounts of the two metals, which could be further reduced after optimization of the reaction conditions.

Other catalytic couplings. There is only one example ${ }^{254}$ in the literature in which the Stille reaction, where an arylhalide (or pseudohalide) is coupled with an organotin compound, has been used for the post-functionalization of an organic film grafted via reduction of diazonium salts. The reaction of 2-(trimethylstannyl)thiophene or 2-(tributylstannyl)thiophene with an immobilized 4-iodobenzene layer on BDD in the presence of diverse Pd catalysts produced structures exhibiting severe Pd and Sn contamination. In contrast, the deposition of similar organic films using the Sonogashira method resulted in cleaner surfaces. Thus, Stille coupling does not seem suitable for controlling the precise composition and architecture of surfaces decorated with molecular species.

Carbon based electrodes functionalized with a monolayer of 4-ethynylbenzene have been subjected to $\mathrm{Cu}$-catalyzed GlaserHay reactions in two different works. ${ }^{121,134}$ In the Glaser-Hay coupling, two terminal alkyne compounds react in the presence of a $\mathrm{Cu}$ catalyst and $\mathrm{O}_{2}$ to form the diyne product. The interfacial version of this reaction using terminal ethynylferrocene derivatives as coupling partners, and $\mathrm{CuBr}$ or $\mathrm{CuCl}_{2}$ (TMEDTA) as catalysts, affords films containing a modest surface concentration in ferrocene compared to structures elaborated via click chemistry or Sonogashira coupling. ${ }^{121}$ Importantly, the heterogeneous electron transfer constants for the ferrocene units in these three distinct kinds of post-functionalized films were similar in spite of the longer calculated distance between the metallic atom and the electrode surface for the structure built using the Glaser-Hay coupling. Thus, the diyne motif seems to improve the electronic communication with the underlying modified substrate.

\subsection{Coordination bonding}

Immobilization of transition metal complexes on conducting surfaces by methods related to the reduction of diazonium salts has been addressed through three different strategies. The first one consists in the direct grafting of a complex containing a ligand bearing a diazonium functional group. ${ }^{259-261}$ In case the diazonium-derived complex is not synthetically accessible, a second approach relies on the preparation of a coordination compound incorporating a ligand functionalized with a motif which can be engaged in one of the diverse postfunctionalization reactions covered in this review: peptide coupling, Cu-catalyzed azide-alkyne cycloaddition (CuAAC), catalytic $\mathrm{C}-\mathrm{C}$ coupling reactions. In the third strategy, the free ligand is first anchored on the electrode surface and it subsequently reacts with a metal ion source to form interfacial coordination bonds resulting in the bottom-up assembly of the transition metal complex on the surface. The metal source can be a simple metal salt, e.g. $\mathrm{CoCl}_{2},{ }^{262}$ or a complex containing one or more labile ligands which can be easily replaced in the interfacial coordination reaction, e.g. the MeCN ligands in $\left[\mathrm{Ru}(\mathrm{bpy})_{2}(\mathrm{MeCN})_{2}\right](\mathrm{OTf})_{2} \cdot{ }^{263}$

The method has been successfully used for the grafting of $\mathrm{Mn},{ }^{264,265} \mathrm{Fe}^{265-269} \mathrm{Co}^{262,265} \mathrm{Ni}^{265,270,271} \mathrm{Cu},{ }^{160,272,273} \mathrm{Zn},{ }^{103}$ $\mathrm{Ru},{ }^{103,263,274,275} \mathrm{Rh}^{153,276}$ and $\operatorname{Ir}^{263}$ complexes. Most of the corresponding ligands were anchored following two different approaches; namely, the direct reduction of their diazonium precursors or the reaction of the conveniently modified ligand, (through one of the other post-functionalization processes examined in this review), with a previously immobilized organic coating. The choice of the strategy usually depends on the chemical stability of the diazonium salt of the ligand. Thus, polypyridine and structurally related nitrogen ligands are commonly grafted from their diazonium derivatives 


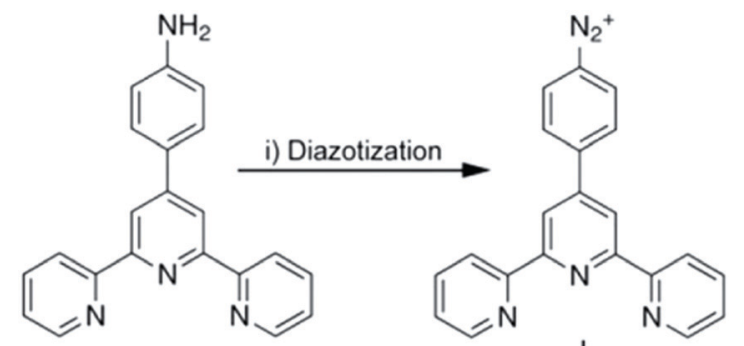

ii) Electrografting

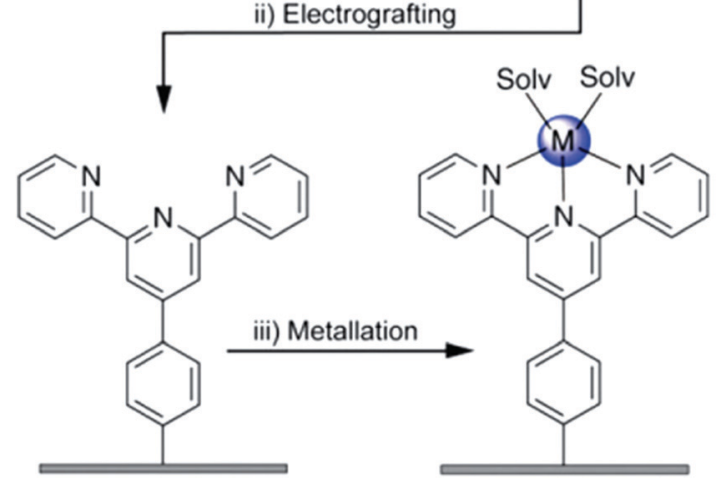

Fig. 16 Simplified synthetic scheme for the preparation of the modified glassy carbon electrodes. Adapted with permission from ref. 262.

(Fig. 16). ${ }^{262,263,265-267,271,274-281}$ However, these compounds are generally prepared "in situ" from diazotization of their amine precursors, as the diazonium species are only stable at low temperature $\left(\approx 0{ }^{\circ} \mathrm{C}\right)$ in the timescale of minutes, preventing their isolation. On the other hand, in some cases, it is convenient to include an alkyl chain as spacer between the coordination moiety of the ligand and the anchoring group. Since aliphatic diazonium salts are extremely unstable, ${ }^{282,283}$ these ligands must be tethered by post-functionalization processes. $^{12,153,270,273}$ Recently, Liu et al. have developed an elegant third strategy based on the building of the ligand scaffold on the surface by a 2-steps process. Firstly, a molecular platform of 2-((triisopropylsilyl)ethynyl)pyridine was deposited on a surface of GO via spontaneous grafting of its "in situ" synthesized diazonium salt. Then, the (triisopropylsilyl)ethynyl protecting group was removed and the resulting structure was subjected to a CuAAC with 2-azidopyridine. The whole process yielded a film of a tetradentate triazole-dipyridine (TADPy) ligand. The GO decorated with the TADPy was subsequently reduced at harsh conditions to obtain a conducting rGO underlying substrate. This hybrid material reacted with $\mathrm{CuCl}_{2}$ with the aim of assembling the Cu-TADPy complex by the on-surface formation of coordination bonds. Analysis by XPS of the metallo-organic material suggested the generation of dinuclear $\left[\mathrm{Cu}_{2}(\mathrm{TADPy})_{2}\right]$ species, thus each metal atom was coordinated by two neighbouring immobilized ligands.

The immobilized ligands usually react quickly and efficiently with fist-row transition metals at room temperature. ${ }^{12,262,272}$ Similarly, the complexation reactions with $\mathrm{Rh}$ seem to be fast without thermal activation of the process (Fig. 17). ${ }^{153,156,276,280}$ The scenario is often dramatically different for more inert metallic atoms like $\mathrm{Ru}$ and Ir. Indeed, the formation of coordination

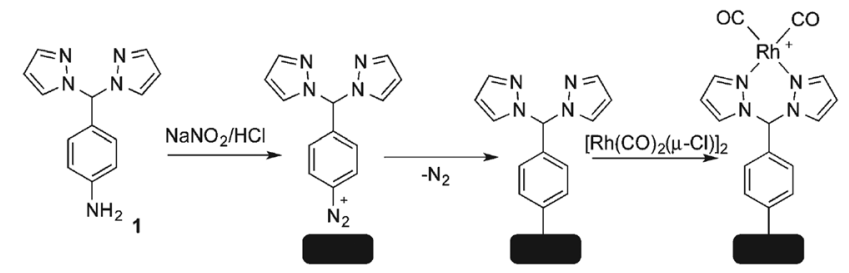

Fig. 17 Immobilization of the Rh(I) bpm complex on the surface of glassy carbon/carbon black. Reprinted with permission from ref. 280.

bonds between a SAM of $4^{\prime}$-(4-mercaptophenyl)-2, $2^{\prime}: 6^{\prime}, 2^{\prime \prime}$ terpyridine on $\mathrm{Au}$ and soluble $\left[\mathrm{Ru}(\operatorname{trpy}) \mathrm{Cl}_{3}\right]$ (where trpy = $2,2^{\prime}: 6^{\prime}, 2^{\prime \prime}$-terpyridine) takes several weeks at room temperature, ${ }^{284}$ whereas similar on-surface processes with $\mathrm{Fe}$ or Co sources are accomplished in the timescale of minutes or hours. ${ }^{285,286}$ The reduction of diazonium salts results in the formation of strong covalent bonds with the conducting surface which are thermally stable. ${ }^{245,246}$ Therefore, ligands immobilized directly or indirectly following this method, are amenable to interfacial complexation reactions requiring moderate or high temperatures $\left(50-100{ }^{\circ} \mathrm{C}\right)$. Several $\mathrm{Ru}$ and Ir complexes ${ }^{103,263,279}$ have been successfully assembled under these conditions, showing the fundamental advantage of ligand platforms built from diazonium salts for this kind of post-functionalization reactivity.

Before engineering of an appropriately modified ligand, a fundamental question can arise: which is more convenient, the immobilization of the ligand and its subsequent metalation on surface (post-coordination strategy) or the synthesis of the full complex followed by anchoring of the assembly to the surface through the reduction of the diazonium precursor or other post-functionalization reactions (pre-coordination strategy)? This aspect has received a poor attention in the literature related to diazonium grafting. In a first report, Geneste et al. showed that the grafting, by both strategies, of $\mathrm{a} \mathrm{Cu}^{2+}$ complex containing a $N, N$-bis((1H-pyrazol-1-yl)methyl)hexane-1-amine ligand scaffold resulted in closely related, but distinct, immobilized molecular species on the basis of a slight difference in redox potentials. ${ }^{273}$ The disparity was potentially attributed to diverse fifth and sixth coordinated ligands. Although the precoordination method afforded higher electrochemically determined surface concentrations, the electrochemical response of the material elaborated with the post-coordination approach was more reversible in the cyclic voltammetry timescale. A second interesting study on the topic was carried out by Fischer and coworkers. ${ }^{268}$ A Fe-porphyrin oxygen reduction electrocatalyst was tethered to transparent semiconducting metal oxide surfaces by electrochemical reduction of an axially coordinated 4-(1H-imidazol-1-yl)benzenediazonium ligand (pre-coordination) or interfacial bond formation between the previously anchored imidazole ligand and the dissolved porphyrin complex (post coordination). Both methods led to the same immobilized molecular structure. However, the electrochemically determined surface concentration for the pre-coordinated film was significantly higher than that for the post-coordinated one. A combination of electrochemical and spectroscopic analyses revealed that all the metal complexes in the post-coordinated 
structure are redox active while only around $75 \%$ are electrochemically accessible in the pre-coordinated film.

In a number of cases; the choice of the post-coordination method can obey to the function of the envisaged hybrid ligand-electrode material. Hence, anchored ligands have been employed as copper ion sensors, ${ }^{12}$ molecular platforms for the oriented immobilization of histidine-tagged proteins via previous metalation with $\mathrm{Cu}^{2+}$ or $\mathrm{Ni}^{2+},{ }^{270,272}$ and versatile materials for the construction of libraries suitable for electrochemical high-throughput screening. ${ }^{103}$ Moreover, interfacial coordination reactions can give access to supramolecular structures which are hardly conceivable to synthesize and subsequently anchor. This is the case of long metal-containing molecular nanowires elaborated by a controlled stepwise method..$^{277-279,287}$

\subsection{Other methods}

Epoxide ring opening. One of the first approach developped for functionnalizing electrodes modified via diazonium reduction was to exploit the epoxide ring-opening reaction by nucleophilic attack. Savéant $e t$ al. showed, as early as 1997, that it was possible to functionalize a glassy carbon surface by reduction of nitrobenzene diazonium, electrochemically reduce it into an amine, and then react it with a chlorinated epoxide (epichlorydrin). ${ }^{288}$ This method was then transposed to carbon fibers, and in both cases, proof of grafting was obtained by XPS analysis, showing an increase in the atomic percentage of chlorine from 0 to $1.8 \%$. The functionalization of carbon fibers was also carried out by a bis-diazonium, transformed into an alcohol function once immobilized, then coupled with epichlorydrin. ${ }^{289}$ In the latter case, the evolution of the XPS chlorine signal increased in the same proportions. Epoxide opening reaction was exploited ten years later by Hapiot's group to produce layers of GOx on glassy carbon. ${ }^{290}$ A simpler protocol, involving the monodiazotization of the paraphenylene diamine, made possible the attachment of phenylamine functions. These functions were then exploited to react, via addition of poly(oxyethylene) bis(diglycidyl ether), with the enzymes at room temperature. The resulting electrode was covered with a crosslinked hydrogel containing the enzyme at a concentration of about $6 \times 10^{-9} \mathrm{~mol} \mathrm{~cm}^{-2}$. Epoxide opening reaction remains today a technique for marginal postfunctionalization, but has been used recently in the context of the interfacial coupling of carbon fibers tethered with phenylcarboxy moieties by epoxy resin. ${ }^{291}$

Nucleophilic substitution. Nucleophilic substitution has also been used in a more conventional manner, by carrying out reactions between amine, alcohol or thiol derivatives with halogenated derivatives. The first example was reported in 2002 by Pinson et al. for the preparation of combinatorial chemistry supports and involved the immobilization of benzyl chloride and bromide from electrografting of their corresponding diazonium salts. ${ }^{251}$ The subsequent coupling with thiolate derivatives was carried out at $80{ }^{\circ} \mathrm{C}$ and good yields are obtained, as attested by elemental analysis (44 to $100 \%$ depending on the substitution of the thiophenol involved). A similar approach was reported by the Bélanger's group by performing the grafting of benzyl diazonium chloride, subsequently coupled to a ferrocene amino derivative. These well-supported studies showed that the yield of the nucleophilic substitution was of the order of $20 \%$, leading to a very high surface coverage of $7.8 \times 10^{-9} \mathrm{~mol} \mathrm{~cm}^{-2}$ after 16 hours of reaction at $70{ }^{\circ} \mathrm{C}^{292}$ Bélanger has also shown that it is possible to carry out a nucleophilic substitution directly on the grafted aromatic ring after immobilization of 4-bromophenyldiazonium. ${ }^{293}$ In this study, an amino derivative of ferrocene was coupled to the tethered bromophenyl electrode under reflux in acetonitrile for $16 \mathrm{~h}$. The surface coverage, evaluated by cyclic voltammetry, was found equal to $3.5 \times 10^{-10} \mathrm{~mol} \mathrm{~cm}{ }^{-2}$, in perfect agreement with the extracted estimation from XPS analysis $\left(3.1 \times 10^{-10} \mathrm{~mol} \mathrm{~cm}^{-2}\right)$. The same type of strategy was followed by the Park's group on gold electrodes for the preparation of immunosensors using a diazotized fluorine derivative. ${ }^{294}$ The coupling between the aromatic ring and amine functions of the anti-InterLeukin 2 was this time carried out in a phosphate buffer at $37^{\circ} \mathrm{C}$ for $1.5 \mathrm{~h}$. Finally, two examples of nucleophilic substitution via the use of sulfonate ester, ${ }^{205}$ and more recently sulfonyl chloride, have been reported to respectively graft fullerenes and surfactants. In the first case, the immobilization of fullerene was carried out after activation of a silicon surface with methanesulfonyl chloride followed by substitution with a pirolidone derivative. XPS analysis validated the presence of fullerene. In the second case, the gold surface was functionalized with $\mathrm{SO}_{3} \mathrm{H}$ groups, transformed into sulfonyl chloride by $\mathrm{PCl}_{5}$ and then coupled to the alcohol functions of surfactant molecules to form sulfonic esters.

Nucleophilic addition. Nucleophilic addition represents another post-functionalization route that has been exploited on several occasions. The most explored one, but also the first reported, lies in the addition of aldehyde derivatives to surfaces grafted with aromatic amines. Like the two techniques aforementioned, this route has the advantage of using a modified surface obtained by simple grafting of 4-nitrobenzene diazonium followed by its electroreduction. The first example, reported by the Laurence's group, was focused on the immobilization of oligonucleotides on silicon by adding an aldehyde function to an amine one to generate an imine bond. The originality of this work resides in the use of glutaraldehyde as a spacer, which allowed a double coupling, both with the amino surface and the probe sequence which also carries amine groups. The reactions were carried out under mild conditions, involving two successive condensations of a few tens of minutes. ${ }^{295}$ Lawrence has implemented the same approach more recently to develop an impedimetric sensor intended for the detection of B. anthracis Sterne bacteria by immobilization of Gamma phage on SPCE. ${ }^{296}$ Marty et al. also exploited the glutaraldehyde-based technique to make $\mathrm{HRP}^{297}$ and tyroynase $^{298}$ based biosensors from post-functionalized SPCEs. In both cases, the first step, corresponding to the 4-nitrobenzene diazonium reduction led to a surface coverage of about $7 \times 10^{-10} \mathrm{~mol} \mathrm{~cm}^{-2}$. After reduction into amine and double coupling using glutaraldehyde, the peroxidase surface coverage was estimated at $7 \times 10^{-12} \mathrm{~mol} \mathrm{~cm} \mathrm{~cm}^{-2}$, very close to the theoretical value calculated for a compact monolayer (7-13 $\times$ $10^{-10} \mathrm{~mol} \mathrm{~cm}^{-2}$ ), confirming the successful immobilization. The "glutaraldehyde technique" was finally successfully 
applied to graphene sheets for the preparation of an immunosensor for the detection of cancer biomarkers. ${ }^{299}$ Postfunctionalization by generation of a Schiff base was also implemented to prepare biosensors by directly coupling amino-tethered surfaces with oxidized glycosidic moieties beared by laccases. The work of Jolivalt $e t$ al. showed very good activity of these laccases when immobilized on carbon nanorods, but very poor reproducibility compared to the use of peptide coupling performed on carboxylated surfaces. ${ }^{21}$ Cuesta et al. adopted a more complex approach involving the immobilization of laccase on gold by a Schiff base preparation, followed by the formation of an amide bond by exploiting the acid functions of this laccase. This double functionalization made it possible to obtain a better orientation of the enzyme and consequently a better activity at low overpotential than for a simple attachment. ${ }^{20}$ This type of coupling was also exploited to produce a glucose biosensor from glassy carbon electrodes. The voltammetric results showed a high enzyme surface concentration of $1.23 \times 10^{-10} \mathrm{~mol} \mathrm{~cm} \mathrm{~cm}^{-2}$ and a very good cycling stability. The very high efficiency of the sensor was attributed to a direct electron transfer between the enzyme and the carbonaceous substrate. ${ }^{300}$ Coupling by generation of a Schiff base has also been exploited by adopting the reverse strategy, namely the immobilization of an aldehyde function on ITO, followed by coupling with amine groups. This approach was illustrated by the work of the Kim's group, who grafted 2-(4aminophenyl)-1,3-dithiane, before deprotecting it to generate a reactive layer. This work has shown that the immobilization of proteins (i.e. anti-rabbit IgG) via this technique was quite relevant and allowed the development of immunosensors in a selective manner. ${ }^{301}$ Finally, we can cite the nucleophilic addition of the "Michael" type, which allows the coupling of amine derivatives to aromatic dihydroxy rings. This route was exploited by Cougnon et al. from the grafting of a catechol phenyldiazotized derivative followed by bias-assisted coupling with model molecules bearing an amine function. After the first step (i.e. catechol attachment), a surface concentration of $9.5 \times$ $10^{-10} \mathrm{~mol} \mathrm{~cm}^{-2}$ was estimated by cyclic voltammetry. The subsequent coupling of a ferrocene derivative was confirmed by the presence of the characteristic signal of the latter, but no surface coverage was mentioned. ${ }^{302}$ Brozik et al. have reported a similar "Michael addition" based strategy from an immobilized maleimide derivative on glassy carbon. ${ }^{303}$ In this paper, a ferrocene thiol derivative was coupled to the phenylmaleimide reactive layer (obtained by electroreduction of the corresponding diazonium salt) by simple dipping in a $0.5 \mathrm{mM}$ solution for two hours. A surface concentration of $1.9 \times 10^{-10} \mathrm{~mol} \mathrm{~cm}^{-2}$ was found, corresponding to $42 \%$ of a hexagonal close packed monolayer of ferrocene. The modified carbon surface was then successfully exploited to attach Cyt. $c$ via the two thiol groups beared by the enzymatic protein, showing a surface coverage of $8.8 \times 10^{-12} \mathrm{~mol} \mathrm{~cm}^{-2}$ (i.e. $93 \%$ of an estimated monolayer). The approach was extended to DNA grafting, demonstrating the versatility of such type of nucleophilic addition. Few years later, carbon nano-onions were modified following the same route to develop DNA sensors. ${ }^{60}$ In a primarily study, the authors validated the method by attaching ferrocene derivatives with a surface concentration of $2.4 \times 10^{-9}$ mol $\mathrm{cm}^{-2}$. This article clearly highlighted that carbon nanoonions allow to increase surface coverage, leading to improved sensitivities and lower limits of detection. The same diazoniated maleimide derivative was used to couple BSA to iron-carbon coreshell nanoparticles ${ }^{168}$ and peptides to graphene ${ }^{304}$ and SWCNT, ${ }^{104}$ showing the versatility of the Michael addition reaction for bio-entities immobilization.

Sulfur-gold interaction. This type of interaction has been, since $1983,{ }^{305}$ at the basis of the self-assembled monolayers building on gold. These molecular structures result from the spontaneous adsorption and organization of organosulfur derivatives on a gold substrate. The reaction involves the formation of a $\mathrm{S}-\mathrm{Au}$ bond, characterized by an energy of $\approx 45 \mathrm{kcal} \mathrm{mol}^{-1}$ $\left(170 \mathrm{~kJ} \mathrm{~mol}^{-1}\right),{ }^{306}$ twice lower than that obtained for a $\mathrm{C}-\mathrm{C}$ bond $\left(350 \mathrm{~kJ} \mathrm{~mol}^{-1}\right)$, which gives the S-Au bond a labile character.

The formation of S-Au bonds has been exploited by some authors to post-functionalize various materials (glassy carbon, ${ }^{193,307}$ screen-printed carbon electrode, ${ }^{308}$ Silicon, ${ }^{309}$ ITO, ${ }^{310}$ and gold $^{49,228}$ ) by gold nanoparticles (AuNP) from the reduction of a diazonium salt (4-mercaptobenzene diazonium in most of cases). The grafting of AuNP by this method can be put into perspective with that based on the diazotization of immobilized 4-aminophenyl followed by electrochemical reduction of the diazonium functions thus formed. Gooding and coworkers have compared the stability of AuNP-modified glassy carbon electrodes obtained by gold-sulfur interaction (GC-Ph-S-AuNP) and via diazonium electrochemistry (GC-Ph-AuNP) (Fig. 18). ${ }^{193}$

Their study highlighted a good stability of GC-Ph-AuNP under sonication in water, during electrochemical treatment in $0.05 \mathrm{M} \mathrm{H}_{2} \mathrm{SO}_{4}$ solution, and over several weeks, whereas GC-Ph-SAuNP showed significant losses under similar conditions. This stability gap is probably related to the lability of the S-Au bond. Due to their low background capacitance these nanostructured assemblies have good potential in electrochemical sensing. This point is well illustrated by the works published by Liu et al. ${ }^{49}$ and by Serafin $e t ~ a l .{ }^{308}$ which described the use of these edifices for the development of electrochemical immunosensors. Other sensing applications has been described by Gam-Derouich et $a .^{228}$ for the preparation of molecularly imprinted polymer grafts with embedded gold nanoparticles, able to detect dopamine or by Ait-Touchente et al. for $\mathrm{Cu}^{2+}$ ion detection. ${ }^{310}$

This method has also been used to bind thiophenolfunctionalized single-walled carbon nanotubes to a gold electrode surface ${ }^{188}$ or to achieve STM based molecular junction conductance measurements. ${ }^{257}$

Electrostatic interaction. The post-functionalization of surfaces through electrostatic interactions can involve two scenarios; either the surface carries a positive charge and is able to interact with anions, or the surface carries a negative charge and is able to interact with cations.

The most frequent examples relate to the immobilization of anions on surfaces, bearing primary ${ }^{170,182,311-314}$ or quaternary $^{315,316}$ ammoniums. Quaternary ammoniums were immobilized in a single step, by direct reduction of the corresponding diazonium salt. These platforms, featuring positive 


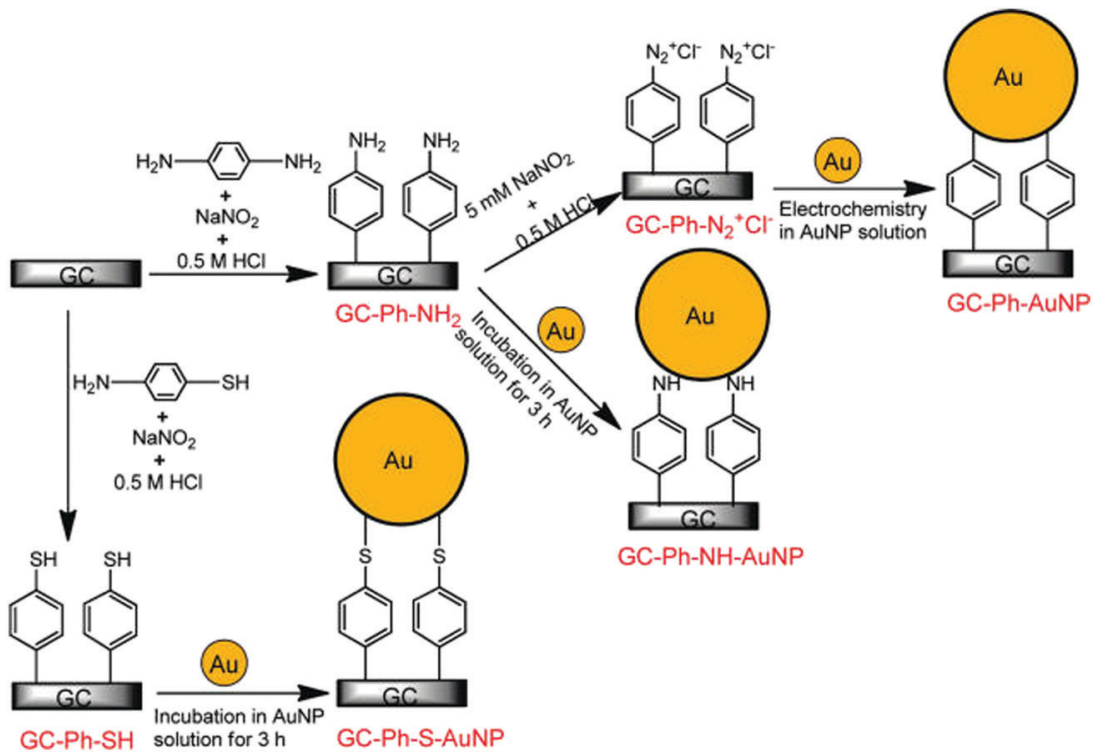

Fig. 18 Fabrication of different AuNP-modified GC surfaces. Reprinted with permission from ref. 193.

charges, were used to anchor inorganic anions such as polyoxometalate derivatives. ${ }^{315,316}$

The means of obtaining surfaces with primary ammonium functionality are more diverse. The surfaces developed by Gehan $e$ e al. ${ }^{170,182}$ required several preliminary steps including electrochemical grafting of hydroxyethyl-aryl groups on a gold substrate, esterification, azidation (or even polymerization) and click chemistry reaction with a propargylamine to bring the $\mathrm{NH}_{3}{ }^{+}$functionality to the surface. Immobilization of citrate coated gold nanoparticles (negatively charged) on these surfaces led to an amplified enhanced Raman scattering activity due to the presence of a very strong local electric field confinement between the particles and the gold surface.

More simply, surfaces modified by primary ammoniums can be obtained by two other methods. The first one, the most widely described, consisted in the 4-nitrobenzene diazonium grafting, followed by its electroreduction to give the amine group in protic medium. By this way, Liu et al. succeeded in immobilizing a Keggin-type heteropolyanion $\mathrm{SiW}_{12} \mathrm{O}_{40}{ }^{4-312}$ while Harper et al. ${ }^{313}$ and Kumsapaya et al. ${ }^{311}$ used the positively charged surfaces to electrostatically immobilize citrate capped metal nanoparticles. The second method, preferred by Vilà et al., ${ }^{314}$ was based on the monodiazotization of $p$-phenylenediamine followed by reduction of the diazonium formed. The latter, reduced concomitantly with 4-sulfophenyl diazonium, allowed the preparation of $\mathrm{Cu} / \mathrm{Pt}$ bimetallic surfaces able to capture $\mathrm{PtCl}_{6}^{2-}$ (by ammonium groups) and $\mathrm{Cu}^{2+}$ (by sulfonyl anions) and the subsequent chemical reduction of captured metal ions (Fig. 19).

This type of bimetallic electrodes had already been obtained by the same group from surfaces resulting from the exclusive reduction of 4-sulfophenyl diazonium and by replacement of metallic copper by immersion of modified substrate in a $\mathrm{K}_{2} \mathrm{PtCl}_{6}$ aqueous solution. ${ }^{317} \mathrm{~A}$ second type of negatively charged surface, exploiting carboxylate groups, has been described in the literature. These surfaces, obtained by direct
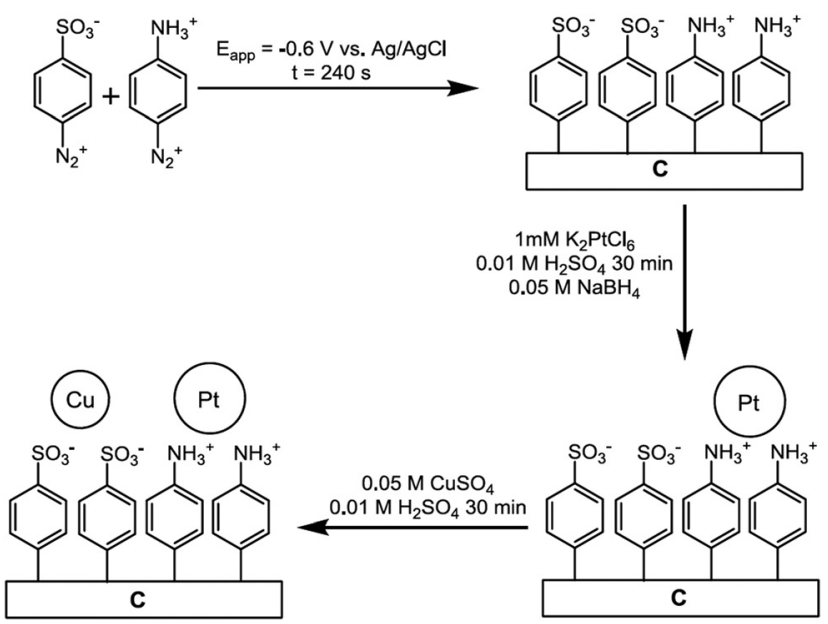

Fig. 19 General procedure for the grafting of 4-aminophenyl and 4sulfophenyl groups from mixed solutions of their corresponding diazonium cations and subsequent loading of the metallic $\mathrm{Cu}$ and $\mathrm{Pt}$ species. Reprinted with permission from ref. 314

reduction of 4-carboxyphenyl diazonium ${ }^{232}$ or 4-phenylacetic acid diazonium salt, ${ }^{318}$ have been used to immobilize charged polymers to protect iron surfaces against corrosion ${ }^{232}$ or suppress non-specific binding of biomolecules. ${ }^{318}$

\section{Summary table: coupling reaction finder}

The table presented below groups together all the references cited in the article and aims to allow readers to quickly identify the type of coupling reaction which may be suitable depending on the strategy adopted. The left columns allow to target the entity to be grafted and the various reactions identified to immobilize these structures. The reactive platforms are drawn 


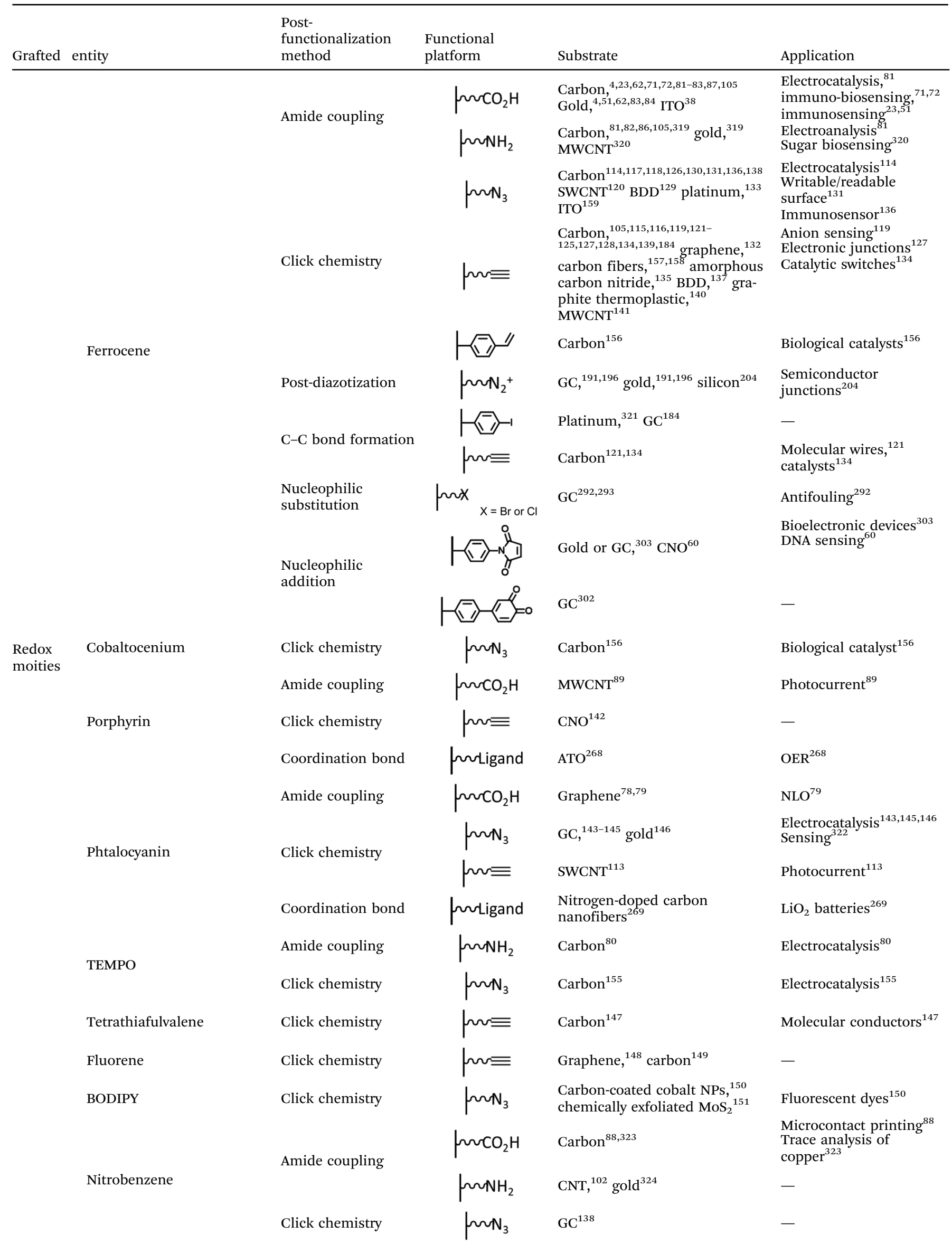


Table (continued)

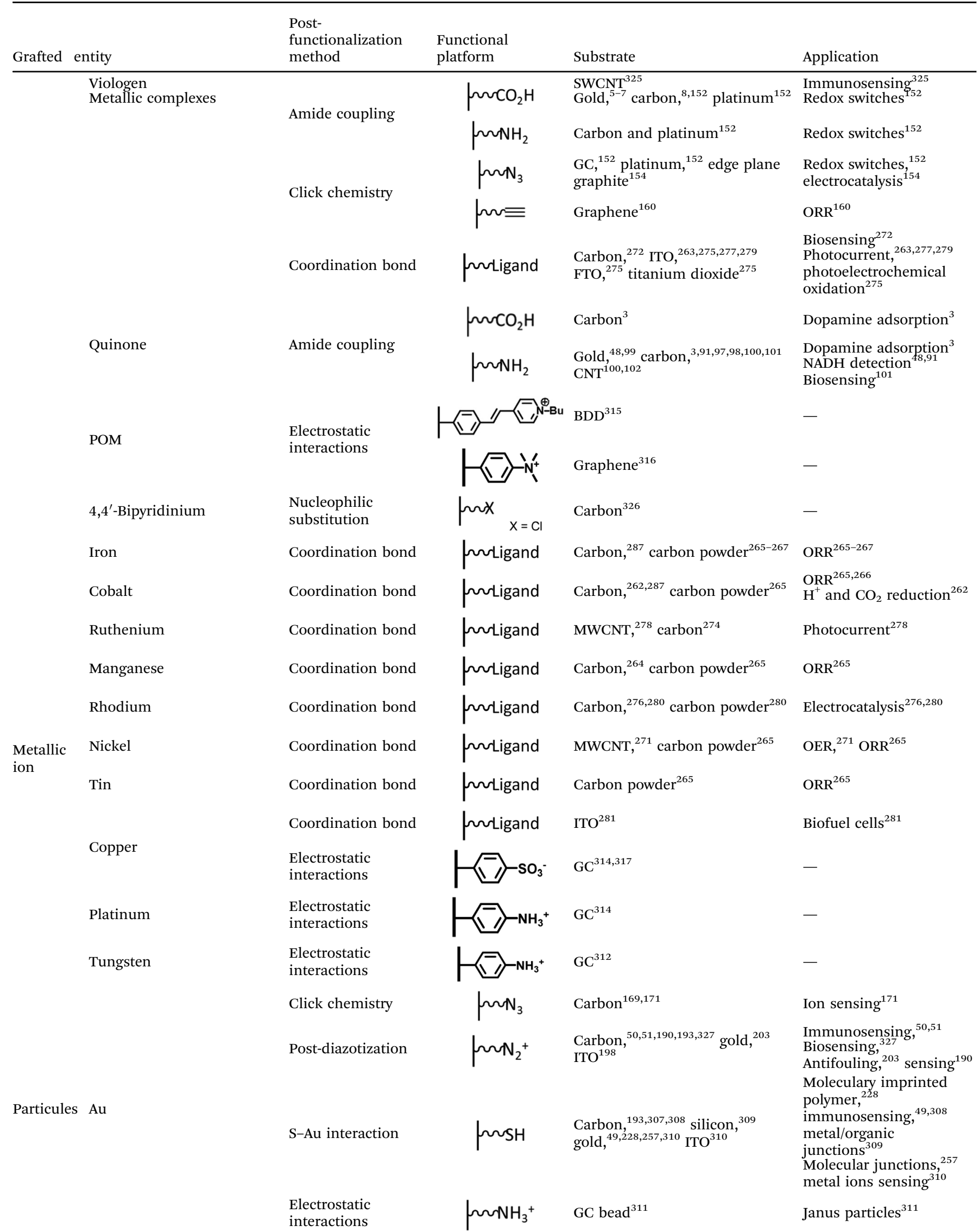


Table (continued)

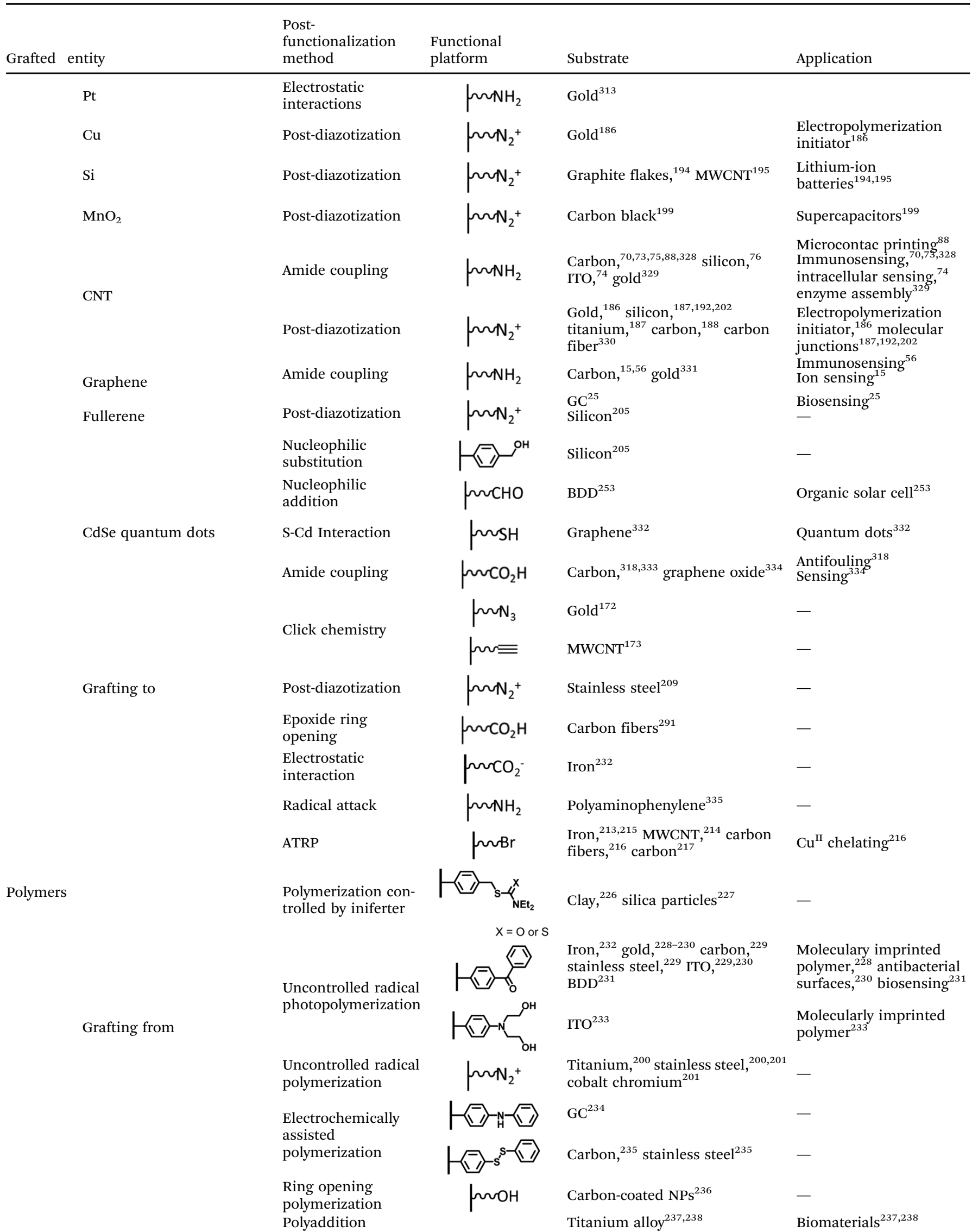


Table (continued) 
Table (continued)

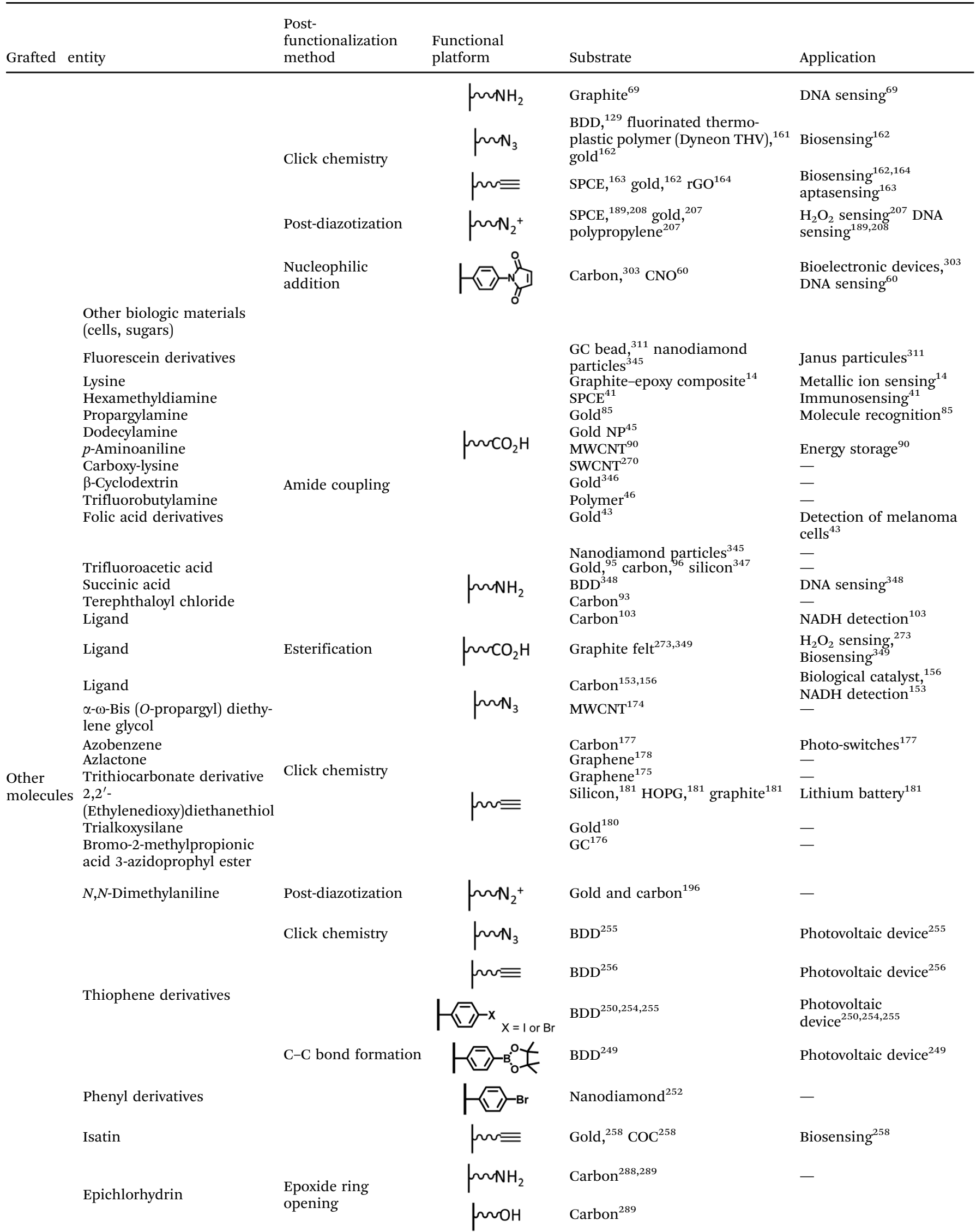


Table (continued)

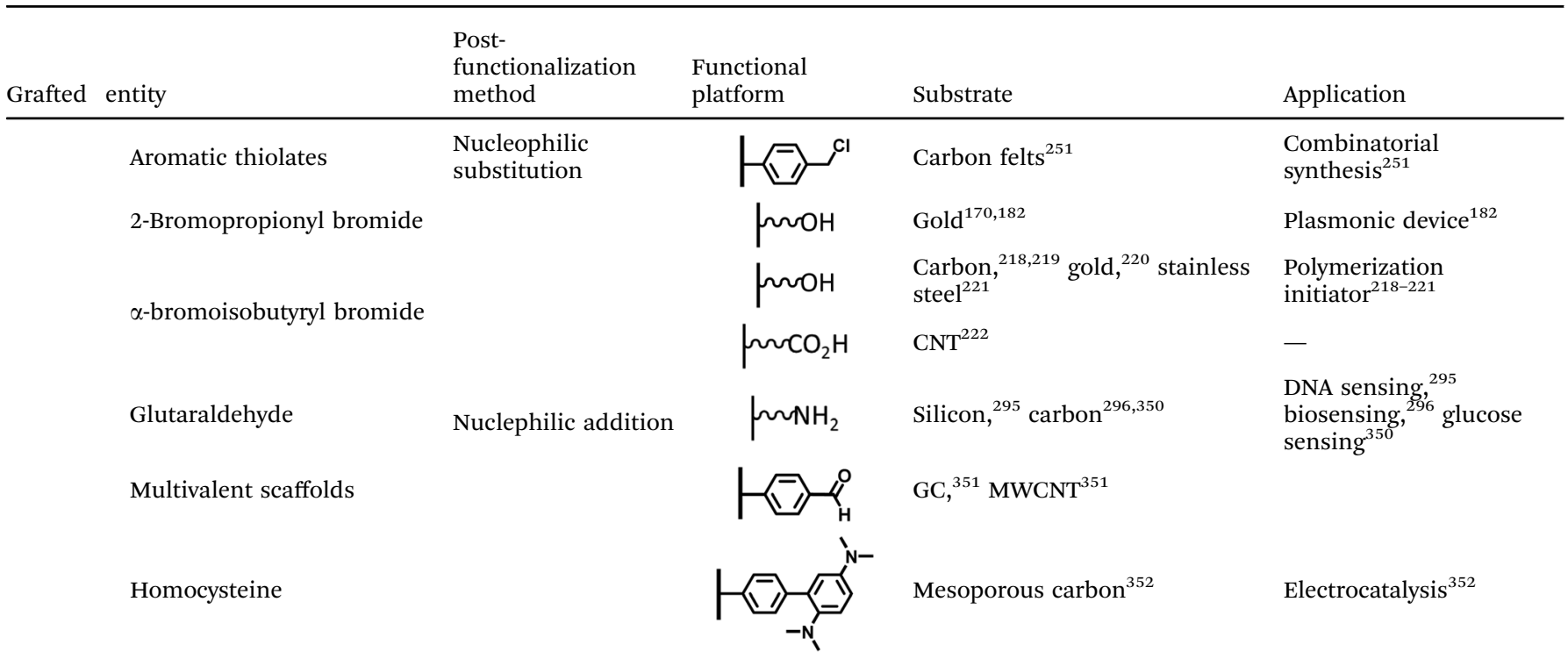

List of abbreviations: ATO: antimony doped tin oxide; BDD, boron-doped diamond; CNO: carbon nano-onions; COC, cyclic olefin copolymer; FTO: fluorine-doped tin oxide GC: glassy carbon; HOPG, highly oriented pyrolytic graphite; ITO, idium tin oxide; CNT, carbon nanotube; MWCNT: multiwalled carbon nanotube; NP: nanoparticle; rGO: reduced graphene oxide; SPCE: screen-printed carbon electrode; SWCNT: single walled carbon nanotube.

in the central column and the corresponding material involved are placed in the following one. When possible, the targeted application or, at least, the field in which the proof of concept was demonstrated, is detailed on the right.

\section{Conclusion}

The post-functionalization of surfaces modified by diazonium salts represents a key technique for the preparation of nanomaterials with ever more varied and ever more complex structures. It offers the possibility of obtaining surface functions covalently bonded to the substrate by implementing relatively simple chemistry. If the grafting of diazonium salts in itself has been studied from a fundamental point of view by some groups for about thirty years, it is clear that the extension of the possibilities that it offers, via post-functionalization, has hardly been the subject of systematic studies. Indeed, surface modification often appears to be a molecular glue whose structureproperties relationships are complex to assess and optimize. The main issue comes from that, in addition to the structural heterogeneity of the reactive sublayer inherent to the radical grafting, a heterogeneous chemical coupling reaction is added. This kind of reaction is impacted by the electronic activation/ deactivation of the surface, but is also subject to steric constraints, which do not exist in homogeneous media. This review shows that a large panel of coupling reactions has been implemented over the past twenty years and that the diversity of chemical functions involved makes it possible to cover almost all scenarios while adapting to synthetic constraints. While it is clear that peptide coupling is the most popular choice, especially for the development of biological sensors in aqueous media, this approach seems to suffer from a significant variability of yields, probably attributable to the formation of bulky activated intermediates. Click chemistry using 1,3-dipolar cycloaddition generally offers better coupling yields but requires the synthesis of chemical functions that are sometimes less compatible with the structures of interest. The other types of coupling, even if they are less widespread in the literature, demonstrate the diversity of this approach, but also the high potential offered by this multistep approach. However, it must be remembered that the expression of this potential will require an advanced understanding of 2D organic nanomaterials, because at present, we lack the data to properly establish the rules for reactivity at the electrode-solution interface. The preparation of reactive sublayers controlled in thickness and structure appears to be an important avenue for progress to minimize the uncertainty about the morphology of the final material and to allow organic films to be modeled more efficiently. Beyond the major role played by this reactive sublayer, a real reflection should be undertaken on the effects of the architecture resulting from the chemical coupling, in particular on the role of the spacers, in order to optimize the yields, but also to guarantee satisfactory reactivity. In this field, it is clear that the presence of a covalent bond, which is certainly a weighty argument to justify the use of diazonium salts, does not guarantee the best system if all the steps are not streamlined. The post-functionalization of surfaces modified by electrografting is an extremely versatile tool, but more than raw performance, today we need fundamental studies, which will allow, in the medium term, significant progress in the fields of biosensors, sensors, molecular electronics, energy conversion and others. 


\section{Conflicts of interest}

There are no conflicts to declare.

\section{References}

1 C. Bourdillon, M. Delamar, C. Demaille, R. Hitmi, J. Moiroux and J. Pinson, J. Electroanal. Chem., 1992, 336, 113-123.

2 X. Yang, S. B. Hall and S. Ngin Tan, Electroanalysis, 2003, 15, 885-891.

3 B. D. Bath, H. B. Martin, R. M. Wightman and M. R. Anderson, Langmuir, 2001, 17, 7032-7039.

4 G. Liu, J. Liu, T. Böcking, P. K. Eggers and J. J. Gooding, Chem. Phys., 2005, 319, 136-146.

5 A. Ricci, C. Rolli, S. Rothacher, L. Baraldo, C. Bonazzola, E. J. Calvo, N. Tognalli and A. Fainstein, J. Solid State Electrochem., 2007, 11, 1511-1520.

6 A. M. Ricci, N. Tognalli, E. de la Llave, C. Vericat, L. P. M. D. Leo, F. J. Williams, D. Scherlis, R. Salvarezza and E. J. Calvo, Phys. Chem. Chem. Phys., 2011, 13, 5336-5345.

7 A. M. Ricci, L. P. Méndez De Leo, F. J. Williams and E. J. Calvo, ChemPhysChem, 2012, 13, 2119-2127.

8 S. Boland, F. Barrière and D. Leech, Langmuir, 2008, 24, 6351-6358.

9 G. Liu, T. Böcking and J. J. Gooding, J. Electroanal. Chem., 2007, 600, 335-344.

10 G. Liu, Q. T. Nguyen, E. Chow, T. Böcking, D. B. Hibbert and J. J. Gooding, Electroanalysis, 2006, 18, 1141-1151.

11 C. Fairman, G. Liu, D. B. Hibbert and J. J. Gooding, in Nanoscience and Nanotechnology (ICONN), 2010 International Conference on, IEEE, 2010, pp. 308-311.

12 U. E. Wawrzyniak, P. Ciosek, M. Zaborowski, G. Liu and J. J. Gooding, Electroanalysis, 2013, 25, 1461-1471.

13 N. Serrano, B. Prieto-Simón, X. Cetó and M. del Valle, Talanta, 2014, 125, 159-166.

14 N. Serrano, A. González-Calabuig and M. del Valle, Talanta, 2015, 138, 130-137.

15 V. K. Gupta, M. L. Yola, N. Atar, Z. Ustundağ and A. O. Solak, Electrochim. Acta, 2013, 112, 541-548.

16 V. Vijaikanth, J.-F. Capon, F. Gloaguen, P. Schollhammer and J. Talarmin, Electrochem. Commun., 2005, 7, 427-430.

17 O. Rüdiger, J. M. Abad, E. C. Hatchikian, V. M. Fernandez and A. L. De Lacey, J. Am. Chem. Soc., 2005, 127, 16008-16009.

18 M. A. Alonso-Lomillo, O. Domínguez-Renedo, A. HernándezMartín and M. J. Arcos-Martínez, Anal. Biochem., 2009, 395, 86-90.

19 M. A. Alonso-Lomillo, O. Domínguez-Renedo, P. Matos and M. J. Arcos-Martínez, Anal. Chim. Acta, 2010, 665, 26-31.

20 C. Vaz-Domínguez, M. Pita, A. L. de Lacey, S. Shleev and A. Cuesta, J. Phys. Chem. C, 2012, 116, 16532-16540.

21 M. Zheng, S. Griveau, C. Dupont-Gillain, M. J. Genet and C. Jolivalt, Bioelectrochemistry, 2015, 106, 77-87.

22 G. Liu and J. J. Gooding, Langmuir, 2006, 22, 7421-7430.
23 G. Liu, S. M. Khor, S. G. Iyengar and J. J. Gooding, Analyst, 2012, 137, 829-832.

24 G. Liu, M. N. Paddon-Row and J. Justin Gooding, Electrochem. Commun., 2007, 9, 2218-2223.

25 M. Qi, Y. Zhang, C. Cao, Y. Lu and G. Liu, RSC Adv., 2016, 6, 39180-39187.

26 M. Pellissier, F. Barrière, A. J. Downard and D. Leech, Electrochem. Commun., 2008, 10, 835-838.

27 A.-E. Radi, V. Lates and J.-L. Marty, Electroanalysis, 2008, 20, 2557-2562.

28 C. Baffert, K. Sybirna, P. Ezanno, T. Lautier, V. Hajj, I. Meynial-Salles, P. Soucaille, H. Bottin and C. Léger, Anal. Chem., 2012, 84, 7999-8005.

29 D. Sharma, J. Lee, J. Seo and H. Shin, Sensors, 2017, 17, 2128.

30 M. Liu, Y. Qi and G. Zhao, Electroanalysis, 2008, 20, 900-906.

31 M. Liu, G. Zhao and Y. Qi, Int. J. Environ. Anal. Chem., 2012, 92, 534-547.

32 T. Siepenkoetter, U. Salaj-Kosla and E. Magner, ChemElectroChem, 2017, 4, 905-912.

33 B. P. Corgier, C. A. Marquette and L. J. Blum, J. Am. Chem. Soc., 2005, 127, 18328-18332.

34 C. A. Mandon, L. J. Blum and C. A. Marquette, ChemPhysChem, 2009, 10, 3273-3277.

35 S. Abdellaoui, B. C. Corgier, C. A. Mandon, B. Doumèche, C. A. Marquette and L. J. Blum, Electroanalysis, 2013, 25, 671-684.

36 S. Phal, B. Shatri, A. Berisha, P. Geladi, B. LindholmSethson and S. Tesfalidet, J. Electroanal. Chem., 2018, 812, 235-243.

37 C. Jiang, M. T. Alam, S. M. Silva, S. Taufik, S. Fan and J. J. Gooding, ACS Sens., 2016, 1, 1432-1438.

38 C. Jiang, M. T. Alam, S. G. Parker, N. Darwish and J. J. Gooding, Langmuir, 2016, 32, 2509-2517.

39 E. Sánchez-Tirado, A. González-Cortés, P. Yáñez-Sedeño and J. M. Pingarrón, Talanta, 2020, 211, 120761.

40 A.-E. Radi, X. Muñoz-Berbel, V. Lates and J.-L. Marty, Biosens. Bioelectron., 2009, 24, 1888-1892.

41 A. Hayat, L. Barthelmebs, A. Sassolas and J.-L. Marty, Talanta, 2011, 85, 513-518.

42 A. Hayat, L. Barthelmebs and J.-L. Marty, Sens. Actuators, B, 2012, 171-172, 810-815.

43 O. Guselnikova, B. Dvorankova, K. Kakisheva, Y. Kalachyova, P. Postnikov, V. Svorcik and O. Lyutakov, Anal. Bioanal. Chem., 2019, 411, 3309-3319.

44 N. Li, A. M. Chow, H. V. S. Ganesh, M. Ratnam, I. R. Brown and K. Kerman, Biosensors, 2019, 9, 88.

45 L. Troian-Gautier, H. Valkenier, A. Mattiuzzi, I. Jabin, N. V. den Brande, B. V. Mele, J. Hubert, F. Reniers, G. Bruylants, C. Lagrost and Y. Leroux, Chem. Commun., 2016, 52, 10493-10496.

46 L. Troian-Gautier, D. E. Martínez-Tong, J. Hubert, F. Reniers, M. Sferrazza, A. Mattiuzzi, C. Lagrost and I. Jabin, J. Phys. Chem. C, 2016, 120, 22936-22945.

47 M. Retout, P. Blond, I. Jabin and G. Bruylants, Bioconjugate Chem., 2021, 32, 290-300. 
48 J. C. Harper, R. Polsky, S. M. Dirk, D. R. Wheeler and S. M. Brozik, Electroanalysis, 2007, 19, 1268-1274.

49 G. Liu, J. Liu, T. P. Davis and J. J. Gooding, Biosens. Bioelectron., 2011, 26, 3660-3665.

50 G. Liu, S. G. Iyengar and J. J. Gooding, Electroanalysis, 2012, 24, 1509-1516.

51 G. Liu, S. G. Iyengar and J. J. Gooding, Electroanalysis, 2013, 25, 881-887.

52 F. Lamberti, S. Agnoli, L. Brigo, G. Granozzi, M. Giomo and N. Elvassore, ACS Appl. Mater. Interfaces, 2013, 5, 12887-12894.

53 M. B. Lerner, J. Dailey, B. R. Goldsmith, D. Brisson and A. T. Charlie Johnson, Biosens. Bioelectron., 2013, 45, 163-167.

54 S. Guerrero, G. Martínez-García, V. Serafín, L. Agüí, P. Yáñez-Sedeño and J. M. Pingarrón, Analyst, 2015, 140, 7527-7533.

55 F. H. Cincotto, G. Martínez-García, P. Yáñez-Sedeño, T. C. Canevari, S. A. S. Machado and J. M. Pingarrón, Talanta, 2016, 147, 328-334.

56 J. Narayanan, M. K. Sharma, S. Ponmariappan, R. Sarita, M. Shaik and S. Upadhyay, Biosens. Bioelectron., 2015, 69, 249-256.

57 N. S. Surgutskaya, P. S. Postnikov, A. G. Pershina, A. I. Galanov, M. E. Trusova and A. E. Sazonov, Adv. Mater. Res., 2014, 1040, 194-198.

58 J. C. Harper, R. Polsky, D. R. Wheeler, S. M. Dirk and S. M. Brozik, Langmuir, 2007, 23, 8285-8287.

59 L. V. Hai, S. Reisberg, A. Chevillot-Biraud, V. Noel, M. C. Pham and B. Piro, Electrochim. Acta, 2014, 140, 49-58.

60 J. P. Bartolome, L. Echegoyen and A. Fragoso, Anal. Chem., 2015, 87, 6744-6751.

61 M. Torréns, M. Ortiz, D. Bejarano-Nosas and C. K. O’Sullivan, Anal. Bioanal. Chem., 2015, 407, 5579-5586.

62 M. Torréns, M. Ortiz, A. P. F. Turner, V. Beni and C. K. O'Sullivan, Chem. - Eur. J., 2015, 21, 671-681.

63 C. Ocaña, A. Hayat, R. K. Mishra, A. Vasilescu, M. del Valle and J.-L. Marty, Bioelectrochemistry, 2015, 105, 72-77.

64 Z. Bagheryan, J.-B. Raoof, M. Golabi, A. P. F. Turner and V. Beni, Biosens. Bioelectron., 2016, 80, 566-573.

65 G. Gökçe, S. Ben Aissa, K. Nemčeková, G. Catanante, N. Raouafi and J.-L. Marty, Food Control, 2020, 115, 107271.

66 S. Rabai, M. Benounis, G. Catanante, A. Baraket, A. Errachid, N. Jaffrezic Renault, J.-L. Marty and A. Rhouati, Anal. Biochem., 2021, 612, 113956.

67 J. A. Rather, E. A. Khudaish and P. Kannan, Analyst, 2018, 143, 1835-1845.

68 L. Civit, A. Fragoso and C. K. O'Sullivan, Electrochem. Commun., 2010, 12, 1045-1048.

69 J. Hajdukiewicz, S. Boland, P. Kavanagh and D. Leech, Biosens. Bioelectron., 2010, 25, 1037-1042.

70 G. Liu and J. J. Gooding, Electrochem. Commun., 2009, 11, 1982-1985.

71 S. M. Khor, G. Liu, C. Fairman, S. G. Iyengar and J. J. Gooding, Biosens. Bioelectron., 2011, 26, 2038-2044.
72 S. M. Khor, G. Liu, J. R. Peterson, S. G. Iyengar and J. J. Gooding, Electroanalysis, 2011, 23, 1797-1804.

73 G. Liu, S. Wang, J. Liu and D. Song, Anal. Chem., 2012, 84, 3921-3928.

74 F. J. Rawson, C. L. Yeung, S. K. Jackson and P. M. Mendes, Nano Lett., 2013, 13, 1-8.

75 D. J. Garrett, B. S. Flavel, J. G. Shapter, K. H. R. Baronian and A. J. Downard, Langmuir, 2010, 26, 1848-1854.

76 B. S. Flavel, D. J. Garrett, J. Lehr, J. G. Shapter and A. J. Downard, Electrochim. Acta, 2010, 55, 3995-4001.

77 B. S. Flavel, A. J. Gross, D. J. Garrett, V. Nock and A. J. Downard, ACS Appl. Mater. Interfaces, 2010, 2, 1184-1190.

78 C. Peng, Y. Xiong, Z. Liu, F. Zhang, E. Ou, J. Qian, Y. Xiong and W. Xu, Appl. Surf. Sci., 2013, 280, 914-919.

79 F. Zhang, R. Man, Z. Peng and Z. Liu, Asian J. Chem., 2014, 26, 4819-4826.

80 T. Menanteau, S. Dabos-Seignon, E. Levillain and T. Breton, ChemElectroChem, 2017, 4, 278-282.

81 J.-M. Noël, B. Sjöberg, R. Marsac, D. Zigah, J.-F. Bergamini, A. Wang, S. Rigaut, P. Hapiot and C. Lagrost, Langmuir, 2009, 25, 12742-12749.

82 D. Zigah, J.-M. Noël, C. Lagrost and P. Hapiot, J. Phys. Chem. C, 2010, 114, 3075-3081.

83 A. Mattiuzzi, I. Jabin, C. Mangeney, C. Roux, O. Reinaud, L. Santos, J.-F. Bergamini, P. Hapiot and C. Lagrost, Nat. Commun., 2012, 3, 1130.

84 L. Santos, A. Mattiuzzi, I. Jabin, N. Vandencasteele, F. Reniers, O. Reinaud, P. Hapiot, S. Lhenry, Y. Leroux and C. Lagrost, J. Phys. Chem. C, 2014, 118, 15919-15928.

85 G. De Leener, F. Evoung-Evoung, A. Lascaux, J. Mertens, A. G. Porras-Gutierrez, N. Le Poul, C. Lagrost, D. Over, Y. R. Leroux, F. Reniers, P. Hapiot, Y. Le Mest, I. Jabin and O. Reinaud, J. Am. Chem. Soc., 2016, 138, 12841-12853.

86 L. Lee, Y. R. Leroux, P. Hapiot and A. J. Downard, Langmuir, 2015, 31, 5071-5077.

87 L. Lee, H. Ma, P. A. Brooksby, S. A. Brown, Y. R. Leroux, P. Hapiot and A. J. Downard, Langmuir, 2014, 30, 7104-7111.

88 J. Lehr, D. J. Garrett, M. G. Paulik, B. S. Flavel, P. A. Brooksby, B. E. Williamson and A. J. Downard, Anal. Chem., 2010, 82, 7027-7034.

89 M. E. Lipińska, S. L. H. Rebelo, M. F. R. Pereira, J. L. Figueiredo and C. Freire, Mater. Chem. Phys., 2013, 143, 296-304.

90 M. Radtke and A. Ignaszak, RSC Adv., 2017, 7, 35060-35074.

91 M. A. Ghanem, J.-M. Chrétien, J. D. Kilburn and P. N. Bartlett, Bioelectrochemistry, 2009, 76, 115-125.

92 S. Dauphas, A. Corlu, C. Guguen-Guillouzo, S. AbabouGirard, O. Lavastre and F. Geneste, New J. Chem., 2008, 32, 1228-1234.

93 A. Blacha-Grzechnik, K. Piwowar, K. Krukiewicz, P. Koscielniak, J. Szuber and J. K. Zak, Appl. Surf. Sci., 2016, 371, 151-159.

94 J. Wang and J. A. Carlisle, Diamond Relat. Mater., 2006, 15, 279-284.

95 J. Lyskawa and D. Bélanger, Chem. Mater., 2006, 18, 4755-4763. 
96 J. Lyskawa, A. Grondein and D. Bélanger, Carbon, 2010, 48, 1271-1278.

97 J.-M. Chrétien, M. A. Ghanem, P. N. Bartlett and J. D. Kilburn, Chem. - Eur. J., 2008, 14, 2548-2556.

98 M. A. Ghanem, J.-M. Chrétien, A. Pinczewska, J. D. Kilburn and P. N. Bartlett, J. Mater. Chem., 2008, 18, 4917-4927.

99 A. Celiktas, M. A. Ghanem and P. N. Bartlett, J. Electroanal. Chem., 2012, 670, 42-49.

100 M. A. Ghanem, I. Kocak, A. Al-Mayouf, M. AlHoshan and P. N. Bartlett, Electrochim. Acta, 2012, 68, 74-80.

101 M. Sosna, J.-M. Chrétien, J. D. Kilburn and P. N. Bartlett, Phys. Chem. Chem. Phys., 2010, 12, 10018-10026.

102 M. A. Ghanem, I. Kocak, A. Al-Mayouf and P. N. Bartlett, Electrochem. Commun., 2013, 34, 258-262.

103 A. Pinczewska, M. Sosna, S. Bloodworth, J. D. Kilburn and P. N. Bartlett, J. Am. Chem. Soc., 2012, 134, 18022-18033.

104 F. A. Mann, N. Herrmann, F. Opazo and S. Kruss, Angew. Chem., Int. Ed., 2020, 59, 17732-17738.

105 L. Lee, N. R. Gunby, D. L. Crittenden and A. J. Downard, Langmuir, 2016, 32, 2626-2637.

106 H. C. Kolb, M. G. Finn and K. B. Sharpless, Angew. Chem., Int. Ed., 2001, 40, 2004-2021.

107 V. V. Rostovtsev, L. G. Green, V. V. Fokin and K. B. Sharpless, Angew. Chem., Int. Ed., 2002, 41, 2596-2599.

108 J. P. Collman, N. K. Devaraj and C. E. D. Chidsey, Langmuir, 2004, 20, 1051-1053.

109 N. K. Devaraj, G. P. Miller, W. Ebina, B. Kakaradov, J. P. Collman, E. T. Kool and C. E. D. Chidsey, J. Am. Chem. Soc., 2005, 127, 8600-8601.

110 Y. Zhang, S. Luo, Y. Tang, L. Yu, K.-Y. Hou, J.-P. Cheng, X. Zeng and P. G. Wang, Anal. Biochem., 2006, 78, 2001-2008.

111 J. P. Collman, N. K. Devaraj, R. A. Decreau, Y. Yang, Y.-L. Yan, W. Ebina, T. A. Eberspacher and C. E. D. Chidsey, Science, 2007, 315, 1565-1568.

112 D. Pearson, A. J. Downard, A. Muscroft-Taylor and A. D. Abell, J. Am. Chem. Soc., 2007, 129, 14862-14863.

113 S. Campidelli, B. Ballesteros, A. Filoramo, D. D. Díaz, G. de la Torre, T. Torres, G. M. A. Rahman, C. Ehli, D. Kiessling, F. Werner, V. Sgobba, D. M. Guldi, C. Cioffi, M. Prato and J.-P. Bourgoin, J. Am. Chem. Soc., 2008, 130, 11503-11509.

114 D. Evrard, F. Lambert, C. Policar, V. Balland and B. Limoges, Chem. - Eur. J., 2008, 14, 9286-9291.

115 Y. R. Leroux, H. Fei, J.-M. Noël, C. Roux and P. Hapiot, J. Am. Chem. Soc., 2010, 132, 14039-14041.

116 Y. R. Leroux, F. Hui, J.-M. Noël, C. Roux, A. J. Downard and P. Hapiot, Langmuir, 2011, 27, 11222-11228.

117 A. Cernat, S. Griveau, P. Martin, J. C. Lacroix, C. Farcau, R. Sandulescu and F. Bedioui, Electrochem. Commun., 2012, 23, 141-144.

118 M. Coates, H. Elamari, C. Girard, S. Griveau, T. Nyokong and F. Bedioui, J. Electroanal. Chem., 2012, 670, 79-84.

119 Y. R. Leroux, F. Hui, J. Ruiz, D. Astruc and P. Hapiot, Chem. - Eur. J., 2012, 18, 7041-7044.

120 G. Tuci, C. Vinattieri, L. Luconi, M. Ceppatelli, S. Cicchi, A. Brandi, J. Filippi, M. Melucci and G. Giambastiani, Chem. - Eur. J., 2012, 18, 8454-8463.
121 A. A. Gietter, R. C. Pupillo, G. P. Yap, T. P. Beebe, J. Rosenthal and D. A. Watson, Chem. Sci., 2013, 4, 437-443.

122 L. Lee, P. A. Brooksby, Y. R. Leroux, P. Hapiot and A. J. Downard, Langmuir, 2013, 29, 3133-3139.

123 Y. R. Leroux and P. Hapiot, Chem. Mater., 2013, 25, 489-495.

124 Y. R. Leroux, F. Hui and P. Hapiot, J. Electroanal. Chem., 2013, 688, 298-303.

125 S. Lhenry, Y. R. Leroux and P. Hapiot, Anal. Chem., 2013, 85, 1840-1845.

126 D. Quinton, A. Maringa, S. Griveau, T. Nyokong and F. Bedioui, Electrochem. Commun., 2013, 31, 112-115.

127 S. Y. Sayed, A. Bayat, M. Kondratenko, Y. Leroux, P. Hapiot and R. L. McCreery, J. Am. Chem. Soc., 2013, 135, 12972-12975.

128 J. Jalkh, Y. R. Leroux, C. Lagrost and P. Hapiot, J. Phys. Chem. C, 2014, 118, 28640-28646.

129 W. S. Yeap, M. S. Murib, W. Cuypers, X. Liu, B. van Grinsven, M. Ameloot, M. Fahlman, P. Wagner, W. Maes and K. Haenen, ChemElectroChem, 2014, 1, 1145-1154.

130 W. Liu and T. D. Tilley, Langmuir, 2015, 31, 1189-1195.

131 V. Badets, D. Duclos, D. Quinton, O. Fontaine and D. Zigah, Electrochim. Acta, 2016, 201, 274-278.

132 P. Fortgang, T. Tite, V. Barnier, N. Zehani, C. Maddi, F. Lagarde, A.-S. Loir, N. Jaffrezic-Renault, C. Donnet, F. Garrelie and C. Chaix, ACS Appl. Mater. Interfaces, 2016, 8, 1424-1433.

133 L. Gonzalez-Macia, S. Griveau, F. d'Orlyé, A. Varenne, C. Sella, L. Thouin and F. Bedioui, Electrochem. Commun., 2016, 70, 78-81.

134 Y. Kamamoto, Y. Nitta, K. Kubo, T. Mizuta and S. Kume, Chem. Commun., 2016, 52, 10486-10489.

135 C. Maddi, F. Bourquard, T. Tite, A.-S. Loir, C. Donnet, F. Garrelie, V. Barnier, K. Wolski, P. Fortgang, N. Zehani, M. Braiek, F. Lagarde, C. Chaix, N. Jaffrezic-Renault, T. C. Rojas and J. C. Sánchez-López, Diamond Relat. Mater., 2016, 65, 17-25.

136 I. Strzemińska, S. Sainte Rose Fanchine, G. Anquetin, S. Reisberg, V. Noël, M. C. Pham and B. Piro, Biosens. Bioelectron., 2016, 81, 131-137.

137 T. Yamamoto, M. Akahori, K. Natsui, T. Saitoh and Y. Einaga, Carbon, 2018, 130, 350-354.

138 M. Cesbron, E. Levillain, T. Breton and C. Gautier, ACS Appl. Mater. Interfaces, 2018, 10, 37779-37782.

139 J. P. Buttress, D. P. Day, J. M. Courtney, E. J. Lawrence, D. L. Hughes, R. J. Blagg, A. Crossley, S. E. Matthews, C. Redshaw, P. C. Bulman Page and G. G. Wildgoose, Langmuir, 2016, 32, 7806-7813.

140 K. E. Berg, Y. R. Leroux, P. Hapiot and C. S. Henry, ChemElectroChem, 2019, 6, 4811-4816.

141 S. Gentil, P. Rousselot-Pailley, F. Sancho, V. Robert, Y. Mekmouche, V. Guallar, T. Tron and A. Le Goff, Chem. Eur. J., 2020, 26, 4798-4804.

142 K. Flavin, M. N. Chaur, L. Echegoyen and S. Giordani, Org. Lett., 2010, 12, 840-843. 
143 S. R. Nxele, P. Mashazi and T. Nyokong, Electroanalysis, 2015, 27, 2468-2478.

144 C. S. J. N. O’Donoghue, G. Fomo and T. Nyokong, Electroanalysis, 2016, 28, 3019-3027.

145 C. S. J. N. O'Donoghue, M. Shumba and T. Nyokong, Electroanalysis, 2017, 29, 1731-1740.

146 D. Mwanza, S. Mvango, S. Khene, T. Nyokong and P. Mashazi, Electrochim. Acta, 2017, 254, 89-100.

147 J. Jalkh, Y. R. Leroux, A. Vacher, D. Lorcy, P. Hapiot and C. Lagrost, J. Phys. Chem. C, 2016, 120, 28021-28030.

148 M. Castelaín, G. Martínez, P. Merino, J. Á. Martín-Gago, J. L. Segura, G. Ellis and H. J. Salavagione, Chem. - Eur. J., 2012, 18, 4965-4973.

149 J. Jalkh, S. Thiery, J.-F. Bergamini, P. Hapiot, C. Poriel and Y. R. Leroux, J. Phys. Chem. C, 2017, 121, 14228-14237.

150 Q. M. Kainz, A. Schätz, A. Zöpfl, W. J. Stark and O. Reiser, Chem. Mater., 2011, 23, 3606-3613.

151 G. Tuci, D. Mosconi, A. Rossin, L. Luconi, S. Agnoli, M. Righetto, C. Pham-Huu, H. Ba, S. Cicchi, G. Granozzi and G. Giambastiani, Chem. Mater., 2018, 30, 8257-8269.

152 R. T. Jane, E. Gaudemer and R. Lomoth, J. Mater. Chem. C, 2015, 3, 10023-10030.

153 L. Zhang, N. Vilà, G.-W. Kohring, A. Walcarius and M. Etienne, ACS Catal., 2017, 7, 4386-4394.

154 M. E. Ahmed, S. Dey, B. Mondal and A. Dey, Chem. Commun., 2017, 53, 8188-8191.

155 M. Cesbron, S. Dabos-Seignon, C. Gautier and T. Breton, Electrochim. Acta, 2020, 345, 136190.

156 L. Zhang, N. Vilà, A. Walcarius and M. Etienne, ChemElectroChem, 2018, 5, 2208-2217.

157 Y. Yang, A. A. Ibrahim, J. L. Stockdill and P. Hashemi, Anal. Methods, 2015, 7, 7352-7357.

158 L. Servinis, K. M. Beggs, T. R. Gengenbach, E. H. Doeven, P. S. Francis, B. L. Fox, J. M. Pringle, C. Pozo-Gonzalo, T. R. Walsh and L. C. Henderson, J. Mater. Chem. A, 2017, 5, 11204-11213.

159 T. N. Pham-Truong, F. Lafolet, J. Ghilane and H. Randriamahazaka, Electrochem. Commun., 2016, 70, 13-17.

160 Y.-T. Xi, P.-J. Wei, R.-C. Wang and J.-G. Liu, Chem. Commun., 2015, 51, 7455-7458.

161 C. Perréard, Y. Ladner, F. d'Orlyé, S. Descroix, V. Taniga, A. Varenne, F. Kanoufi, C. Slim, S. Griveau and F. Bedioui, RSC Adv., 2015, 5, 11128-11131.

162 K. Levrie, K. Jans, R. Vos, N. Ardakanian, N. Verellen, C. Van Hoof, L. Lagae and T. Stakenborg, Bioelectrochemistry, 2016, 112, 61-66.

163 A. Hayat, A. Sassolas, J.-L. Marty and A.-E. Radi, Talanta, 2013, 103, 14-19.

164 Q. Wang, A. Vasilescu, Q. Wang, Y. Coffinier, M. Li, R. Boukherroub and S. Szunerits, ACS Appl. Mater. Interfaces, 2017, 9, 12823-12831.

165 Q. Ran, R. Peng, C. Liang, S. Ye, Y. Xian, W. Zhang and L. Jin, Anal. Chim. Acta, 2011, 697, 27-31.

166 A. Hayat, J.-L. Marty and A.-E. Radi, Electroanalysis, 2012, 24, 1446-1452.
167 H. Qi, M. Li, R. Zhang, M. Dong and C. Ling, Anal. Chim. Acta, 2013, 792, 28-34.

168 A. Bunge, L. Magerusan, I. Morjan, R. Turcu, G. Borodi and J. Liebscher, J. Nanopart. Res., 2015, 17, 379.

169 A. Lesniewski, J. Matyjewicz, B. Palys and J. NiedziolkaJonsson, Electrochem. Commun., 2015, 53, 20-23.

170 H. Gehan, L. Fillaud, N. Felidj, J. Aubard, P. Lang, M. M. Chehimi and C. Mangeney, Langmuir, 2010, 26, 3975-3980.

171 J. Matyjewicz, A. Lesniewski and J. Niedziolka-Jonsson, Electrochem. Commun., 2014, 48, 73-76.

172 S. Mahouche, N. Mekni, L. Abbassi, P. Lang, C. Perruchot, M. Jouini, F. Mammeri, M. Turmine, H. B. Romdhane and M. M. Chehimi, Surf. Sci., 2009, 603, 3205-3211.

173 S. Mahouche Chergui, A. Ledebt, F. Mammeri, F. Herbst, B. Carbonnier, H. Ben Romdhane, M. Delamar and M. M. Chehimi, Langmuir, 2010, 26, 16115-16121.

174 A. Bensghaïer, Z. Salmi, B. Le Droumaguet, A. Mekki, A. A. Mohamed, M. Beji and M. M. Chehimi, Surf. Interface Anal., 2016, 48, 509-513.

175 Y. Yang, X. Song, L. Yuan, M. Li, J. Liu, R. Ji and H. Zhao, J. Polym. Sci., Part A: Polym. Chem., 2012, 50, 329-337.

176 T. Wu, E. R. Lankshear and A. J. Downard, ChemElectroChem, 2019, 6, 5149-5154.

177 Y. R. Leroux and P. Hapiot, Electrochem. Commun., 2013, 33, 107-110.

178 G. Neri, A. Scala, F. Barreca, E. Fazio, P. G. Mineo, A. Mazzaglia, G. Grassi and A. Piperno, Chem. Commun., 2015, 51, 4846-4849.

179 L. Zhang, N. Vilà, T. Klein, G.-W. Kohring, I. Mazurenko, A. Walcarius and M. Etienne, ACS Appl. Mater. Interfaces, 2016, 8, 17591-17598.

180 M. Bengamra, A. Khlifi, N. Ktari, S. Mahouche-Chergui, B. Carbonnier, N. Fourati, R. Kalfat and M. M. Chehimi, Langmuir, 2015, 31, 10717-10724.

181 D. S. Moock, S. O. Steinmüller, I. D. Wessely, A. Llevot, B. Bitterer, M. A. R. Meier, S. Bräse, H. Ehrenberg and F. Scheiba, ACS Appl. Mater. Interfaces, 2018, 10, 24172-24180.

182 H. Gehan, L. Fillaud, M. M. Chehimi, J. Aubard, A. Hohenau, N. Felidj and C. Mangeney, ACS Nano, 2010, 4, 6491-6500.

183 C. E. D. Chidsey, C. R. Bertozzi, T. M. Putvinski and A. M. Mujsce, J. Am. Chem. Soc., 1990, 112, 4301-4306.

184 E. Touzé, F. Gohier, S. Dabos-Seignon, T. Breton and C. Cougnon, Synth. Met., 2019, 247, 37-45.

185 A. Berisha, M. Chehimi, J. Pinson and F. Podvorica, Electrode Surface Modification Using Diazonium Salts, CRC Press, CRC Press, 2016, vol. 26.

186 P. Viel, X. T. Le, V. Huc, J. Bar, A. Benedetto, A. L. Goff, A. Filoramo, D. Alamarguy, S. Noël, L. Baraton and S. Palacin, J. Mater. Chem., 2008, 18, 5913-5920.

187 X. Joyeux, P. Mangiagalli and J. Pinson, Adv. Mater., 2009, 21, 4404-4408.

188 O. Arias de Fuentes, T. Ferri, M. Frasconi, V. Paolini and R. Santucci, Angew. Chem., Int. Ed., 2011, 50, 3457-3461. 
189 A. Ruffien, M. Dequaire and P. Brossier, Chem. Commun., 2003, 912-913.

190 J.-P. Jasmin, C. Cannizzo, E. Dumas and A. Chaussé, Electrochim. Acta, 2014, 133, 467-474.

191 L. Lee, P. A. Brooksby and A. J. Downard, Electrochem. Commun., 2012, 19, 67-69.

192 A. K. Flatt, B. Chen and J. M. Tour, J. Am. Chem. Soc., 2005, 127, 8918-8919.

193 G. Liu, E. Luais and J. J. Gooding, Langmuir, 2011, 27, 4176-4183.

194 C. Martin, M. Alias, F. Christien, O. Crosnier, D. Bélanger and T. Brousse, Adv. Mater., 2009, 21, 4735-4741.

195 C. Martin, O. Crosnier, R. Retoux, D. Bélanger, D. M. Schleich and T. Brousse, Adv. Funct. Mater., 2011, 21, 3524-3530.

196 N. Marshall and J. Locklin, Langmuir, 2011, 27, 13367-13373.

197 N. Marshall, A. Rodriguez and S. Crittenden, RSC Adv., 2018, 8, 6690-6698.

198 X. Chen, M. Chockalingam, G. Liu, E. Luais, A. L. Gui and J. J. Gooding, Electroanalysis, 2011, 23, 2633-2642.

199 C. Ramirez-Castro, O. Crosnier, L. Athouël, R. Retoux, D. Bélanger and T. Brousse, J. Electrochem. Soc., 2015, 162, A5179-A5184.

200 O. Alageel, M.-N. Abdallah, Z. Y. Luo, J. Del-Rio-Highsmith, M. Cerruti and F. Tamimi, Dent. Mater., 2015, 31, 105-114.

201 Y. Oweis, O. Alageel, P. Kozak, M.-N. Abdallah, J.-M. Retrouvey, M. Cerruti and F. Tamimi, Dent. Mater., 2017, 33, e393-e404.

202 B. Chen, A. K. Flatt, H. Jian, J. L. Hudson and J. M. Tour, Chem. Mater., 2005, 17, 4832-4836.

203 S. Taufik, A. Barfidokht, M. T. Alam, C. Jiang, S. G. Parker and J. J. Gooding, J. Electroanal. Chem., 2016, 779, 229-235.

204 C. R. Peiris, Y. B. Vogel, A. P. Le Brun, A. C. Aragonès, M. L. Coote, I. Díez-Pérez, S. Ciampi and N. Darwish, J. Am. Chem. Soc., 2019, 141, 14788-14797.

205 B. Chen, M. Lu, A. K. Flatt, F. Maya and J. M. Tour, Chem. Mater., 2008, 20, 61-64.

206 A.-E. Radi, X. Muñoz-Berbel, M. Cortina-Puig and J.L. Marty, Electroanalysis, 2009, 21, 696-700.

207 T. Berthelot, A. Garcia, X. T. Le, J. El Morsli, P. Jégou, S. Palacin and P. Viel, Appl. Surf. Sci., 2011, 257, 3538-3546.

208 M. Revenga-Parra, T. García-Mendiola, J. González-Costas, E. González-Romero, A. G. Marín, J. L. Pau, F. Pariente and E. Lorenzo, Anal. Chim. Acta, 2014, 813, 41-47.

209 X. T. Le, N. D. Doan, T. Dequivre, P. Viel and S. Palacin, ACS Appl. Mater. Interfaces, 2014, 6, 9085-9092.

210 J.-S. Wang and K. Matyjaszewski, J. Am. Chem. Soc., 1995, 117, 5614-5615.

211 K. Matyjaszewski, S. Gaynor and J.-S. Wang, Macromolecules, 1995, 28, 2093-2095.

212 M. Kato, M. Kamigaito, M. Sawamoto and T. Higashimura, Macromolecules, 1995, 28, 1721-1723.

213 T. Matrab, M. M. Chehimi, C. Perruchot, A. Adenier, A. Guillez, M. Save, B. Charleux, E. Cabet-Deliry and J. Pinson, Langmuir, 2005, 21, 4686-4694.
214 T. Matrab, J. Chancolon, M. M. L'hermite, J.-N. Rouzaud, G. Deniau, J.-P. Boudou, M. M. Chehimi and M. Delamar, Colloids Surf., A, 2006, 287, 217-221.

215 T. Matrab, M. Save, B. Charleux, J. Pinson, E. Cabet-deliry, A. Adenier, M. M. Chehimi and M. Delamar, Surf. Sci., 2007, 601, 2357-2366.

216 S. Mahouche Chergui, N. Abbas, T. Matrab, M. Turmine, E. Bon Nguyen, R. Losno, J. Pinson and M. M. Chehimi, Carbon, 2010, 48, 2106-2111.

217 S. U. Nielsen, L. Koefoed, H. Lund, K. Daasbjerg and S. U. Pedersen, Electroanalysis, 2016, 28, 2849-2854.

218 J. Iruthayaraj, S. Chernyy, M. Lillethorup, M. Ceccato, T. Røn, M. Hinge, P. Kingshott, F. Besenbacher, S. U. Pedersen and K. Daasbjerg, Langmuir, 2011, 27, 1070-1078.

219 M. Lillethorup, K. Torbensen, M. Ceccato, S. U. Pedersen and K. Daasbjerg, Langmuir, 2013, 29, 13595-13604.

220 S. Chernyy, J. Iruthayaraj, M. Ceccato, M. Hinge, S. U. Pedersen and K. Daasbjerg, J. Polym. Sci., Part A: Polym. Chem., 2012, 50, 4465-4475.

221 J. E. Friis, K. Brøns, Z. Salmi, K. Shimizu, G. Subbiahdoss, A. H. Holm, O. Santos, S. U. Pedersen, R. L. Meyer, K. Daasbjerg and J. Iruthayaraj, ACS Appl. Mater. Interfaces, 2016, 8, 30616-30627.

222 F. Mammeri, J. Teyssandier, C. Darche-Dugaret, S. Debacker, E. Le Bourhis and M. M. Chehimi, J. Colloid Interface Sci., 2014, 433, 115-122.

223 J. Chiefari, Y. K. (Bill) Chong, F. Ercole, J. Krstina, J. Jeffery, T. P. T. Le, R. T. A. Mayadunne, G. F. Meijs, C. L. Moad, G. Moad, E. Rizzardo and S. H. Thang, Macromolecules, 1998, 31, 5559-5562.

224 T. Otsu and M. Yoshida, Makromol. Chem., Rapid Commun., 1982, 3, 127-132.

225 T. Otsu, M. Yoshida and T. Tazaki, Makromol. Chem., Rapid Commun., 1982, 3, 133-140.

226 H. Salmi-Mani, Z. Ait-Touchente, A. Lamouri, B. Carbonnier, J.-F. Caron, K. Benzarti and M. M. Chehimi, RSC Adv., 2016, 6, 88126-88134.

227 N. Griffete, R. Ahmad, H. Benmehdi, A. Lamouri, P. Decorse and C. Mangeney, Colloids Surf., A, 2013, 439, 145-150.

228 S. Gam-Derouich, S. Mahouche-Chergui, S. Truong, D. Ben Hassen-Chehimi and M. M. Chehimi, Polymer, 2011, 52, 4463-4470.

229 S. Gam-Derouich, S. Mahouche-Chergui, M. Turmine, J.-Y. Piquemal, D. B. Hassen-Chehimi, M. Omastová and M. M. Chehimi, Surf. Sci., 2011, 605, 1889-1899.

230 R. Ben Slama, B. Mrabet, A. Bakhrouf, Z. Salmi, I. Bakas and M. M. Chehimi, Surf. Innovations, 2015, 3, 103-114.

231 Z. Salmi, A. Lamouri, P. Decorse, M. Jouini, A. Boussadi, J. Achard, A. Gicquel, S. Mahouche-Chergui, B. Carbonnier and M. M. Chehimi, Diamond Relat. Mater., 2013, 40, 60-68.

232 A. Adenier, E. Cabet-Deliry, T. Lalot, J. Pinson and F. Podvorica, Chem. Mater., 2002, 14, 4576-4585.

233 Z. Salmi, H. Benmehdi, A. Lamouri, P. Decorse, M. Jouini, Y. Yagci and M. M. Chehimi, Microchim. Acta, 2013, 180, 1411-1419. 
234 L. M. Santos, J. Ghilane, C. Fave, P.-C. Lacaze, H. Randriamahazaka, L. M. Abrantes and J.-C. Lacroix, J. Phys. Chem. C, 2008, 112, 16103-16109.

235 K. Shimizu, F. H. Blaikie, M. Kongsfelt, K. D. S. Sørensen, S. U. Pedersen and K. Daasbjerg, J. Polym. Sci., Part A: Polym. Chem., 2016, 54, 91-98.

236 S. Doswald and W. J. Stark, Chem. - Eur. J., 2020, 27, 4108-4114.

237 M. Sandomierski, T. Buchwald and A. Voelkel, Surf. Coat. Technol., 2020, 385, 125389.

238 M. Sandomierski, T. Buchwald, A. Patalas and A. Voelkel, Sci. Rep., 2020, 10, 19289.

239 K. C. Nicolaou, P. G. Bulger and D. Sarlah, Angew. Chem., Int. Ed., 2005, 44, 4442-4489.

240 A. O. King and N. Yasuda, Organometallics in Process Chemistry, Springer Berlin Heidelberg, Berlin, Heidelberg, 2004, vol. 6, pp. 205-245.

241 T. Mede, M. Jäger and U. S. Schubert, Chem. Soc. Rev., 2018, 47, 7577-7627.

242 K. Köhler, K. Wussow and A. S. Wirth, Palladium-Catalyzed Coupling Reactions, Wiley-VCH Verlag GmbH\&Co. KGaA, 2013, pp. 1-30.

243 G. Collins, C. O’Dwyer, M. Morris and J. D. Holmes, Langmuir, 2013, 29, 11950-11958.

244 L. E. O'Leary, M. J. Rose, T. X. Ding, E. Johansson, B. S. Brunschwig and N. S. Lewis, J. Am. Chem. Soc., 2013, 135, 10081-10090.

$245 \mathrm{~J} . \mathrm{Ru}, \mathrm{B}$. Szeto, A. Bonifas and R. L. McCreery, ACS Appl. Mater. Interfaces, 2010, 2, 3693-3701.

246 M. Toupin and D. Bélanger, J. Phys. Chem. C, 2007, 111, 5394-5401.

247 J. H. Kirchhoff, M. R. Netherton, I. D. Hills and G. C. Fu, J. Am. Chem. Soc., 2002, 124, 13662-13663.

248 H. Doucet, Eur. J. Org. Chem., 2008, 2013-2030.

249 W. S. Yeap, D. Bevk, X. Liu, H. Krysova, A. Pasquarelli, D. Vanderzande, L. Lutsen, L. Kavan, M. Fahlman, W. Maes and K. Haenen, RSC Adv., 2014, 4, 42044-42053.

250 W. S. Yeap, X. Liu, D. Bevk, A. Pasquarelli, L. Lutsen, M. Fahlman, W. Maes and K. Haenen, ACS Appl. Mater. Interfaces, 2014, 6, 10322-10329.

251 E. Coulon, J. Pinson, J.-D. Bourzat, A. Commerçon and J.-P. Pulicani, J. Org. Chem., 2002, 67, 8513-8518.

252 W. S. Yeap, S. Chen and K. P. Loh, Langmuir, 2009, 25, 185-191. 253 Y. L. Zhong, K. P. Loh, A. Midya and Z.-K. Chen, Chem. Mater., 2008, 20, 3137-3144.

254 J. Raymakers, A. Artemenko, S. S. Nicley, P. Štenclová, A. Kromka, K. Haenen, W. Maes and B. Rezek, J. Phys. Chem. C, 2017, 121, 23446-23454.

255 J. Raymakers, H. Krysova, A. Artemenko, J. Čermák, S. S. Nicley, P. Verstappen, S. Gielen, A. Kromka, K. Haenen, L. Kavan, W. Maes and B. Rezek, RSC Adv., 2018, 8, 33276-33290.

256 J. Raymakers, A. Artemenko, F. Verstraeten, H. Krysova, J. Cermák, S. S. Nicley, D. Lopez-Carballeira, A. Kromka, K. Haenen, L. Kavan, W. Maes and B. Rezek, Electrochim. Acta, 2020, 337, 135762.
257 J. Liang, R. E. G. Smith, A. Vezzoli, L. Xie, D. C. Milan, R. Davidson, A. Beeby, P. J. Low, S. J. Higgins, B. Mao and R. J. Nichols, Electrochim. Acta, 2016, 220, 436-443.

258 C. Soulignac, B. Cornelio, F. Brégier, F. Le Derf, J. F. Brière, T. Clamens, O. Lesouhaitier, F. Estour and J. Vieillard, Colloids Surf., B, 2019, 181, 639-647.

259 R. Matheu, L. Francàs, P. Chernev, M. Z. Ertem, V. Batista, M. Haumann, X. Sala and A. Llobet, ACS Catal., 2015, 5, 3422-3429.

260 R. Bangle, R. N. Sampaio, L. Troian-Gautier and G. J. Meyer, ACS Appl. Mater. Interfaces, 2018, 10, 3121-3132.

261 V. Q. Nguyen, X. Sun, F. Lafolet, J.-F. Audibert, F. Miomandre, G. Lemercier, F. Loiseau and J.-C. Lacroix, J. Am. Chem. Soc., 2016, 138, 9381-9384.

262 N. Elgrishi, S. Griveau, M. B. Chambers, F. Bedioui and M. Fontecave, Chem. Commun., 2015, 51, 2995-2998.

263 C. Wang, M. Amiri, R. T. Endean, O. Martinez Perez, S. Varley, B. Rennie, L. Rasu and S. H. Bergens, ACS Appl. Mater. Interfaces, 2018, 10, 24533-24542.

264 Q. T. Tran, J.-F. Bergamini, C. Mangeney, C. Lagrost and P. Pellon, Electrochem. Commun., 2011, 13, 844-847.

265 H. M. Fruehwald, I. I. Ebralidze, O. V. Zenkina and E. B. Easton, ChemElectroChem, 2021, 8, 53-61.

266 A. D. Pauric, E. B. Easton and B. J. MacLean, $\mathrm{Fe}-\mathrm{N} / \mathrm{C}$ Oxygen Reduction Catalysts Prepared by Surface Functionalization of Carbon Black with 5,6-diamino,1-10-phenanthroline, Vancouver, Canada, 2010, pp. 55-62.

267 H. M. Fruehwald, I. I. Ebralidze, O. V. Zenkina and E. B. Easton, ChemElectroChem, 2019, 6, 1350-1358.

268 T. G. A. A. Harris, R. Götz, P. Wrzolek, V. Davis, C. E. Knapp, K. Ly, P. Hildebrandt, M. Schwalbe, I. Weidinger, I. Zebger and A. Fischer, J. Mater. Chem. A, 2018, 6, 15200-15212.

269 Y.-H. Tsou, Y.-Y. Chuang and J.-S. Chen, J. Colloid Interface Sci., 2020, 562, 213-223.

270 R. A. Graff, T. M. Swanson and M. S. Strano, Chem. Mater., 2008, 20, 1824-1829.

271 M. Tavakkoli, M. Nosek, J. Sainio, F. Davodi, T. Kallio, P. M. Joensuu and K. Laasonen, ACS Catal., 2017, 7, 8033-8041.

272 R. Blankespoor, B. Limoges, B. Schöllhorn, J.-L. SyssaMagalé and D. Yazidi, Langmuir, 2005, 21, 3362-3375.

273 R. Marion, G. Muthusamy and F. Geneste, J. Catal., 2012, 286, 266-272.

274 A. Yeşildağ and D. Ekinci, Electrochim. Acta, 2010, 55, 7000-7009.

275 M. Amiri, O. M. Perez, R. T. Endean, L. Rasu, P. Nepal, S. Xu and S. H. Bergens, Dalton Trans., 2020, 49, 10173-10184.

276 A. A. Tregubov, K. Q. Vuong, E. Luais, J. J. Gooding and B. A. Messerle, J. Am. Chem. Soc., 2013, 135, 16429-16437.

277 W. Zhao, B. Tong, Y. Pan, J. Shen, J. Zhi, J. Shi and Y. Dong, Langmuir, 2009, 25, 11796-11801.

278 Y. Pan, B. Tong, J. Shi, W. Zhao, J. Shen, J. Zhi and Y. Dong, J. Phys. Chem. C, 2010, 114, 8040-8047.

279 B. Tong, H. Yang, W. Xiong, F. Xie, J. Shi, J. Zhi, W. K. Chan and Y. Dong, J. Phys. Chem. B, 2013, 117, 5338-5344. 
280 A. A. Tregubov, D. B. Walker, K. Q. Vuong, J. J. Gooding and B. A. Messerle, Dalton Trans., 2015, 44, 7917-7926.

281 S. Zhao, P. Gai, W. Yu, H. Li and F. Li, Chem. Commun., 2019, 55, 1887-1890.

282 J. R. Mohrig and K. Keegstra, J. Am. Chem. Soc., 1967, 89, 5492-5493.

283 D. Berner and J. F. McGarrity, J. Am. Chem. Soc., 1979, 101, 3135-3136.

284 N. Tuccitto, V. Torrisi, M. Cavazzini, T. Morotti, F. Puntoriero, S. Quici, S. Campagna and A. Licciardello, ChemPhysChem, 2007, 8, 227-230.

285 N. Tuccitto, V. Ferri, M. Cavazzini, S. Quici, G. Zhavnerko, A. Licciardello and M. A. Rampi, Nat. Mater., 2009, 8, 41-46.

286 Y. Nishimori, K. Kanaizuka, M. Murata and H. Nishihara, Chem. - Asian J., 2007, 2, 367-376.

287 W. Kubo, M. Nagao, Y. Otsuka, T. Homma and H. Miyata, Langmuir, 2009, 25, 13340-13343.

288 P. Allongue, M. Delamar, B. Desbat, O. Fagebaume, R. Hitmi, J. Pinson and J.-M. Savéant, J. Am. Chem. Soc., 1997, 119, 201-207.

289 M. Delamar, G. Désarmot, O. Fagebaume, R. Hitmi, J. Pinson and J.-M. Savéant, Carbon, 1997, 35, 801-807.

290 M. Pellissier, D. Zigah, F. Barrière and P. Hapiot, Langmuir, 2008, 24, 9089-9095.

291 Y. Wang, L. Meng, L. Fan, G. Wu, L. Ma, M. Zhao and Y. Huang, Appl. Surf. Sci., 2016, 362, 341-347.

292 C. Gautier, O. Ghodbane, D. D. M. Wayner and D. Belanger, Electrochim. Acta, 2009, 54, 6327-6334.

293 O. Ghodbane, G. Chamoulaud and D. Bélanger, Electrochem. Commun., 2004, 6, 254-258.

294 S. K. Arya and M. K. Park, Biosens. Bioelectron., 2014, 61, 260-265.

295 A. Shabani, A. W. H. Mak, I. Gerges, L. A. Cuccia and M. F. Lawrence, Talanta, 2006, 70, 615-623.

296 A. Shabani, C. A. Marquette, R. Mandeville and M. F. Lawrence, Analyst, 2013, 138, 1434-1440.

297 A.-E. Radi, X. Muñoz-Berbel, M. Cortina-Puig and J.-L. Marty, Electroanalysis, 2009, 21, 1624-1629.

298 M. Cortina-Puig, X. Muñoz-Berbel, C. Calas-Blanchard and J.-L. Marty, Microchim. Acta, 2010, 171, 187-193.

299 R. Wang and C. Xue, Anal. Methods, 2013, 5, 5195-5200.

300 Z. Nasri and E. Shams, Electrochim. Acta, 2013, 112, 640-647.

301 A.-M. J. Haque and K. Kim, Langmuir, 2011, 27, 882-886.

302 N. H. Nguyen, C. Esnault, F. Gohier, D. Bélanger and C. Cougnon, Langmuir, 2009, 25, 3504-3508.

303 J. C. Harper, R. Polsky, D. R. Wheeler and S. M. Brozik, Langmuir, 2008, 24, 2206-2211.

304 T. J. Neubert, F. Rösicke, G. Sun, S. Janietz, M. A. Gluba, K. Hinrichs, N. H. Nickel and J. Rappich, Appl. Surf. Sci., 2017, 421, 755-760.

305 R. G. Nuzzo and D. L. Allara, J. Am. Chem. Soc., 1983, 105, 4481-4483.

306 R. G. Nuzzo, B. R. Zegarski and L. H. Dubois, J. Am. Chem. Soc., 1987, 109, 733-740.
307 J. A. Harnisch, A. D. Pris and M. D. Porter, J. Am. Chem. Soc., 2001, 123, 5829-5830.

308 V. Serafín, R. M. Torrente-Rodríguez, A. González-Cortés, P. García de Frutos, M. Sabaté, S. Campuzano, P. YáñezSedeño and J. M. Pingarrón, Talanta, 2018, 179, 131-138.

309 S. W. Howell, S. M. Dirk, K. Childs, H. Pang, M. Blain, R. J. Simonson, J. M. Tour and D. R. Wheeler, Nanotechnology, 2005, 16, 754-758.

310 Z. Ait-Touchente, S. Falah, E. Scavetta, M. M. Chehimi, R. Touzani, D. Tonelli and A. Taleb, Molecules, 2020, 25, 3903.

311 C. Kumsapaya, M.-F. Bakaï, G. Loget, B. Goudeau, C. Warakulwit, J. Limtrakul, A. Kuhn and D. Zigah, Chem. - Eur. J., 2013, 19, 1577-1580.

312 S. Liu, Z. Tang, Z. Shi, L. Niu, E. Wang and S. Dong, Langmuir, 1999, 15, 7268-7275.

313 J. C. Harper, R. Polsky, D. R. Wheeler, D. M. Lopez, D. C. Arango and S. M. Brozik, Langmuir, 2009, 25, 3282-3288.

314 N. Vilà and D. Bélanger, Electrochim. Acta, 2012, 85, 538-547.

315 Y. L. Zhong, W. Ng, J.-X. Yang and K. P. Loh, J. Am. Chem. Soc., 2009, 131, 18293-18298.

316 C. Hadad, X. Ke, M. Carraro, A. Sartorel, C. Bittencourt, G. Van Tendeloo, M. Bonchio, M. Quintana and M. Prato, Chem. Commun., 2014, 50, 885-887.

317 N. Vilà, M. V. Brussel, M. D’Amours, J. Marwan, C. BuessHerman and D. Bélanger, J. Electroanal. Chem., 2007, 609, 85-93.

318 H. Y. Shedge and S. E. Creager, Anal. Chim. Acta, 2010, 657, 154-162.

319 F. Hauquier, N. Debou, S. Palacin and B. Jousselme, J. Electroanal. Chem., 2012, 677-680, 127-132.

320 A. Le Goff, F. Moggia, N. Debou, P. Jegou, V. Artero, M. Fontecave, B. Jousselme and S. Palacin, J. Electroanal. Chem., 2010, 641, 57-63.

321 M. Müri, B. Gotsmann, Y. Leroux, M. Trouwborst, E. Lörtscher, H. Riel and M. Mayor, Adv. Funct. Mater., 2011, 21, 3706-3714.

322 C. S. J. N. O'Donoghue, G. Fomo and T. Nyokong, Electroanalysis, 2016, 28, 3019-3027.

323 B. Feier, I. Fizesan, C. Mériadec, S. Ababou Girard, C. Cristea, R. Sandulescu and F. Geneste, J. Electroanal. Chem., 2015, 744, 1-7.

324 F. Rösicke, G. Sun, T. Neubert, S. Janietz, K. Hinrichs and J. Rappich, J. Phys.: Condens. Matter, 2016, 28, 094004.

325 E. Sánchez-Tirado, L. M. Arellano, A. González-Cortés, P. Yáñez-Sedeño, F. Langa and J. M. Pingarrón, Biosens. Bioelectron., 2017, 98, 240-247.

326 A. H. Holm, R. Møller, K. H. Vase, M. Dong, K. Norrman, F. Besenbacher, S. U. Pedersen and K. Daasbjerg, New J. Chem., 2005, 29, 659-666.

327 G. Liu, W. Guo and Z. Yin, Biosens. Bioelectron., 2014, 53, 440-446.

328 G. Liu, W. Guo and D. Song, Biosens. Bioelectron., 2014, 52, 360-366. 
329 R. M. E. Hjelm, K. E. Garcia, S. Babanova, K. Artyushkova, I. Matanovic, S. Banta and P. Atanassov, Biochim. Biophys. Acta, Bioenerg., 2016, 1857, 612-620.

330 Y. Wang, L. Meng, L. Fan, G. Wu, L. Ma and Y. Huang, RSC Adv., 2015, 5, 44492-44498.

331 S. Uluok, M. S. Erdoğan, A. Aslıerkal, I. Aşık, G. Kuzu, H. Ekşi and Z. Üstündağ, J. Comput. Theor. Nanosci., 2015, 12, 1787-1794.

332 J. Debgupta and V. K. Pillai, Nanoscale, 2013, 5, 3615-3619.

333 P. Abiman, G. G. Wildgoose, A. Crossley, J. H. Jones and R. G. Compton, Chem. - Eur. J., 2007, 13, 9663-9667.

334 B. Gulbakan, E. Yasun, M. I. Shukoor, Z. Zhu, M. You, X. Tan, H. Sanchez, D. H. Powell, H. Dai and W. Tan, J. Am. Chem. Soc., 2010, 132, 17408-17410.

335 V. Mévellec, S. Roussel, L. Tessier, J. Chancolon, M. MayneL'Hermite, G. Deniau, P. Viel and S. Palacin, Chem. Mater., 2007, 19, 6323-6330.

336 N. D. Yates, M. R. Dowsett, P. Bentley, J. A. DickensonFogg, A. Pratt, C. F. Blanford, M. A. Fascione and A. Parkin, Langmuir, 2020, 36, 5654-5664.

337 S. M. Khor, G. Liu, J. B. Harper, S. G. Iyengar and J. J. Gooding, in Nanoscience and Nanotechnology (ICONN), 2010 International Conference on, IEEE, 2010, pp. 230-233.

338 S. Eissa, N. Alshehri, A. M. A. Rahman, M. Dasouki, K. M. AbuSalah and M. Zourob, Biosens. Bioelectron., 2018, 101, 282-289.

339 S. Eissa, G. C. Jimenez, F. Mahvash, A. Guermoune, C. Tlili, T. Szkopek, M. Zourob and M. Siaj, Nano Res., 2015, 8, 1698-1709.

340 M. Brodowski, M. Kowalski, M. Skwarecka, K. Pałka, M. Skowicki, A. Kula, T. Lipiński, A. Dettlaff, M. Ficek,
J. Ryl, K. Dziąbowska, D. Nidzworski and R. Bogdanowicz, Talanta, 2021, 221, 121623.

341 A. Latus, J.-M. Noël, E. Volanschi, C. Lagrost and P. Hapiot, Langmuir, 2011, 27, 11206-11211.

342 Md. Mohibul Islam Khan, M. K. Poduval, T.-H. Kim and K. Kim, Electroanalysis, 2015, 27, 1952-1959.

343 P. Viel, J. Walter, S. Bellon and T. Berthelot, Langmuir, 2013, 29, 2075-2082.

344 S. Z. Mousavisani, J.-B. Raoof, A. P. F. Turner, R. Ojani and W. C. Mak, Sens. Actuators, B, 2018, 264, 59-66.

345 J. Fraczyk, A. Rosowski, B. Kolesinska, A. Koperkiewcz, A. Sobczyk-Guzenda, Z. J. Kaminski and M. Dudek, Nanomaterials, 2018, 8, 908.

346 M. García, S. Bollo, G. A. Rivas, N. F. Ferreyra and C. Yáñez, Electrochim. Acta, 2016, 203, 292-300.

347 D. Ullien, P. C. Thüne, W. F. Jager, E. J. R. Sudhölter and L. C. P. M. de Smet, Phys. Chem. Chem. Phys., 2014, 16, 19258-19265.

348 Ĺ. Švorc, D. Jambrec, M. Vojs, S. Barwe, J. Clausmeyer, P. Michniak, M. Marton and W. Schuhmann, ACS Appl. Mater. Interfaces, 2015, 7, 18949-18956.

349 R. Marion, G. Muthusamy and F. Geneste, J. Mol. Catal. A: Chem., 2013, 377, 51-56.

350 D. Sharma, Y. Lim, Y. Lee and H. Shin, Anal. Chim. Acta, 2015, 889, 194-202.

351 S. Gentil, C. Pifferi, P. Rousselot-Pailley, T. Tron, O. Renaudet and A. Le Goff, Langmuir, 2021, 37, 1001-1011.

352 M. T. Ghafari, F. Varmaghani, B. Karimi and V. Khakyzadeh, Analyst, 2020, 145, 596-606. 